\title{
Desenvolvimento e comparação de dois protocolos para multicast atômico em computação móvel
}

\author{
Mateus de Freitas Ribeiro
}

\author{
DissertaÇÃo APRESENTADA AO \\ Instituto DE MatemáticA E EstatísticA DA \\ Universidade de São Paulo \\ PARA OBTENÇÃO DO GRAU DE \\ Mestre em CiênCia da ComputaÇÃo.
}

Área de ConcentraÇão: Computação Móvel Orientador: Prof. Dr. Markus Endler

Durante parte do desenvolvimento deste trabalho, o autor recebeu apoio financeiro do CNPq

- São Paulo, SP - Setembro de 2002 - 


\title{
Desenvolvimento e Comparação de Dois Protocolos para Multicast Atômico em Computação Móvel
}

\author{
Este exemplar corresponde à redação final \\ da dissertação devidamente corrigida \\ e defendida por Mateus de Freitas Ribeiro \\ e aprovada pela comissão julgadora.
}

São Paulo, 09 de setembro de 2002.

Banca Examinadora:

- Prof. Dr. Markus Endler (orientador) - DI-PUC-Rio

- Prof. PhD. Fábio Kon - DCC-IME-USP

- Prof. PhD. Antônio Alfredo Ferreira Loureiro - DCC-UFMG 
À minha noiva Déa. 


\section{Agradecimentos}

A Deus, que me deu forças, discernimento, equilíbrio e confiança para mudar para São Paulo diante de tantos novos desafios, estudar e atingir meus objetivos.

A todos aqueles que contribuíram diretamente no meu trabalho:

Ao Markus, pela confiança em mim e pela ótima orientação, mesmo distante fisicamente, sempre com muita dedicação, paciência, empolgação, estímulo, exigência e persistência para tornar o trabalho cada vez melhor.

Ao Fábio, que me aceitou como seu co-orientando (mesmo que informalmente) quando Markus se transferiu para o Rio, contribuindo muito no trabalho, especialmente até a qualificação.

Ao Antônio Loureiro, com suas críticas sempre construtivas que foram muito importantes para aumentar a qualidade da dissertação.

Ao Ricardo da Rocha, que mesmo já tendo defendido sua dissertação, trabalhando, não mediu esforços para implementar os time-outs no MobiCS, além de tirar, sempre que possível, minhas dúvidas durante a implementação dos protocolos.

A todos aqueles que contribuíram indiretamente no meu trabalho:

Ao Weslley, a Bianka, o Leandro, o Alessandro, a Rosianni, o Daniel, o Marcelo, o Francisco, a Vera e todos os outros que sempre me ajudaram no que foi preciso e possível, além de toda amizade que construímos durante este período.

Ao Alfredo, o Marcelo Finger, o Alan, a Cris e todos os demais docentes que ajudaram seja de forma específica no trabalho, seja com a ampliação dos meus conhecimentos na área, ou incentivando-me sempre que possível.

Ao Denis Montini e ao Luca Lavorante, que foram grandes amigos, apoiando-me e ajudando-me para que eu apresentasse bem no dia da defesa. Valeu à pena simular tanto a apresentação. Obrigado mesmo (mas não pensem que eu esqueci as cinco perguntas durante a defesa - brincadeira). Também agradeço a Maria Alice, que sempre me apoiou para que eu pudesse concluir o trabalho. 
Aos meus tios Josenildo e Cecília, e primos Marcelo e Mariana, que me acolheram como sendo parte da família, durante dois anos e meio. Meu agradecimento a vocês é especial, pois tornaram este sonho possível. Muito obrigado!

A Déa, que sempre acreditou em mim, no nosso amor, e mesmo ficando longe (fisicamente) de mim durante tanto tempo, sempre foi minha companheira, sempre me ajudou e me deu forças para que eu fosse em frente. Déa, este trabalho também é seu!

A minha família: meu pai, minha mãe, Lucinha, Kiko e Isis, que sempre me apoiaram e ajudaram no que foi preciso. Amo vocês! A meus avós e parentes que torceram e torcem por mim.

Ao meu tio Walter e a meu avô Pedro que, tenho certeza, sempre estiveram presentes, de uma forma ou de outra. 


\section{Resumo}

Aplicações que demandam uma sincronização entre usuários móveis requerem um mecanismo para a difusão (multicast) de mensagens entre dispositivos móveis. Em alguns casos, o multicast deve ser atômico, isto é, ou todos os elementos do grupo processam a mensagem difundida, ou nenhum deles. $\mathrm{O} A M^{2} C$ é um protocolo para multicast atômico em Computação Móvel. Entretanto, o principal problema do $A M^{2} C$ é sua falta de escalabilidade, uma vez que este protocolo faz uma difusão para todas as estações-base na rede fixa.

Esta dissertação descreve o projeto, implementação, simulação e avaliação dos protocolos $A M^{2} C$ e $i A M^{2} C$, onde o segundo protocolo é uma variante escalável do primeiro. As implementações e simulações foram feitas usando o ambiente MobiCS-Mobile Computing Simulator, que é uma ferramenta para o teste e a análise de desempenho de protocolos distribuídos em redes móveis. A dissertação apresenta uma comparação detalhada dos protocolos para diferentes configurações de rede e diversos padrões de migração dos hosts móveis.

\footnotetext{
Abstract

Applications that demand some synchronization among mobile users require a mechanism for reliable delivery of multicast messages to a group of mobile hosts. In some cases, the multicast must be atomic, i.e., either all or none of the mobile hosts accept each message. The $A M^{2} C$ is a protocol for atomic multicast in Mobile Computing. However, the main problem of $A M^{2} C$ is its lack of scalability, since it is based on broadcasts to all base stations in the fixed network.

This work describes the project, implementation, simulation and evaluation of the protocols $A M^{2} C$ and $i A M^{2} C$, where the second protocol is a scalable variant of the first. The implementations and simulations were performed using MobiCS-Mobile Computing Simulator, that is a tool for testing and doing performance analysis of distributed protocols in mobile networks. This work presents a detailed comparison of the protocols for different network configurations and various patterns of mobile hosts migrations.
} 


\section{Sumário}

1 Introdução 1

1.1 Motivação . . . . . . . . . . . . . . . . . . . . . 3

1.2 Objetivos e Resultados . . . . . . . . . . . . . . . . . . . 4

1.3 Principais Contribuições . . . . . . . . . . . . . . . . . . . . . 4

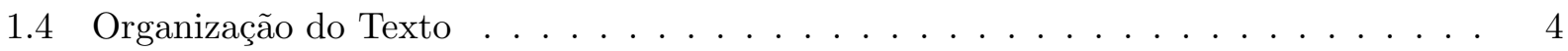

2 Trabalhos Relacionados $\quad 5$

2.1 Trabalhos Relacionados com Multicast . . . . . . . . . . . . . . . 5

2.2 Localização de Dispositivos Móveis . . . . . . . . . . . . . . . . . . . 8

3 O Protocolo $A M^{2} C \quad 11$

3.1 Motivação . . . . . . . . . . . . . . . . . . . . . . . 11

3.2 Modelo de Sistema e Suposições . . . . . . . . . . . . . . . . . . . . 12

3.3 Descrição do Protocolo . . . . . . . . . . . . . . . . . . . . . . . . . . 14

3.4 Exemplo de Funcionamento do $A M^{2} C \ldots \ldots \ldots \ldots$

3.5 O protocolo de Hand-off . . . . . . . . . . . . . . . . . . . 18

3.5 .1 A Estrutura $h \_R E C D$ no $A M^{2} C \ldots \ldots \ldots \ldots \ldots$

3.5.2 O Protocolo de Hand-off no $A M^{2} C \ldots \ldots \ldots \ldots$

3.6 Limitações do $A M^{2} C \ldots \ldots \ldots \ldots \ldots \ldots \ldots \ldots \ldots$

4 Uma Variante: o $i A M^{2} C \quad \mathbf{2 5}$

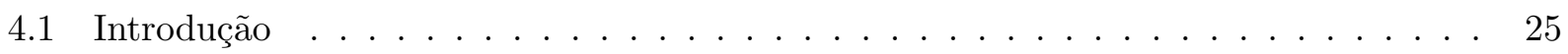

4.2 Motivação . . . . . . . . . . . . . . . . . . . . 25

4.3 Modelo de Sistema e Suposições . . . . . . . . . . . . . . . . . . . . . 25

4.4 Descrição do Protocolo . . . . . . . . . . . . . . . . . . . . . . 28 
4.5 Exemplo de Funcionamento do $i A M^{2} C \ldots \ldots \ldots$

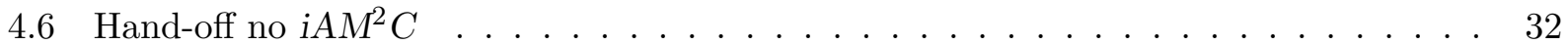

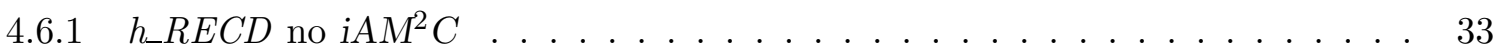

4.6 .2 O Protocolo de Hand-off . . . . . . . . . . . . . . . . . . . . 34

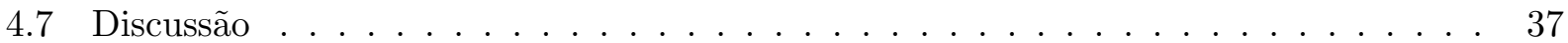

4.7.1 Consequência do Acréscimo de Mais um Nível de Indireção . . . . . . . . . . 37

4.7 .2 Papel Desempenhado Pelos Msss e IMSs _ . . . . . . . . . . . . . . . . . . 38

4.7 .3 Semântica de Resposta de um Mss . . . . . . . . . . . . . . . . . . . 38

4.7.4 Estimativa do Número de Mensagens Transmitidas . . . . . . . . . . . . . . . 39

5 Implementação e Simulação $\quad 42$

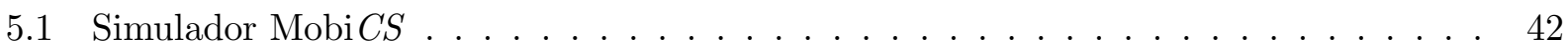

5.1 .1 Simulação Determinística . . . . . . . . . . . . . . . . . 43

5.1 .2 Simulação Estocástica . . . . . . . . . . . . . . . . . . . . 43

5.2 Modelo de Composição . . . . . . . . . . . . . . . . . . . . . . . . . . 44

5.3 Principais Interfaces $\ldots \ldots \ldots \ldots \ldots$

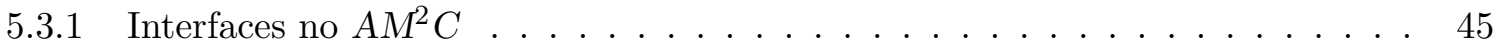

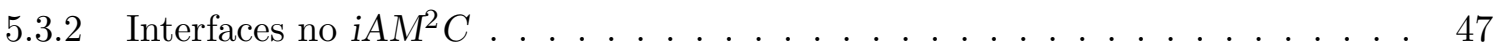

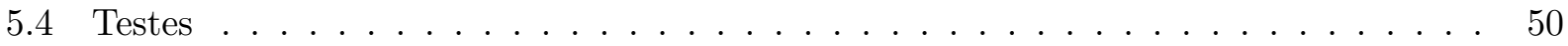

5.4 Testes Determinísticos . . . . . . . . . . . . . . . 50

5.4 .2 Testes Estocásticos . . . . . . . . . . . . . . . 53

5.4 .3 Dados Medidos . . . . . . . . . . . . . . . . . . 55

5.5 Análise dos Resultados . . . . . . . . . . . . . . . . . . . 56

5.5 .1 Custo Wired Total . . . . . . . . . . . . . . . . . . . . 57

5.5.2 Influência do Número de Msss no Custo Wired Total . . . . . . . . . . . . . 58

5.5 .3 Distribuição da Sobrecarga no $i A M^{2} C \ldots \ldots \ldots$. . . . . . . . . . 59

5.5 .4 Custo Wireless . . . . . . . . . . . . . . . . . 61

5.5.5 Porcentagem de Multicasts Abortados . . . . . . . . . . . . . . 62

5.5 .6 Duração Média de um Multicast . . . . . . . . . . . . . . . . . . . 64

5.5 .7 Avaliação Geral . . . . . . . . . . . . . . . . . . . . 65

6 Experiência Adquirida e Dificuldades Encontradas $\quad 68$

6.1 Implementação Utilizando o MobiCS . . . . . . . . . . . . . . . . . . . . 68 
6.2 Principais Dificuldades . . . . . . . . . . . . . . . . . . . 69

7 Conclusões $\quad 72$

7.1 Trabalhos Futuros . . . . . . . . . . . . . . . . . 73

A Diagrama de Classes no $A M^{2} C$

$\begin{array}{ll}\text { B Diagrama de Classes no } i A M^{2} C & 76\end{array}$

$\begin{array}{lll}\text { C Estruturas de Dados e Tratamento de Mensagens no } A M^{2} C & 77\end{array}$

C.1 Introdução . . . . . . . . . . . . . . . . . . 77

C.2 Estruturas de Dados . . . . . . . . . . . . . . . . . . 78

C.2.1 Estruturas de Dados Gerais . . . . . . . . . . . . . . . . 78

C.2.2 Estruturas de Dados em Mssinit $\ldots \ldots \ldots \ldots$. . . . . . . . . . 79

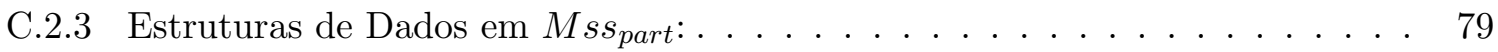

C.3 Definição das Mensagens . . . . . . . . . . . . . . . . . . . . . . 80

C.3.1 Mensagens Tratadas por $M s s_{\text {init }}$. . . . . . . . . . . . . . . 80

C.3.2 Mensagens Tratadas pelo $M s s_{\text {part }}$. . . . . . . . . . . . . 81

C.3.3 Mensagens Tratadas por um Mh: . . . . . . . . . . . . . 83

C.4 Tratamento das Mensagens . . . . . . . . . . . . . . . . . . . 83

C.4.1 Mensagens Tratadas por Mssinit . . . . . . . . . . . . . 85

C.4.2 Mensagens Tratadas por $M s s_{\text {part }}: \ldots \ldots \ldots \ldots$

C.4.3 Mensagens Tratadas no Mh: . . . . . . . . . . . . . . . . . 90

D Estruturas de Dados e Tratamento de Mensagens no iAM $M^{2} C \quad 91$

D.1 Introdução . . . . . . . . . . . . . . . . . . . . . . . . 91

D.2 Estruturas de Dados . . . . . . . . . . . . . . . . . . . . . . . 91

D.2.1 Estruturas de Dados Gerais . . . . . . . . . . . . . . . . . 92

D.2.2 Estruturas de Dados em Mss $_{\text {init }}$. . . . . . . . . . . . . . . . 92

D.2.3 Estruturas de Dados em Mss $s_{\text {part }}$. . . . . . . . . . . . . . . . . . 92

D.2.4 Estruturas de Dados no $I M S: \ldots \ldots \ldots \ldots$. . . . . . . . . . . . . 93

D.3 Definição das Mensagens . . . . . . . . . . . . . . . . . . . 93

D.3.1 Mensagens Tratadas por Mssinit . . . . . . . . . . . . . . . . 94

D.3.2 Mensagens Tratadas pelo $M s s_{\text {part }}: \ldots \ldots \ldots \ldots \ldots$. . . . . . . . 94 
D.3.3 Mensagens Tratadas por um IMS: . . . . . . . . . . . . . . . . . 96

D.3.4 Mensagens Tratadas por um Mh: . . . . . . . . . . . . . . . . . 97

D.4 Tratamento das Mensagens _ . . . . . . . . . . . . . . . . . . . . 97

D.4.1 Mensagens Tratadas por Mssinit . . . . . . . . . . . . . . . . 99

D.4.2 Mensagens Tratadas por Mss part $\ldots \ldots \ldots \ldots$. . . . . . . . . 101

D.4.3 Mensagens Tratadas no IMS: . . . . . . . . . . . . . . . 105

D.4.4 Mensagens Tratadas no Mh: . . . . . . . . . . . . . . . . 107 


\section{Lista de Figuras}

1.1 Rede móvel estruturada . . . . . . . . . . . . . . . . . . . . . 2

2.1 Esquema Hierárquico Utilizando Técnicas de Caching . . . . . . . . . . . . . . 9

3.1 Modelo de Sistema no Protocolo $A M^{2}$ C . . . . . . . . . . . . . . . . . 13

3.2 Funcionamento do protocolo $A M^{2} C \ldots \ldots \ldots \ldots \ldots \ldots$

3.3 Exemplo de Hand-off no $A M^{2} C \ldots \ldots \ldots \ldots$

4.1 Comparação entre os protocolos $A M^{2} C$ e $i A M^{2} C \ldots \ldots \ldots \ldots$

4.2 Modelo de Sistema no Protocolo $i A M^{2}$ C . . . . . . . . . . . . . . . . . 27

4.3 Exemplo de Funcionamento do protocolo $i A M^{2} C \ldots \ldots \ldots \ldots$

4.4 Protocolo de Hand-off no $i A M^{2} C \ldots \ldots \ldots \ldots \ldots \ldots$

5.1 Composição do protocolo $A M^{2} C \ldots \ldots \ldots \ldots \ldots \ldots$

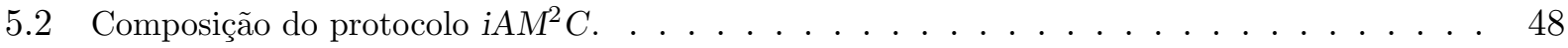

5.3 Exemplo de cenário determinístico no protocolo $A M^{2} C \ldots \ldots \ldots \ldots$

5.4 Exemplo de cenário determinístico no protocolo $i A M^{2} C \ldots \ldots \ldots \ldots$

5.5 Comparação do custo wired total. . . . . . . . . . . . . . . . . . 57

5.6 Comparação do custo wired total. . . . . . . . . . . . . . . . . . 58

5.7 Influência do número de Msss no custo wired. . . . . . . . . . . . . . . . . . . . 59

5.8 Influência do número de Msss no custo wired. . . . . . . . . . . . . . . . . . . . 59

5.9 Distribuição da sobrecarga no $i A M^{2} C \ldots \ldots \ldots \ldots \ldots$

5.10 Comparação do custo wireless nos protocolos. . . . . . . . . . . . . . . . . . . 61

5.11 Comparação da porcentagem de multicasts abortados. . . . . . . . . . . . . . . . . 62

5.12 Comparação da porcentagem de multicasts abortados. . . . . . . . . . . . . . . 63

5.13 Comparação da duração média de um multicast. . . . . . . . . . . . . . . . . . 64 
5.14 Comparação da duração média de um multicast. . . . . . . . . . . . . . . . . . . . 65

A.1 Diagrama de Classes do $A M^{2} C \ldots \ldots \ldots \ldots \ldots \ldots$

B.1 Diagrama de Classes do $i A M^{2} C \ldots \ldots \ldots \ldots \ldots \ldots$ 


\section{Lista de Tabelas}

3.1 Mensagens do protocolo $A M^{2} C \ldots \ldots \ldots \ldots \ldots$

3.2 Seqüência de eventos mais relevantes ocorridas em $M s s_{o}$ e $M s s_{n}$. . . . . . . . . . 20

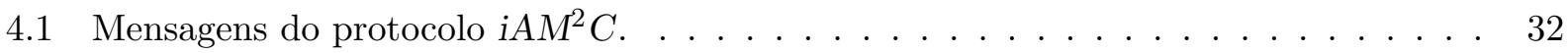

4.2 Seqüência de eventos mais relevantes ocorridas em $M s s_{o}$ e $M s s_{n}$. . . . . . . . . . . 34

5.1 Resumo comparativo dos protocolos $A M^{2} C$ e $i A M^{2} C \ldots \ldots \ldots 6$

C.1 Principais Métodos Utilizados no Tratamento das Mensagens no $A M^{2} C$. . . . . 84

C.2 Principais Métodos Utilizados no Tratamento das Mensagens no $A M^{2} C$. . . . . 85

C.3 Eventos ocorridos em um $M s s$ no $A M^{2} C \ldots \ldots \ldots \ldots$

D.1 Principais Métodos Utilizados no Tratamento das Mensagens no $i A M^{2} C \ldots \ldots$. . . 98

D.2 Principais Métodos Utilizados no Tratamento das Mensagens no $i A M^{2}$ C . . . . . . 99

D.3 Eventos ocorridos em um Mss. . . . . . . . . . . . . . . . 100 


\section{Capítulo 1}

\section{Introdução}

Com o grande crescimento ocorrido nas áreas de telefonia celular, redes locais sem fio [4, 16] e serviços via satélite, em um futuro próximo será possível que informações e recursos sejam acessíveis a seus usuários a qualquer momento, independente do lugar onde estejam situados. Cada vez mais computadores portáteis e assistentes pessoais digitais ( $P D A$ 's) estão disponíveis no mercado e cada vez mais esses equipamentos deverão ter a capacidade de se comunicar com outros computadores em rede e computadores móveis. Esse ambiente computacional é chamado de Computação Móvel ou Computação Nômade [23].

A computação móvel constitui um novo paradigma computacional que está revolucionando o desenvolvimento e uso de sistemas distribuídos [15]. Nesse novo ambiente, usuários têm acesso a serviços independentemente de suas localizações durante suas movimentações. Dessa forma, computação móvel amplia o conceito de computação distribuída. Na Figura 1.1 é apresentado o modelo de rede móvel estruturada de um sistema distribuído com computadores móveis. Este modelo consiste de duas partes: uma formada por uma infra-estrutura fixa de comunicação, com componentes convencionais como hosts, roteadores, bridges, etc (rede fixa); e outra, interligada à primeira, representada por um conjunto de áreas geográficas (células) onde é possível haver comunicação sem fio entre os dispositivos móveis (computadores móveis localizados na célula). Cada célula é atendida por transmissores de rádio-freqüência (estações-bases ou Msss, de Mobility Support Station). A comunicação entre um dispositivo móvel e qualquer outro dispositivo é intermediada por uma estação-base. Neste trabalho estamos assumindo que toda a comunicação na rede fixa e entre Msss é confiável, isto é, que não há perdas e/ou corrupção de mensagens.

A computação móvel introduz uma série de problemas inexistentes em sistemas distribuídos 


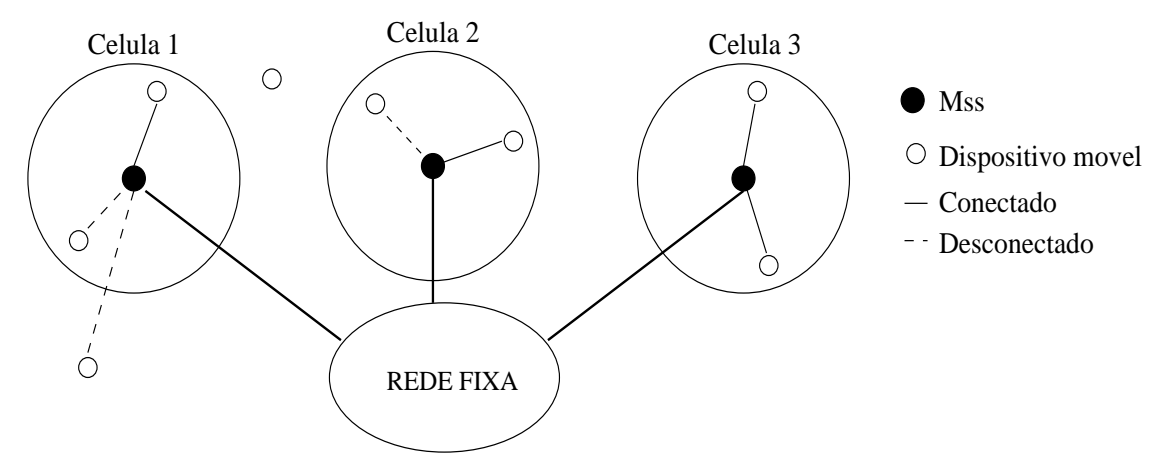

Figura 1.1: Rede móvel estruturada

tradicionais, que são causados, principalmente, pelos seguintes fatores:

- Comunicação sem fio: a conexão sem fio é muito mais instável do que a conexão com fio, pois está sujeita às interferências na transmissão de sinais, regiões não cobertas, ecos, etc. Além disto, conexões sem fio apresentam problemas como largura de banda menor, alta taxa de erros (cerca de cinco a dez vezes a ordem de grandeza da taxa de erros na comunicação com fio), desconexões freqüentes (sejam voluntárias ou não), maior risco à segurança (mais facilidade na interceptação de mensagens e no rastreamento de computadores móveis), entre outros.

- Mobilidade: a capacidade de um computador móvel mudar de localização enquanto está se comunicando com a rede provoca diferenças na maneira como algumas informações são vistas. Certos dados de configuração estáticos na computação tradicional assumem uma natureza dinâmica na computação móvel. Por exemplo, um computador com endereço fixo pode ser configurado estaticamente para acessar o servidor mais próximo (ou adequado), enquanto que um computador móvel necessita de um mecanismo para selecionar dinamicamente o servidor a ser usado. Além disto, precisa-se tratar de determinar o endereço atual de um dispositivo móvel a fim de que a comunicação com tal dispositivo torne-se viável.

A mobilidade dos computadores móveis também gera problemas relacionados à gerência de localização de tais elementos (como o custo de pesquisa da localidade de um determinado dispositivo), à heterogeneidade da computação móvel (como, por exemplo, a carga dinâmica das estações-base), entre outros problemas.

- Portabilidade: em contraste com computadores tradicionais, dispositivos móveis são meno- 
res e mais leves a fim de facilitar a portabilidade. Por isso, recursos como energia ${ }^{1}$, capacidade de processamento, memória principal, existência de memória secundária e interface com o usuário são limitados e precisam ser levados em conta no projeto de aplicações, serviços e protocolos para computação móvel.

\subsection{Motivação}

Apesar dos problemas mencionados anteriormente, é provável que em um futuro próximo seja possível usufruir de uma série de aplicações a partir de computadores móveis. Algumas dessas aplicações podem requerer alguma forma de coordenação ou sincronização entre grupos de clientes móveis. Exemplos de tais aplicações são planejamento e execução estratégica de missões, otimização de rotas de veículos, trabalho corporativo, e outros. Para dar suporte à coordenação entre usuários, um dispositivo móvel deve ser capaz de difundir uma mensagem (multicast) para um grupo fixo de computadores móveis de forma confiável. Algumas aplicações exigem ainda que o multicast seja atômico (com uniformidade dinâmica [3]), ou seja, que a mensagem de multicast seja processada ou por todos ou por nenhum dos membros do grupo, garantindo assim uma visão consistente de um estado global distribuído. Em outras palavras, aplicações que utilizam multicast baseado em uma semântica de entrega atômica de mensagens adotam o conceito de validade de um multicast, que estipula o seguinte:

- Se algum elemento destinatário de um multicast $M$ não confirmar o recebimento do mesmo ou não for capaz de processar a mensagem, então $M$ não será processado por nenhum outro membro do grupo;

- Se todos os destinatários de um multicast $M$ confirmarem seu recebimento e forem capazes de processá-lo, então $M$ é confirmado e todos os destinatários que estiverem ativos irão processar o multicast.

Desta forma, é relevante a disponibilização de serviços de multicast confiável que garantam a entrega de mensagens todos-ou-nenhum em uma rede móvel, onde os dispositivos podem mudar de ponto de acesso e/ou ficarem desconectados freqüentemente.

\footnotetext{
${ }^{1}$ Uma vez que a tecnologia de construção de baterias não tem acompanhado a evolução de outros segmentos da informática, o fator "energia" é considerado o maior problema no uso de computadores móveis.
} 


\section{$1.2 \quad$ Objetivos e Resultados}

O trabalho de pesquisa aqui proposto diz respeito ao desenvolvimento, implementação, avaliação e comparação de dois protocolos para multicast atômico em computação móvel (o $A M^{2} C$ [13] e o $\left.i A M^{2} C[10]\right)$. Os protocolos foram concebidos para redes móveis estruturadas, como exemplificado na Figura 1.1. Simulamos o $A M^{2} C$ e o $i A M^{2} C$ e obtivemos dados que permitiram comparar os dois protocolos, identificando as vantagens e desvantagens de cada um. Os resultados das simulações também demonstraram que ambos os protocolos garantem a atomicidade de entrega de mensagens requerida, realizando multicast de forma confiável.

\subsection{Principais Contribuições}

A principal contribuição deste trabalho consiste no projeto e implementação de dois protocolos que realizam multicast confiável e atômico entre grupos de usuários móveis. Os protocolos podem ser úteis para aplicações que necessitem dar suporte à ações coordenadas entre dispositivos móveis. O trabalho compara (através de simulações) os protocolos em diversas configurações de rede e padrões de mobilidade dos Mhs, identificando em quais cenários um ou outro protocolo é mais adequado.

\subsection{Organização do Texto}

Esta dissertação está organizada da seguinte forma: o próximo capítulo apresenta os resumos de alguns trabalhos relacionados com os protocolos aqui propostos. Os Capítulos 3 e 4 descrevem, respectivamente, os protocolos $A M^{2} C$ e $i A M^{2} C$ em detalhes. O Capítulo 5 apresenta a forma como os protocolos foram implementados e os testes realizados com as simulações, juntamente com suas interpretações. No Capítulo 6 é relatada a experiência adquirida com as implementações e simulações dos protocolos, bem como as principais dificuldades encontradas durante este processo. Finalmente, o Capítulo 7 resume os princiapis pontos do trabalho, concluindo o mesmo e apresentando os trabalhos futuros. 


\section{Capítulo 2}

\section{Trabalhos Relacionados}

Este capítulo descreve sucintamente os principais trabalhos relacionados aos protocolos $A M^{2} \mathrm{C}$ e $i A M^{2} C$. Desta maneira, a seção 2.1 apresenta protocolos e algoritmos relacionados com multicast de mensagens. Já a seção 2.2 aborda algumas das técnicas utilizadas para o gerenciamento da localização de unidades móveis que, como veremos nos capítulos seguintes, serão utilizadas pelo protocolo $i A M^{2} C$.

\subsection{Trabalhos Relacionados com Multicast}

Existem vários protocolos e/ou algoritmos relacionados com a entrega confiável de mensagens multicast para grupos de hosts móveis. Em outros trabalhos são implementados protocolos que realizam multicast de forma não confiável. Porém, com exceção dos protocolos analisados e implementados neste trabalho, desconhecemos outros protocolos que realizem multicast atômico, ou seja, que implementem uma semântica de entrega todos-ou-nenhum.

O protocolo MCAST [1], de Acharya e Badrinath, garante a entrega confiável de mensagens a seus respectivos destinatários. Neste caso, confiabilidade significa que eventualmente a mensagem de multicast será entregue "exatamente uma vez" a todos os hosts móveis destinatários alcançáveis. A política de entrega de mensagens no $M C A S T$ é garantida mesmo considerando que um $M h$ pode se conectar a diferentes Msss e em diferentes momentos, e que cópias de uma mensagem podem chegar nos Msss em momentos diferentes devido à latência de comunicação na rede. O protocolo utiliza a estratégia de difundir cópias de uma mensagem para todos os Msss, os quais se encarregam de retransmitir a mensagem para todo $M h$ local e que seja um elemento destinatário.

O modelo de sistema do MCAST para interconexão móvel é semelhante ao utilizado pelo pro- 
tocolo $A M^{2} C$ (como veremos no capítulo seguinte), o qual é baseado em estações de suporte à mobilidade na rede fixa. O MCAST assume que a rede fixa garante a entrega confiável e seqüencial de mensagens entre dois Msss e que a rede sem fio garante a entrega de mensagens em ordem FIFO para os hosts móveis.

Uma implementação de um mecanismo de retransmissão de pacotes para lidar com as características dinâmicas de um grupo multicast é vista em [11]. Este mecanismo foi implementado no protocolo RM2 [27] (Reliable Mobile Multicast), que é um protocolo adaptativo para multicast confiável projetado tanto para ambientes fixos como para ambientes móveis.

O RM2 provê a entrega em seqüência e sem perda de pacotes para usuários móveis, utilizando uma abordagem hierárquica para o multicast. Além dos hosts móveis, também fazem parte do modelo de sistema do protocolo os $R S$ s (servidores de retransmissão) e os $M R$ s (roteadores de multicast).

O protocolo RM2 se utiliza dos resultados de uma análise entre a carga na rede gerada quando pacotes são retransmitidos via multicast ou unicast, e a carga excedente gerada pela quantidade de pacotes duplicados observados na rede. A partir desta análise, chega-se a um algoritmo eficiente que leva em consideração essas duas medidas e que faz o melhor uso possível dos recursos da rede.

Em Raynal et. al. [26] é apresentado um algoritmo eficiente para a entrega de mensagens em ordem causal, onde é utilizado um vetor de timestamps. Para garantir esta semântica de entrega, uma mensagem (seja na rede fixa ou no enlace sem fio) precisa carregar consigo somente a informação das mensagens predecessoras diretas em relação a cada elemento destinatário. Assim, se duas mensagens M1 e M2 possuem o mesmo elemento destinatário e se o envio de M1 precede causalmente o envio de $M 2$, então a entrega de $M 1$ será feita antes da entrega de M2. Ainda, o algoritmo leva em consideração a informação extra que é mantida nos algoritmos existentes (como a dependência transitiva entre as mensagens) e como essa sobrecarga pode ser eliminada sem comprometer a corretude do algoritmo.

Alagar e Venkatesan [2] apresentam três algoritmos (que são uma extensão do algoritmo de Schiper, Raynal e Toueg [21]) para entrega causal e confiável de mensagens em sistemas de computação móvel. O primeiro algoritmo lida com restrições de recursos dos elementos móveis, mas não é facilmente escalável em relação ao número de Mhs no sistema. Já o segundo, elimina a desvantagem do primeiro pelo custo de restringir alguns tipos de mensagens. O terceiro algoritmo é uma combinação dos dois anteriores. Nestes algoritmos, diferentemente do que ocorre em [26], a maioria das tarefas de ordenação e filtro de mensagens são processadas nos Msss, que atuam como representantes dos 
seus Mhs locais.

Outros trabalhos $[20,18,31]$ tratam de extensões do protocolo de multicast IP para hosts móveis, que não provê quaisquer garantias de entrega dos multicasts. A versão atual do Mobile IP [24] possui dois métodos para multicast entre hosts móveis, chamados de assinatura remota e tunelamento bidirecional (remote subscription e bi-directional tunneling). Os dois métodos são baseados no uso de home agent e foreing agent, como no Mobile IP original.

Harrison et al. propõe um mecanismo chamado MoM [18] para serviços de multicast. Tal mecanismo resolve problemas de ajuste de convergência e duplicação de multicast definindo um Provedor Específico de Multicast (Designated Multicast Service Provider - DMSP) dentre todos os home agents que têm um host móvel conectado em um link diferente.

A idéia básica do MoM é usar a funcionalidade do home agent do IETF Mobile IP [24] para entregar pacotes multicast aos dispositivos móveis de forma eficiente. O modelo mantém a escalabilidade do mecanismo através de uma otimização do DMSP por grupo multicast e do uso de tunelamentos dinâmicos de multicast para foreing networks.

Em [30] muitas alternativas na escolha do DMSP são consideradas e seus desempenhos são avaliados usando um simulador de eventos discretos. Ainda, Kanodia et al. em [19] propõem um mecanismo de adaptação utilizando um algoritmo competitivo para chavear dinamicamente entre o protocolo de tunneling e subscription.

Anastasi et. al. [17] propõem um protocolo para multicast confiável entre hosts móveis onde o remetente de cada mensagem pode selecionar a semântica de entrega da mensagem: FIFO, causal ou total. Neste protocolo, o grupo de remetentes e destinatários pode ser dinâmico, ou seja, um $M h$ pode entrar ou sair do grupo dependendo da necessidade da aplicação. Ao contrário de outros protocolos, esta proposta não possui uma componente de hand-off, de forma que nenhuma mensagem neste sentido é trocada entre $M s s$ s durante a migração de um $M h$. Isto torna o protocolo eficiente em cenários com muitas migrações e com um número grande de elementos móveis. Por outro lado, o protocolo requer que os Msss periodicamente re-difundam (re-broadcasting) multicasts pendentes e que os $M h s$ requisitem explicitamente retransmissões de mensagens "perdidas" através de Negative Acks $(N A C K S)$.

Maffeis et al. descrevem em [22] um serviço genérico e confiável na camada de transporte, que oferece multicast preservando-se a ordem de chegada das mensagens para diferentes protocolos de comunicação. Este serviço é implementado como um conjunto chamado de servidores GTS (Generic Multicast Transport Service) que se comunicam com outros servidores GTS ou com os clientes. 
Alguns dos serviços oferecidos pelo GTS são: tolerância a falhas, preservação da ordem de entrega de mensagens multicast, comunicação cifrada, reconfiguração e operações em modo desconectado.

\subsection{Localização de Dispositivos Móveis}

Em Computação Móvel o gerenciamento da localização de unidades móveis se torna essencial para a comunicação com estes tipos de hosts.

O gerenciamento de localização essencialmente consiste de buscas (lookups) pela atual localização de um dispositivo móvel quando uma mensagem é enviada ou uma chamada é gerada por este, e de atualizações de localização (updates), quando o dispositivo se move para uma nova região.

Pitoura e Samaras [25] apresentam técnicas de gerenciamento de estruturas de dados relacionadas à localização (registros de localização, ou Location Databases - LDs), ou seja, registros usados para armazenar a informação sobre a localização de usuários móveis. Neste sentido, são consideradas duas arquiteturas básicas de $L D s$ : a arquitetura de duas camadas (two-tier architecture) e a arquitetura hierárquica, que é o alvo desta discussão. Esses modelos são baseados em três níveis, que são a rede fixa (fixed network), a rede de acesso (access network) e a rede inteligente (intelligent network) [29]. A primeira é a rede com fio convencional; a segunda é a interface entre os usuários móveis e a rede fixa; já a terceira é a rede que conecta qualquer registro de localização.

A arquitetura hierárquica é uma extensão do esquema de duas camadas através de uma hierarquia dos registros de localização conectados por meio da rede inteligente. Neste esquema, um registro em um nível mais alto contém informações de localização de usuários mapeados nos registros dos níveis abaixo. Usualmente, esta arquitetura é baseada em uma estrutura de árvore. Assim, um registro de uma folha serve a uma única célula e contém informações sobre a localização dos usuários localizados em tal célula. Um registro de um nó intermediário mantém informações sobre a localização dos usuários registrados nas células da sub-árvore correspondente. Esta informação pode ser um ponteiro para um registro de um nível mais baixo ou o endereço (identificador da célula) da localização do usuário.

Algumas técnicas são utilizadas pelo modelo hierárquico a fim de reduzir o custo dos lookups e updates. Estaremos nos concentrando no primeiro caso. A partir de agora, adotamos a mesma notação utilizada em [25], onde $L C A(i, j)$ denota o ancestral comum mais próximo entre as células $i$ e $j$.

Uma das técnicas usadas na arquitetura hierárquica é o caching. Quando uma chamada é feita 
(ou mensagem é enviada) da célula $i$ para um usuário $x$, localizado na célula $j$, o procedimento de busca percorre a árvore "subindo" de $i$ até o $L C A(i, j)$, e depois "descendo"até $j$. Da mesma forma, deve-se considerar um acknowledgment que retorna de $j$ até $i$. O caching efetivamente ocorre durante este retorno, quando um par de ponteiros (bypass pointers), chamados de forward bypass e reverse bypass, é criado. O primeiro é uma entrada de um ancestral de $i$, digamos $s$, que aponta para um ancestral de $j$, digamos $t$. O segundo é um ponteiro de $t$ para $s$. Dessa forma, na próxima chamada da célula $i$ para o usuário $x$, a mensagem de busca "sobe" na árvore até encontrar $s$, e então segue direto para o registro $t$. De forma similar, o acknowledgment é processado no sentido inverso.

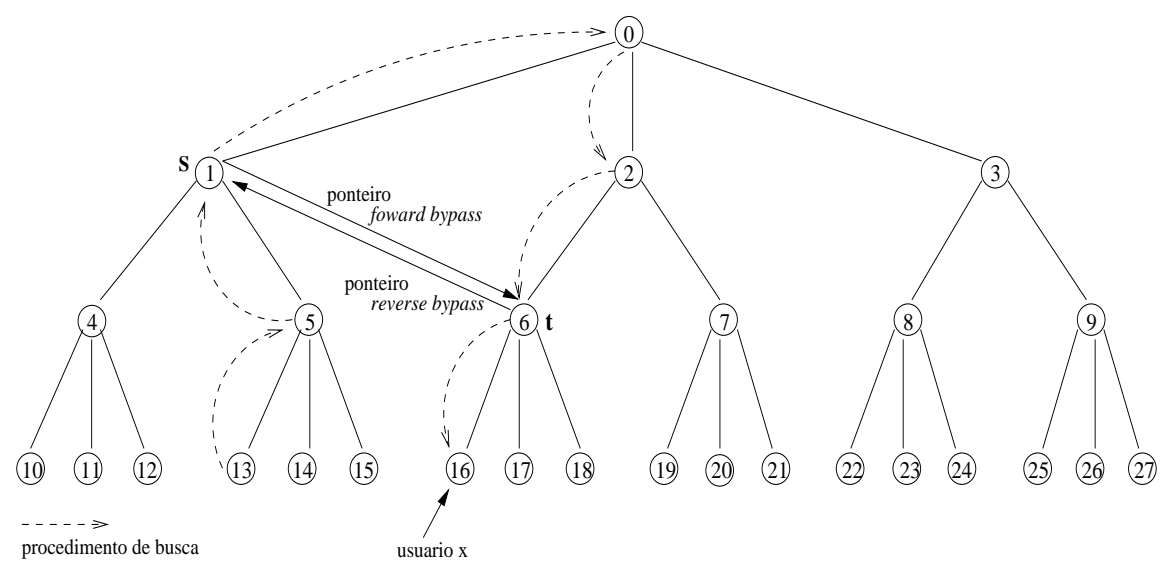

Figura 2.1: Esquema Hierárquico Utilizando Técnicas de Caching

A figura 2.1 exemplifica o esquema hierárquico com a utilização de técnicas de caching, onde uma chamada é feita da célula 13 para o usuário $x$ localizado na célula 16. Um ponteiro forward bypass é inserido na árvore apontando do nó 1 para o nó 6 , enquanto que um ponteiro reverse bypass por sua vez, aponta do nó 6 para o nó 1 . Desta maneira, na próxima chamada da célula 13 para o usuário $x$ o procedimento de busca percorre a árvore do nó 13 até o nó 1 e, então, pode seguir até o nó 6 ou via $L C A(1,6)$, ou seja, o nó 0 , ou através do ponteiro forward bypass (caminho mais curto). Em ambos os casos, nenhuma busca é efetuada nos registros dos nós 0 e 2.

O nível dos nós $s$ e $t$ onde o par de bypass pointers é criado pode variar. No modelo simple caching, $s$ e $t$ são folhas. Já no modelo level caching, $s$ e $t$ são nós de qualquer nível e, geralmente, possuem níveis diferentes. Estes mesmos modelos são utilizados em esquemas hierárquicos que mantém a própria localização do usuário nos registros, ao invés de ponteiros.

Uma outra técnica utilizada para reduzir o custo dos lookups é a replicação. Nesta técnica, a informação sobre a localização de um usuário é replicada (de acordo com certo algoritmo) em 
diversos registros, de forma a encurtar o processo de localização do usuário/dispositivo destinatário de uma chamada (ou mensagem). No entanto, a cada vez que o elemento móvel migrar, o seu endereço em todas as réplicas terá que ser atualizado. Por isto, a replicação só é usada quando o benefício desta é maior que seu custo.

Veremos que um dos protocolos discutidos neste trabalho $\left(i A M^{2} C\right)$ adota um gerenciamento de localização em duas camadas, que se utiliza de uma forma específica de caching e replicação. A principal diferença consiste no fato de que no $i A M^{2} C$ o objetivo principal é reduzir o custo da difusão de mensagens pela rede fixa, e não o de localizar um usuário destinatário de uma mensagem. Ainda assim, este protocolo faz uso de uma representação da área de cobertura em dois níveis hierárquicos (domínio e célula), e usa replicação para paralelizar o acesso e a difusão de multicasts. 


\section{Capítulo 3}

\section{O Protocolo $A M^{2} C$}

\subsection{Motivação}

Um serviço de multicast confiável para redes com computadores (hosts) móveis é essencial para o desenvolvimento de aplicações baseadas na coordenação e sincronização de ações entre usuários móveis. Aplicações que além disto precisam garantir que as cópias de algum dado nos hosts móveis sejam mantidas perfeitamente sincronizadas demandam um protocolo para multicast atômico, ou seja, em que ou todos ou nenhum dos hosts do grupo processem cada mensagem.

Um exemplo de tal aplicação poderia ser um sistema de controle de estoque para vendedores ambulantes, que necessitam manter uma visão consistente dos dados armazenados nos hosts móveis de todos os membros do grupo. Suponha que o computador móvel de cada vendedor contém uma lista de produtos (e quantidades de itens) que podem ser vendidos diretamente sem que se faça necessária uma consulta a outros vendedores ambulantes, e que a quantidade total de itens de produtos disponíveis para venda é a soma das quantidades de itens registrados em cada um dos computadores dos vendedores. Assim, caso um vendedor precise vender mais itens do que a quantidade indicada em seu computador, este terá que requisitar/reservar também itens do produto originalmente alocados a outro(s) vendedor(es). Esta informação sobre a reserva de itens deve estar disponível para todos os vendedores, a fim de garantir uma visão consistente do conjunto total de itens disponíveis e evitar vendas não sincronizadas do mesmo lote de itens. Em particular, a reserva não pode ser confirmada se um dos vendedores não estiver "conectado" à rede (off-line), pois este vendedor pode estar executando a venda de algum lote de itens a ele alocado e que esteja sendo também reservado por outro vendedor.

Protocolos Two Phase Commit (2PC) [14] representam uma possibilidade interessante para a 
implementação de serviços de multicast atômico, devido à sua simplicidade. No entanto, é importante que o protocolo $2 \mathrm{PC}$ seja executado pelos hosts da rede fixa, que apresentam alta confiabilidade e disponibilidade, quando comparados com os hosts móveis. Com isto, e o uso de time-outs para a transmissão sem fio, diminui-se sensivelmente o risco de bloqueios, que são o principal problema de protocolos $2 \mathrm{PC}$.

De forma a dar suporte à aplicações em redes móveis que necessitem de um multicast atômico, foi projetado um protocolo para multicast atômico entre hosts móveis, chamado de $A M^{2} C$ [13]. Essencialmente, o $A M^{2} C$ consiste de um Two Phase Commit com uma fase adicional para "coleta de lixo". Neste protocolo, uma mensagem de multicast só é confirmada se todos os destinatários estiverem disponíveis (alcançáveis e dispostos a processar a mensagem) durante a primeira fase do protocolo. Neste caso o multicast é confirmado, caso contrário é abortado. A segunda fase garante que todos os hosts móveis serão eventualmente informados sobre o estado final do multicast, mesmo que isso requeira várias retransmissões deste estado para os Mhs. Finalmente, a última fase é executada a fim de remover a informação sobre o estado final do multicast. A seção 3.3 discute o $A M^{2} C$ de forma mais detalhada.

\subsection{Modelo de Sistema e Suposições}

O modelo de sistema é composto por duas categorias de máquinas: as estações de suporte à mobilidade (Mobility Support Stations, ou Msss) e os hosts móveis (Mhs).

Um Mss é um host da rede fixa que possui uma interface para comunicação sem fio e que está interligado aos demais Msss pela rede convencional. Cada Mss define uma região geográfica (célula) onde é possível enviar e receber mensagens para/de todos os Mhs que estejam localizados na célula (estes constituem o conjunto LocalMhs). Neste modelo, assumimos que Msss não falham e que a comunicação pela rede fixa é confiável.

Os hosts móveis são elementos que possuem um identificador único no sistema e podem estar em dois possíveis estados: ativados ou desativados. Quando está desativado um $M h$ não é capaz de receber ou enviar nenhuma mensagem. Para entrar no sistema, um $M h$ envia a mensagem Join para o Mss responsável pela célula na qual se encontra. Uma vez que o $M h$ se torna membro do sistema, tal Mss passa a ser o Mss responsável pelo $M h$ (denominado de $M s s_{M h}$ ). De maneira análoga, antes de sair do sistema um $M h$ deve enviar a mensagem Leave para seu $M s s_{M h}$.

Hosts móveis são capazes de migrar de uma célula para outra. Ao entrar na região de uma 
nova célula um $M h$ envia a mensagem $\operatorname{Greet}\left(M s s_{M h}\right)$ para o $M s s$ da nova célula (que chamaremos genericamente de $M s s_{n}$ ), indicando o $M s s$ da célula anterior, $M s s_{M h}$. A partir daí é iniciado o protocolo de hand-off entre o novo e o antigo Mss. Um hand-off pode ser entendido como o processo de transição de um $M h$ de uma célula para outra, onde uma série de ações devem ser tomadas a fim de efetuar o registro do $M h$ na nova célula e de transferir alguns dados considerados relevantes para a aplicação. A seção 3.5 descreve o protocolo de hand-off em detalhes.

Toda vez que um $M h$ volta ao estado ativo na mesma célula na qual se encontrava antes da sua desativação, a mensagem Greet também é enviada. Neste caso específico, o protocolo de hand-off não é iniciado pelo $M s s_{M h}$, uma vez que não houve troca de célula. Neste modelo, abstraímos dos detalhes de como ocorre a "percepção" da entrada de um $M h$ em uma nova célula, por entender que isto pode variar dependendo da tecnologia de comunicação sem fio sendo utilizada e por não ser relevante do ponto de vista dos protocolos sendo estudados.

A interface de comunicação sem fio, além de possuir uma menor largura de banda passante, também apresenta uma taxa maior de erros transientes, ou seja, que podem ocorrer esporadicamente e que geralmente têm curta duração. Por isto, qualquer protocolo envolvendo uma transmissão de dados por um meio sem fio deve contemplar repetidas tentativas de transmissão por este meio. Na descrição do protocolo $A M^{2} C$ (assim como do $i A M^{2} C$ ) de certa forma também abstraímos deste detalhe, simplesmente indicando uma única transmissão pelo meio sem fio e um tempo máximo de espera pela confirmação de um $M h$. Ou seja, no caso do uso de uma tecnologia de rede sem fio que faça repetidas tentativas de transmissão, então o envio de uma mensagem em nosso modelo deve ser interpretado como o período compreendido entre o início de uma série de retransmissões até o recebimento da mensagem pelo seu elemento destino.

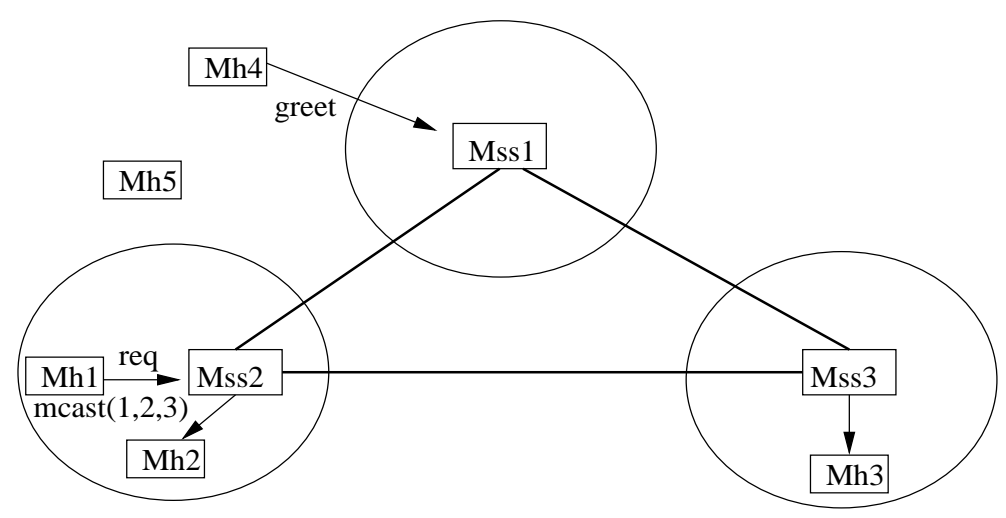

Figura 3.1: Modelo de Sistema no Protocolo $A M^{2} C$. 
A Figura 3.1 exemplifica um sistema composto por três $M s s$ s e cinco $M h s$, onde o $M h 1$ faz uma requisição de multicast de uma mensagem para $M h 2$ e $M h 3$.

Resumindo, as principais suposições do modelo são:

1. Msss não falham e todos os Msss estão conectados. É assumido que os hosts fixos também possuem recursos suficientes para o armazenamento e o processamento de dados e mensagens;

2. A comunicação na rede fixa é confiável, isto é, as mensagens em algum momento chegarão a seu destino. A entrega das mensagens na rede fixa é feita em ordem causal (esta semântica de entrega pode ser facilmente implementada utilizando-se um vetor de timestamps, como proposto por Raynal et. al. [26] - vide seção 2.1);

3. A comunicação sem fio não é confiável, mas a latência máxima de comunicação no meio sem fio é fixa e conhecida, ou seja, é possível determinar uma falha na transmissão sem fio;

4. Em cada instante, todo $M h$ do sistema está associado a um único $M s s\left(M s s_{M h}\right)$;

5. Cada $M h$ possui uma identificação única no sistema que independe de sua localização. Antes de deixar o sistema um $M h$ envia uma mensagem Leave para seu $M s s_{M h}$. Se o mesmo dispositivo eventualmente retornar ao sistema o fará através da mensagem Join, e receberá uma nova identificação;

6. Se um $M h$ está ativo e se encontra na célula de um $M s s_{M h}$, então responde a qualquer mensagem enviada por $M s s_{M h}$. Caso contrário, ele não responde a nenhuma mensagem;

7. Depois de ter se anunciado a um novo $M s s\left(M s s_{n}\right)$, um $M h$ não interage com nenhum outro Mss que não seja $M s s_{n}$.

\subsection{Descrição do Protocolo}

O protocolo de multicast atômico $A M^{2} C$ é uma extensão do protocolo $M C A S T$ [1] de Acharya e Badrinath. Este último implementa uma semântica de entrega exatamente uma vez, garantindo assim que todos os destinatários alcançáveis de uma certa mensagem vão recebê-la uma única vez. Todavia, o MCAST não provê nenhuma confirmação para os destinatários sobre o fato de a mensagem ter sido ou não aceita pelos mesmos. Já o $A M^{2} C$ implementa uma semântica de entrega todos ou nenhum, ou seja, realiza um multicast atômico. Atomicidade significa que uma mensagem 
só será processada pelos destinatários se todos estiverem disponíveis no momento da transmissão do multicast e confirmarem o recebimento do mesmo. Além disso, o $A M^{2} C$ informa ao grupo de destinatários de uma mensagem se esta foi ou não aceita por todos os membros do grupo.

O protocolo de multicast atômico $A M^{2} C$ é executado em 3 fases. A seguir, serão descritos os principais eventos em cada uma das fases:

\section{- FASE I}

Um host móvel, dito $M h_{\text {sender }}$, envia uma requisição de multicast de uma mensagem $M$ para o seu Mss responsável, que neste caso passa a iniciar o processo de difusão na rede fixa e, por isso, será denominado de $M s s_{\text {init }}$. Juntamente com a mensagem segue uma lista dos destinatários do multicast (M.Dest). Mssinit difunde então a nova requisição para todos os Msss (assim como ocorre no MCAST [1]) e fica aguardando uma resposta dos mesmos. Cada $M s s$ por sua vez, envia $M$ para todos os $M h$ s que estão sob sua responsabilidade (LocalMhs) e que fazem parte de M.Dest, e espera T1 unidades de tempo por uma resposta destes. Caso não haja nenhum $M h$ local pertencente à lista de destinatários, ou se todos os $M h$ s locais respondem com um $0 \mathrm{k}_{M}$ antes de T1 se esgotar, então o $M s s$ envia uma mensagem $0 \mathrm{k}_{M}$ para $M s s_{i n i t}$. Caso contrário, é enviada a mensagem NOk $_{M}$. Esta mensagem portanto sintetiza as respostas de todos os Mhs locais que são destinatários. O mesmo é feito pelo $M s s_{\text {init }}$, sendo a única diferença que $M h_{\text {sender }}$ não é incluído na lista de destinatários locais.

Quando um $M h \in M$.Dest recebe $M$ de seu $M s s_{M h}$, ele armazena a mensagem e responde imediatamente ${ }^{1}$ com um $\mathrm{Ok}_{M}$ ou $\mathrm{NOk}_{M}$, dependendo do caso se a mensagem pode ou não ser processada pela aplicação local executada no $M h$ (por exemplo, pode não haver energia suficiente para processar a mensagem). Caso $M$ chegue a um $M s s$ durante um hand-off envolvendo o Mss e um $M h \in M$.Dest, então dependendo do estágio do hand-off (isto será discutido em mais detalhes na seção 3.5.2), eventualmente o tempo de espera no Mss da célula para a qual o $M h$ está migrando é estendido por mais T1 unidades de tempo.

\section{- FASE II}

Depois de receber respostas de todos os $M s s s, M s s_{\text {init }}$ verifica se todas as respostas dos $M s s \mathrm{~s}$ são do tipo $\mathrm{Ok}_{M}$ ou se alguma delas é do tipo $\mathrm{NOk}_{M}$. No primeiro caso, o estado final (status)

\footnotetext{
${ }^{1}$ Assume-se também que o $M h$ possui a capacidade de responder a uma mensagem em um espaço de tempo previsível e conhecido.
} 
do multicast é dito Confirmado (Commited), caso contrário, Abortado (Aborted). Mssinit então difunde o estado final $\left(\mathrm{Comm}_{M}\right.$ ou Abor $\left._{M}\right)$ para todos os Msss.

Quando recebe uma mensagem $\operatorname{Comm}_{M} /$ Abor $_{M}$ de $M s s_{i n i t}$, cada Mss a armazena e encaminha a mensagem para o conjunto de $M h$ s locais que pertencem a M.Dest. O Mss aguarda um período de T2 unidades de tempo por uma confirmação dos referidos $M h$ s locais. Seja C o conjunto de $M h$ s locais que confirmaram o recebimento desta mensagem de status. Então o Mss envia a mensagem AckSet $\{\mathrm{C}\}$ de volta a $M s s_{\text {init }}$.

Caso um Mss se torne responsável por um novo $M h$ que tenha migrado para sua célula, digamos $M h_{\text {new }}$, o $M s s$ verificará se para cada mensagem armazenada $M, M h_{\text {new }}$ pertence a M.Dest. Em caso positivo, o $M s s$ transmite o estado final de $M$ para $M h_{n e w}$ e aguarda até T2 unidades de tempo pela confirmação do recebimento. Se esta confirmação chega a tempo, o Mss envia uma mensagem AckSet $\left\{\mathrm{Mh}_{n e w}\right\}$ para $M s s_{\text {init }}$. Caso contrário, nenhuma mensagem é enviada.

\section{- FASE III}

Toda vez que $M s s_{\text {init }}$ recebe uma mensagem AckSet(C) de um Mss, ele adiciona os elementos contidos em C numa lista chamada M.Confirmados. Quando M.Confirmados for igual a M.Dest, então $M s s_{\text {init }}$ remove a entrada referente à mensagem $M$ armazenada localmente e difunde uma mensagem $\left(D e l_{M}\right)$ a todos os $M s s$ s para que estes apaguem o estado final de $M$ armazenado em seus buffers locais. Ao receber tal mensagem, cada Mss executa a operação solicitada.

\subsection{Exemplo de Funcionamento do $A M^{2} C$}

Nesta seção apresentamos um cenário para demonstrar o funcionamento do protocolo $A M^{2} C$.

Na Figura 3.2 são ilustrados os tipos de mensagens transmitidas pelo protocolo $A M^{2} C$ em um cenário composto por três $M h$ s e três $M s s s$, onde inicialmente $M h_{i}$ encontra-se na célula de $M s s_{i}$, para $1 \leq i \leq 3 . M h_{1}$ requisita um multicast da mensagem $M$ com $M$.Dest $=\left\{M h_{1}, M h_{2}, M h_{3}\right\}$ (a inclusão de $M h_{1}$ como destinatário tem como objetivo possibilitar que o mesmo receba o estado final do multicast) para $M s s_{1}$. Fazendo o papel de $M s s_{\text {init }}$ para esta requisição, $M s s_{1}$ então difunde $M$ para todos os outros $M s s s$, no caso $M s_{2}$ e $M s s_{3}$. Estes, por sua vez, enviam a mensagem para seus $M h$ s locais que pertencem ao conjunto de destinatários de $M\left(M h_{2}\right.$ e $\left.M h_{3}\right)$. Tanto $M h_{2}$ como $M h_{3}$ 


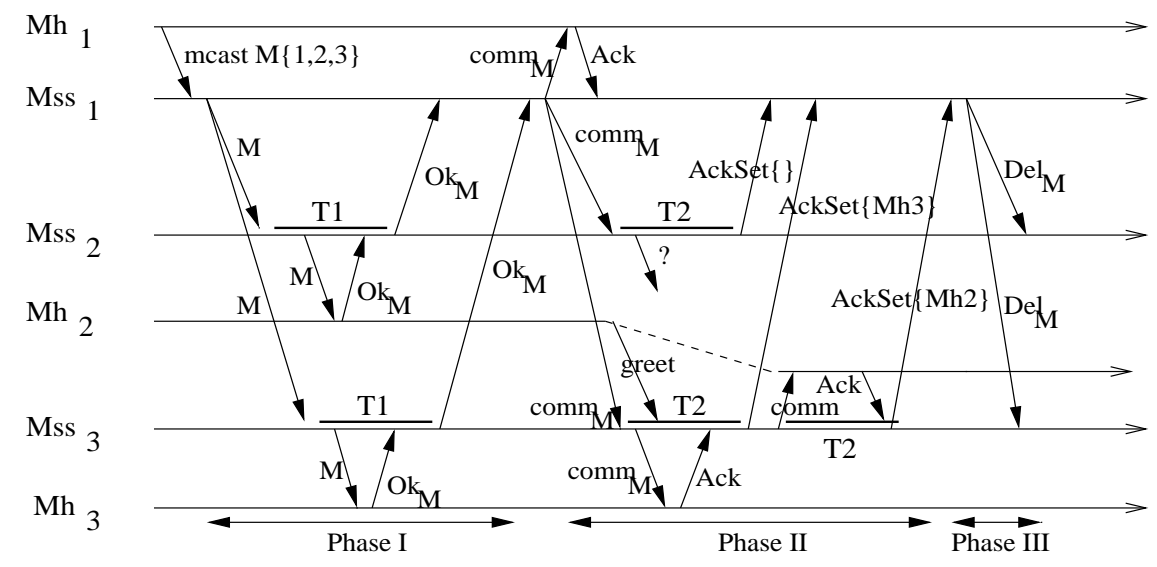

Figura 3.2: Funcionamento do protocolo $A M^{2} C$

respondem a seus respectivos $M s s_{M h}$ antes de T1 se esgotar. $M s s_{2}$ e $M s s_{3}$ enviam então um $0 \mathrm{k}_{M}$ para $M s s_{\text {init }}$, que então estabelece o estado final de $M$ como confirmado (Commited) e envia uma mensagem $C_{0 m m}$ para $M h_{1}$ (solicitante), $M s s_{2}$ e $M s s_{3}$. Ao enviar $C o m m_{M}$ para $M h_{2}, M s s_{2}$ não obtém resposta, pois $M h_{2}$ está migrando para a célula de $M s s_{3}$. Com isto, $M s s_{2}$ envia uma mensagem AckSet\{\} vazia para $M s s_{\text {init }}$. Já $M s s_{3}$ consegue enviar a mensagem $\operatorname{Comm}_{M}$ para $M h_{3}$, o qual confirma o recebimento da mesma, fazendo com que $M s s_{3}$ envie a mensagem AckSet $\left\{M h_{3}\right\}$ a $M s s_{\text {init }}$.

Quando termina o processo de Handoff e $M h_{2}$ passa a pertencer ao conjunto de $M h$ s locais de $M s s_{3}$, este transmite então o estado final do multicast $\left(C o m m_{M}\right)$ para $M h_{2}$, que por sua vez confirma seu recebimento. Em seguida, $M s s_{3}$ envia a mensagem AckSet $\left\{M h_{2}\right\}$ para $M s s_{\text {init }}$. Finalmente, após ter recebido as confirmações de todos os Mhs pertencentes ao conjunto de destinatários de $M, M s s_{\text {init }}$ envia a mensagem $D_{e} l_{M}$ para todos os $M s s$ s, a fim de que estes apaguem os dados relativos à mensagem $M$ armazenados localmente.

Vale notar que todos os Msss guardam o resultado (estado final) do multicast até que todos os Mhs confirmem o recebimento do mesmo. Assim, todos os Mhs $\in$ M.Dest que eventualmente se tornem ativos depois de um certo período de inatividade sempre serão informados sobre o estado final de cada multicast. A fim de evitar que registros de estados finais permaneçam no sistema devido um $M h \in M$.Dest que tenha deixado o sistema, a mensagem Leave faz com o $M s s_{M h}$ desconsidere o acknowledgment do $M h$, causando assim a difusão da mensagem Delete.

Por motivos de simplificação, no exemplo da figura 3.2 apresentamos apenas as mensagens relevantes para o entendimento da situação, bem como abreviamos seus nomes. A tabela 3.1 mostra 
a equivalência das mensagens do protocolo $A M^{2} C$ e as mencionadas no exemplo.

\begin{tabular}{|c|c|}
\hline No Exemplo & Na Implementação \\
\hline mcastM & MulticastRequested \\
\hline M & FwdMsgFromMss $_{\text {init }}$ ou FwdMsgFromMss ${ }_{n}$ \\
\hline $\mathrm{Ok}_{M}$ & RespFromMh ou RespFromMss \\
\hline $\operatorname{comm}_{M}$ & StatusFromMss $_{\text {init }}$ ou StatusFromMss S $_{n}$ \\
\hline Ack & AckMh \\
\hline AckSet & AckMss \\
\hline $\operatorname{Del}_{M}$ & Delete \\
\hline Hand-off & $\begin{array}{l}\text { Greet } \\
\text { Dereg } \\
\text { DeregAck }\end{array}$ \\
\hline $\begin{array}{l}\text { Entrada/Saída } \\
\text { do Sistema }\end{array}$ & $\begin{array}{l}\text { Join } \\
\text { Leave }\end{array}$ \\
\hline
\end{tabular}

Tabela 3.1: Mensagens do protocolo $A M^{2} C$.

\subsection{O protocolo de Hand-off}

A componente de hand-off do $A M^{2} C$ define as interações entre dois $M s s$ s quando um $M h$ migra da célula de $M s s_{o}$ para a célula de $M s s_{n}$. Durante este processo, é essencial que os dois Msss troquem informações sobre o $M h$ migratório consideradas relevantes para o protocolo. Inicialmente descreveremos a estrutura de dados utilizada para a troca de informações entre o $M s s_{o}$ e o $M s s_{n}$. Em seguida, explicaremos em detalhes o funcionamento do hand-off, também através de um exemplo.

\subsubsection{A Estrutura $h \_R E C D$ no $A M^{2} C$}

No $A M^{2} C$, quando um $M h$ (digamos $\left.M h_{n e w}\right)$ migra, o $M s s$ da antiga célula $\left(M s s_{o}\right)$ envia para o Mss da nova célula $\left(M s s_{n}\right)$ uma estrutura de dados que está associada ao $M h$, e que chamamos de $h \_R E C D$. Esta estrutura é um array semelhante ao descrito em [1], que é fundamental para que o $M s s_{n}$ conheça as mensagens que já foram recebidas por $M h_{n e w}$, ou melhor, que já foram tratadas por algum $M s s$. 
Cada elemento $h \_R E C D[\mathrm{i}]$ de um $M h$ contém o maior número de seqüência de um multicast iniciado por $M s s_{i}$ e cuja resposta (ou ausência dela) tenha sido tratada por um dos Msss do sistema. Por exemplo, considere uma mensagem de multicast $M$, cujo $M s s$ inicializador seja $M s s_{i}$ e cujo número de seqüência seja $j$. Quando $M$ chega em um $M s s$, para todo $M h$ local e destinatário da mensagem, o $M s s$ verifica a condição $h \_R E C D\left[M s s_{i}\right]<j$. Se esta for satisfeita, então a mensagem é transmitida para o $M h$. Caso contrário, significa que o $M h$ já recebeu $M$ ou algum outro $M s s$ já tratou tal mensagem. Se o $M h$ não for destinatário da mensagem, o $M s s$ deve incrementar $h \_R E C D\left[M s s_{i}\right]$ para sinalizar aos demais $M s s$ s (caso o $M h$ migre) que esta mensagem já foi tratada e que não precisa ser retransmitida para o $M h$.

Quando um $M s s_{M h}$ recebe uma resposta de um $M h$ referente à mensagem $M$, este deve incrementar o $h \_R E C D$ na posição correspondente, indicando assim que a mensagem já foi recebida pelo Mh. Este mesmo incremento também deve ser realizado para todo $M h$ que não responda com um $\mathrm{Ok}_{M} / \mathrm{NOk}_{M}$ dentro do tempo T1 (primeira fase do protocolo), ou quando o Mss da nova célula opta por não retransmitir $M$ para o $M h$ que tenha acabado de migrar para a sua célula. Este caso será discutido mais adiante.

Notemos que os incrementos na estrutura $h \_R E C D$ são cruciais para que os $M s s$ s considerem apenas as mensagens que realmente não foram recebidas e/ou tratadas em relação aos Mhs do sistema. Todavia, a estrutura $h \_R E C D$ deve estar sempre sincronizada com as mensagens recebidas pelos $M h s$, de forma a evitar que um $M h$ destinatário de uma mensagem deixe de recebê-la e que a mensagem seja retransmitida diversas vezes desnecessariamente para o $M h$. Assim, como a decisão sobre a transmissão de uma mensagem de um $M s s$ para um $M h$ é baseada em um número de seqüência presente em $h \_R E C D$, este não pode ser incrementado mais de uma vez para uma mesma mensagem.

Vale ressaltar ainda que uma implementação da estrutura $h \_R E C D$ da forma como a descrita acima, só garante a entrega de todas as mensagens aos Mhs porque as mensagens de um mesmo $M s s_{\text {init }}$ são entregues em ordem FIFO para cada Mss. Caso isso não fosse garantido, um $M h$ destinatário de um multicast iniciado por um dado $M s s$ (digamos $M s s_{i}$ ) poderia deixar de recebê-lo, pois o número de seqüência do multicast não corresponderia necessariamente a $h \_R E C D[\mathrm{i}]+1$. Por exemplo, suponha que $M s s_{i}$ difunda duas mensagens de multicast (M1 e M2, nesta ordem), sendo o $M h$ destinatário apenas de M1. Se M2 fosse entregue ao Mss da célula onde se encontra o $M h$ antes de M1, o $h \_R E C D$ relacionado ao $M h$ seria incrementado (pois $M h \notin$ M2. Dest) e conteria então o valor "1" (supondo que o valor inicial seja "0"). Dessa forma, quando o Mss fosse testar se o Mh já 
recebera ou não a mensagem M1 (verificando se $h \_R E C D[\mathrm{i}]<1$ ), o $M s s$ concluiria que a mensagem teria sido recebida e, consequentemente, não enviaria M1 para o $M h$.

\subsubsection{O Protocolo de Hand-off no $A M^{2} C$}

A seguir, são descritos os eventos e ações que definem esta componente do protocolo quando um $M h$ (seja $M h_{\text {new }}$ ) migra da célula de $M s s_{o}$ para a célula de $M s s_{n}$. A tabela 3.2 mostra as possíveis seqüências de eventos mais relevantes que podem ocorrer em $M s s_{o}\left(\operatorname{linhas} o_{1}\right.$ a $\left.o_{4}\right)$ e $M s s_{n}\left(\operatorname{linhas} n_{1}\right.$ a $n_{4}$ ) durante o processamento concorrente da primeira fase do $A M^{2} C$ e do hand-off. Nesta tabela, o símbolo " $\prec$ " denota o predicado ocorreu antes de (em tempo real), e as correspondentes ações são descritas no decorrer desta seção.

\begin{tabular}{|c|l|}
\hline Linha & Seqüência de Eventos \\
\hline$o_{1}$ & Dereg $\prec \mathrm{M}$ \\
$o_{2}$ & $\mathrm{M} \prec$ Dereg $\prec \mathrm{M}+\mathrm{T} 1$ \\
$o_{3}$ & $\mathrm{M} \prec \mathrm{Ok}_{M} \prec$ Dereg \\
$o_{4}$ & $\mathrm{M} \prec \mathrm{NOk}_{M}$ ou $\mathrm{M}+\mathrm{T} 1 \prec$ Dereg \\
\hline$n_{1}$ & Greet $\prec$ DeregAck $(\mathrm{j}) \prec \mathrm{M}$ \\
$n_{2}$ & $\mathrm{M} \prec \mathrm{M}+\mathrm{T} 1 \prec \operatorname{Greet}$ \\
$n_{3}$ & Greet $\prec$ DeregAck $(\mathrm{j}) \prec \mathrm{M}+\mathrm{T} 1$ \\
$n_{4}$ & Greet $\prec \mathrm{M}+\mathrm{T} 1 \prec \operatorname{DeregAck}(\mathrm{j})$ \\
\hline
\end{tabular}

Tabela 3.2: Seqüência de eventos mais relevantes ocorridas em $M s s_{o}$ e $M s s_{n}$.

1. Depois que $M h_{n e w}$ se anuncia a $M s s_{n}$ (através da mensagem Greet), este envia a mensagem Dereg para $M s s_{o}$, solicitando o desvinculamento de $M h_{\text {new }}$ da célula de $M s s_{o}$.

2. Ao receber a mensagem Dereg, $M s s_{o}$ imediatamente remove $M h_{\text {new }}$ do grupo LocalMhs para então enviar uma confirmação para $M s s_{n}$ (mensagem DeregAck). Neste momento, quatro situações distintas podem ocorrer. Para isto, seja $M$ uma mensagem de multicast difundida por um determinado $M s s$ inicializador $\left(M s s_{i n i t}\right)$, cujo número de seqüência seja $i$ e, por simplificação, que tenha $M h_{n e w}$ como único destinatário. Considere também que a última mensagem recebida por $M h_{n e w}$ e iniciada por $M s s_{i n i t}$ foi $i$ - 1 .

(a) Caso a chegada de $M$ em $M s s_{o}$ ocorra depois da chegada da mensagem Dereg (linha $o_{1}$ da 
tabela), então $M s s_{o}$ não envia $M$ para $M h_{n e w}$ (note que este não pertence mais ao grupo LocalMhs), responde com um $\mathrm{Ok}_{M}$ para $M s s_{\text {init }}$ e envia a mensagem DeregAck(i-1) para $M s s_{n}$ confirmando o desvinculamento de $M h_{\text {new }}$ de sua antiga célula. O parâmetro $i$ - 1 indica, neste caso, que este é o número de seqüência da última mensagem recebida por $M h_{n e w}$ (e iniciada por $M s s_{\text {init }}$ ).

(b) Se Dereg chega depois de $M$ mas antes do time-out desta ter ocorrido no Mss (linha $o_{2}$ ), então, caso $M$ já tenha sido enviada para $M h_{\text {new }}$ (situação em que $M h_{\text {new }}$ migra sem responder), $M s s_{O}$ responde com um $\mathrm{NOk}_{M}$ para $M s s_{i n i t}$ e envia a mensagem DeregAck(i) para $M s s_{n}$. Ou seja, diante da incerteza se $M s s_{n}$ vai retransmitir $M$ para $M h_{n e w}, M s s_{o}$ opta por indiretamente abortar o multicast (isto é, $M s s_{o}$ trata a chegada de Dereg como se fosse um $\mathrm{NOk}_{M}$ de $\left.M h_{n e w}\right)$.

(c) Quando a mensagem Dereg chega em $M s s_{o}$ depois da chegada de $M$, bem como depois da resposta de $M h_{\text {new }}\left(\right.$ linha $o_{3}$ ), $M s s_{o}$ simplesmente responde com um $\mathrm{Ok}_{M}$ para $M s s_{\text {init }}$ (considerando que a resposta de $M h_{\text {new }}$ foi $\mathrm{Ok}_{M}$ ) e envia DeregAck(i) para $M s s_{n}$. Neste caso, a resposta do $M h$ causa o incremento de $h \_R E C D\left[\mathrm{Mss}_{\text {init }}\right]$.

(d) Caso $M h_{\text {new }}$ tenha respondido com um $\mathrm{NOk}_{M}$ ou caso Dereg chegue em $M s s_{O}$ após o timeout de $M$ (linha $o_{4}$ ), então $M s s_{o}$ responde a $M s s_{i n i t}$ com um NOk $_{M}$ e envia a mensagem DeregAck (i) para $M s s_{n}$. O incremento de $h \_R E C D\left[\mathrm{Mss}_{\text {init }}\right]$ neste caso ocorre ou devido à resposta de $M h_{n e w}$, ou devido à ocorrência do time-out, como descrito na subseção anterior.

3. Quando a mensagem DeregAck chega em $M s s_{n}$, a responsabilidade pelo novo $M h$ é oficialmente passada para $M s s_{n}$, o qual acrescenta $M h_{n e w}$ em seu grupo LocalMhs. Baseado no número de seqüência contido em $h \_R E C D, M s s_{n}$ decide então o que fazer em relação às mensagens multicast que têm $M h_{\text {new }}$ como destinatário e que ainda não foram confirmadas. Existem quatro possibilidades. Considere $M$ uma tal mensagem como a descrita no item 2. Vamos supor que o valor presente em $h \_R E C D\left[\mathrm{Mss}_{\text {init }}\right]$ seja $j$ (proveniente da mensagem $\operatorname{DeregAck}(j)$ ).

(a) Caso a mensagem $M$ chegue em $M s s_{n}$ após a chegada das mensagens Greet e DeregAck(j) (linha $n_{1}$ da tabela) então, se $j<i$, isto é, $M h_{n e w}$ ainda não recebeu a mensagem, $M s s_{n}$ envia $M$ para $M h_{n e w}$ e responde com um $\mathrm{Ok}_{M} / \mathrm{NOk}_{M}$ para $M s s_{\text {init }}$ (a depender da resposta de $\left.M h_{n e w}\right)$. Note que esta é uma situação onde há um atraso na chegada da mensagem $M$ em $M s s_{n}$. 
(b) Se a mensagem Greet chega em $M s s_{n}$ após o time-out de $M$ (linha $n_{2}$ ), nesta altura $M s s_{n}$ já enviou sua resposta a $M s s_{\text {init }}$. Assim, $M s s_{n}$ não envia $M$ para $M h_{\text {new }}$ (e não tomará nenhuma ação até a chegada da mensagem DeregAck).

(c) Quando a mensagem DeregAck(j) chega em $M s s_{n}$ antes do time-out T1 de $M$ ocorrer (linha $n_{3}$ ), então se $j<i$, a mensagem é retransmitida para $M h_{\text {new }}$ e o time-out é prorrogado. A depender da resposta de $M h_{n e w}, M s s_{n}$ responde com um $\mathrm{Ok}_{M} / \mathrm{NOk}_{M}$ para Mssinit.

(d) Caso a mensagem DeregAck(j) chegue após o time-out T1 de $M$, então, se $j<i\left(M h_{n e w}\right.$ ainda não recebeu $M), M s s_{n}$ envia um $\mathrm{NOk}_{M}$ para $M s s_{\text {init }}$, abortando indiretamente o multicast. Nesta caso, o $M s s_{n}$ trata a mensagem para $M h_{n e w}$ (incremento de $h \_R E C D$ ), considerando sua resposta como NOk. Nas situações (a) e (c), o $h \_R E C D$ é incrementado no momento da resposta de $M h_{\text {new }}$.

Portanto, a componente hand-off do $A M^{2} C$ estipula que enquanto o hand-off não é completado, $M s s_{o}$ permanece responsável pelo envio de respostas (para o $M s s_{i n i t}$ correspondente) das mensagens já recebidas. Como $M s s_{o}$ não pode garantir que $M s s_{n}$ irá receber a mensagem DeregAck a tempo de permitir uma retransmissão da mensagem para $M h_{n e w}$, então é mais seguro abortar indiretamente o multicast (através do envio de um $\mathrm{NOk}_{M}$ para $M s s_{\text {init }}$ ). Por outro lado, $M s s_{n}$ não exerce nenhuma influência sobre o estado final de um multicast para qualquer mensagem que já tenha sido tratada por $M s s_{0}$.

É importante observar que assim o protocolo hand-off garante que a propriedade de atomicidade requerida pelo protocolo $A M^{2} C$ é sempre satisfeita. Um multicast só pode ser confirmado garantidamente se todos os destinatários receberem a mensagem. Por isso, se há alguma incerteza quanto ao recebimento da mensagem por alguns desses elementos, então é preferível abortar o multicast.

Na Figura 3.3 temos um exemplo do funcionamento da componente hand-off do $A M^{2} C$ quando um $M h\left(M h_{n e w}\right)$ migra sem responder a $M s s_{0}$ e a mensagem Dereg chega neste antes de $M+\mathrm{T} 1$ (linha $o_{2}$ da tabela 3.2), onde $M$ corresponde a uma mensagem de multicast difundida por um dado $M s s$ inicializador $\left(M s s_{\text {init }}\right)$. Neste caso, $M s s_{o}$ responde com um NOk para $M s s_{\text {init }}$ e envia a mensagem DeregAck para $M s s_{n}$ informando-o, via $h \_R E C D$, que já tratou $M$ para $M h_{n e w}$. Em $M s s_{n}$ a mensagem Greet chega antes de $M+\mathrm{T} 1 . M s s_{n}$ envia então a mensagem Dereg para $M s s_{O}$ e fica aguardando pela chegada da mensagem DeregAck ou pela ocorrência do time-out T1, para então decidir o que fazer. Quando DeregAck chega em $M s s_{n}$ (antes de $M+\mathrm{T} 1$ ), então através de 


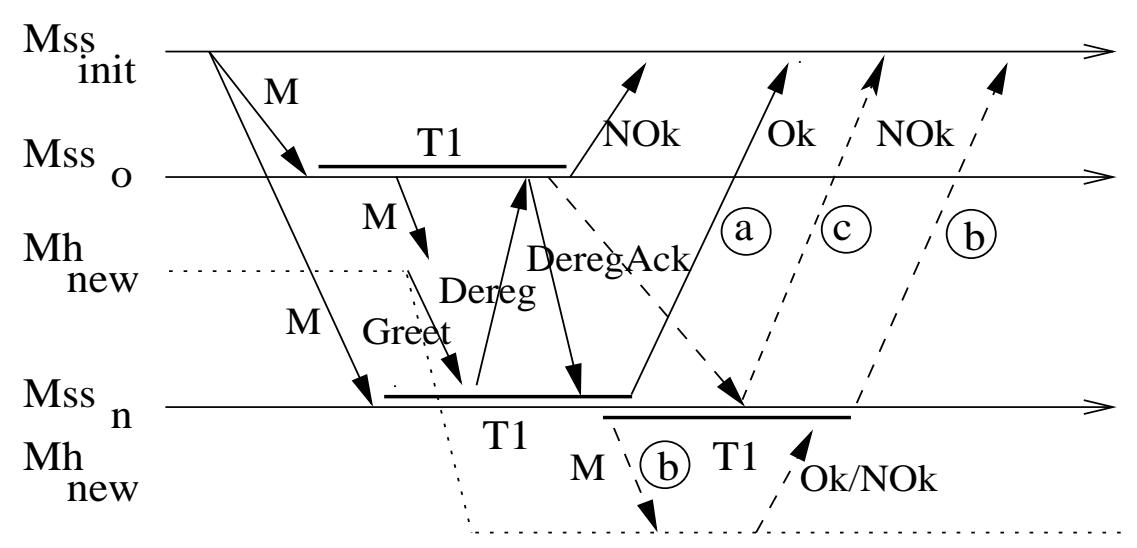

Figura 3.3: Exemplo de Hand-off no $A M^{2} C$

$h \_R E C D M s s_{n}$ percebe que $M s s_{o}$ já enviou uma resposta para $M s s_{i n i t}$. Neste caso (linhas sólidas), após o time-out $M s s_{n}$ responde para $M s s_{i n i t}$ sem considerar $M h_{\text {new }}$ (caso a). Entretanto, caso $M s s_{O}$ não tivesse tratado a mensagem $M$ (linha pontilhada), então $M s s_{n}$ retransmitiria $M$ para $M h_{n e w}$, prorrogaria o time-out $\mathrm{T} 1$, e aguardaria a resposta do $M h$. Após o time-out, $M s s_{n}$ responderia a Mssinit baseado nesta resposta (caso b). Esta situação, assim como o caso (a), correspondem à linha $n_{3}$ da tabela, onde $j=i$ e $j<i$, respectivamente (sendo $i$ o número de seqüência de $M$ ). Se a mensagem DeregAck chegasse em $M s s_{n}$ depois de ocorrido o time-out, então $M s s_{n}$ enviaria um NOk para $M_{s s_{\text {init }}}$ (caso (c) e linha $n_{4}$ da tabela).

\subsection{Limitações do $A M^{2} C$}

O principal problema do protocolo $A M^{2} C$ é sua falta de escalabilidade em relação ao número de $M s s s$ no sistema. Não apenas mensagens de multicast e de estado de um multicast (além da mensagem Delete) são transmitidas do $M s s$ inicializador ( $\left.M s s_{i n i t}\right)$ para todos os Msss do sistema, mas também todos os Msss enviam respostas para $M s s_{\text {init }}$ nas duas primeiras fases do protocolo. Dessa forma, o número de mensagens trocadas na rede fixa pode ser grande e tornar o protocolo inviável para uma rede com um número grande de Msss. Uma estimativa do número de mensagens transmitidas pelo $A M^{2} C$ é apresentada na seção 4.7 .

Além disto, o $A M^{2} C$ causa um certo disperdício de memória, pois durante a primeira fase do protocolo todos os Msss precisam manter armazenada a mensagem de multicast, mesmo que não haja $M h$ na célula do Mss que pertença ao grupo de destinatários da mensagem. 
A fim de solucionar os problemas mencionados acima, projetamos uma variante do protocolo $A M^{2} C$, que é descrito no capítulo seguinte. 


\section{Capítulo 4}

\section{Uma Variante: o $i A M^{2} C$}

\subsection{Introdução}

Este capítulo descreve o Indirect $A M^{2} C$ (ou $i A M^{2} C[10]$ ), um protocolo para multicast atômico que é uma versão com endereçamento indireto do protocolo $A M^{2} C$ [13] e que utiliza um gerenciamento hierárquico de localização de unidades móveis [25] para difundir mensagens na rede fixa. Ao contrário do protocolo original, o $i A M^{2} C$ apresenta boa escalabilidade com relação ao número de Msss.

\subsection{Motivação}

A principal motivação para o desenvolvimento do $i A M^{2} C$ foi obter um protocolo que realize multicast atômico sem as limitações intrínsecas ao $A M^{2} C$ discutidas na seção 3.6.

\subsection{Modelo de Sistema e Suposições}

O modelo de sistema consiste das máquinas descritas na seção 3.2, incluindo um terceiro elemento denominado servidor intermediário de mensagens multicast (Intermediate Multicast Server, ou $I M S \mathrm{~s})$.

Neste novo modelo, cada $M s s$ está associado a um único $I M S$, e o conjunto de $M s s s$ associados a um IMS é denominado o domínio do IMS. Assumimos que a intersecção dos domínios dos IMSs é vazia, e que a união dos domínios corresponde ao conjunto composto por todos os Msss do sistema.

Um IMS é um servidor de mensagens que pode executar em qualquer host fixo da rede e que 
armazena as mensagens multicast durante o processo de difusão. Além disto, cada IMS mantém a informação sobre o conjunto LocalMhs para cada um dos Msss de seu domínio, que chamamos de mapa de localização de Mhs nos Msss do domínio (ou simplesmente, LocMap). Assim, para cada destinatário de um multicast, um IMS pode deduzir para quais Msss deve transmitir uma mensagem de multicast.

A idéia central do protocolo $i A M^{2} C$ é reduzir o número de elementos que armazenam as mensagens multicast a serem transmitidas para os Mhs. Ao invés de usar todos os Msss como repositórios das mensagens multicast, o $i A M^{2} C$ utiliza os $I M S s$ para este propósito.

Os IMSs desempenham um papel semelhante ao dos Msss no protocolo $A M^{2} C$. A principal diferença está na forma como os IMSs difundem uma mensagem na rede. Seja $M$ uma mensagem para um grupo de $M h s$ destinatários. Em vez de difundir $M$ para todos os $M s s$, difunde-se $M$ para todos os IMSs (que formam um conjunto supostamente menor do que o dos Msss). Os IMSs por sua vez irão retransmitir $M$ apenas para aqueles $M s s$ s de seu domínio que possuam algum $M h \in$ (M.Dest $\cap$ Mss.LocalMhs).

A figura 4.1 compara a maneira utilizada pelos protocolos $A M^{2} C$ e $i A M^{2} C$ para difundir uma mensagem. Considere um sistema composto por dezessete $M s s \mathrm{~s}$, e que um dado $M h$ solicitou um multicast de uma mensagem $M$ para seu $M s s$ responsável $\left(M s s_{0}\right)$. Suponha ainda que apenas quatro do conjunto de todos os $M s s$ s possuem algum $M h$ destinatário. Desta forma, no iAM ${ }^{2} C M$ é enviada apenas para os $M s s s$ 3, 6, 12 e 15 (através do $I M S$ ), enquanto que no $A M^{2} C$ todos os Msss recebem a mensagem. Nitidamente, uma conseqüência destes fatos é o tráfego gerado na rede fixa em função da forma de difusão usada por cada protocolo. É importante ressaltar ainda que esse mesmo número de mensagens seria gerado também na segunda e na terceira fases do protocolo $A M^{2} C$ (com exceção da última fase, onde não há respostas dos $M s s \mathrm{~s}$ ).

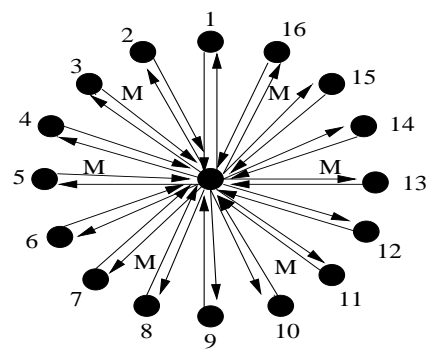

Difusao de M no AM2C

$=$ MSS

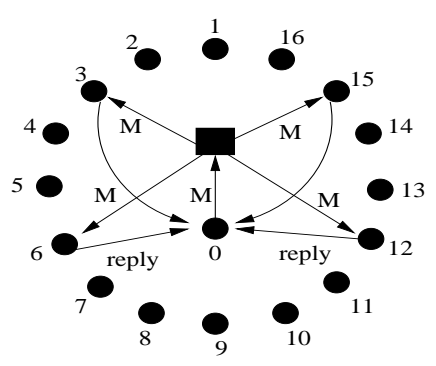

Difusao de M no iAM2C

$=\mathrm{IMS}$

Figura 4.1: Comparação entre os protocolos $A M^{2} C$ e $i A M^{2} C$. 
A informação sobre a atual localização de um dado $M h$ é atualizada pelos $M s s$ s (através da mensagem LocationUpdate) a cada vez que um hand-off é completado (vide seção 4.6). Esta mesma mensagem faz também o papel de requisição de retransmissão de todas as mensagens de multicast "pendentes", e que tenham um determinado $M h$ migrado na lista dos destinatários.

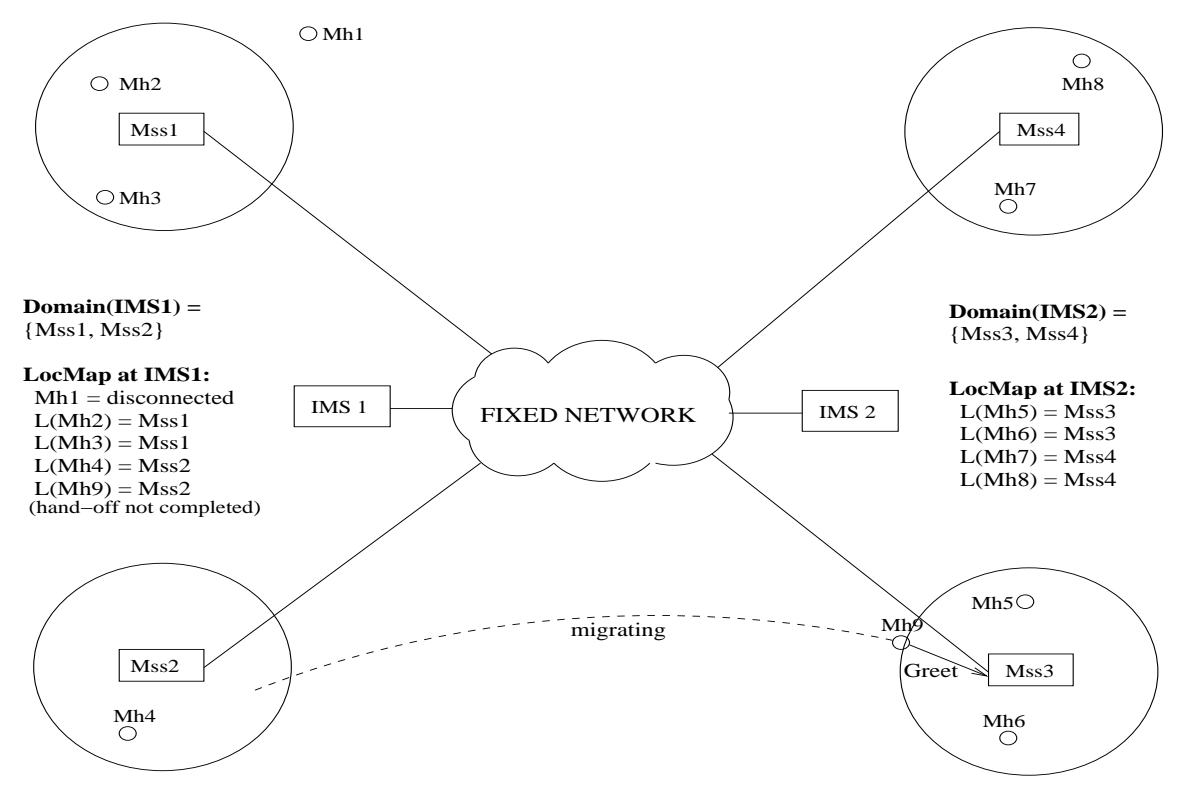

Figura 4.2: Modelo de Sistema no Protocolo $i A M^{2} C$.

A Figura 4.2 exemplifica um sistema composto por quatro $M s s$, nove $M h s$ e dois $I M S s$, onde Mss1 e Mss2 estão no domínio de IMS1, e Mss3 e Mss4 estão no domínio de IMS2. Como mostrado, cada IMS mantém um LocMap dos Mhs presentes nas células dos Msss que pertencem ao seu domínio.

As suposições do modelo do $i A M^{2} C$ são basicamente as mesmas do modelo do protocolo original. Dessa forma, as suposições já comentadas anteriormente ${ }^{1}$ serão apenas citadas e indicadas com um $(*)$. As demais referem-se especificamente ao protocolo $i A M^{2} C$. São elas:

1. Msss e IMSs não falham e todos os hosts da rede fixa estão conectados;

2. Cada Mss está associado a um único $I M S$;

3. Seja $S$ o conjunto de todos os Msss do sistema. Seja $D_{i}$ o conjunto de $M s s$ s pertencentes ao domínio do $I M S i(1 \leq i \leq n$, onde $\mathrm{n}=$ número de $I M S s$ no sistema $)$. Temos que $\left(D_{1} \cup D_{2} \cup\right.$ $\left.\ldots \cup D_{n}\right)=S$, e $\left(D_{1} \cap D_{2} \cap \ldots \cap D_{n}\right)=\emptyset$.

\footnotetext{
${ }^{1}$ Para maiores detalhes consultar a seção 3.2 do Capítulo 3.
} 
4. É assumido que os hosts fixos possuem recursos físicos suficientes para armazenamento e processamento $(*)$;

5. A comunicação na rede fixa é confiável $(*)$;

6. A comunicação sem fio não é confiável, mas é possível detectar uma perda de mensagem (*);

7. Cada $M h$ possui uma identificação única no sistema que independe de sua localização. Antes de deixar o sistema um $M h$ envia uma mensagem Leave para seu $\left.M s s_{M h}{ }^{*}\right)$;

8. Em um dado momento um $M h$ está associado a um único Mss (*);

9. Se um $M h$ está ativo, este responde a qualquer mensagem enviada por $M s s_{M h}$. Caso contrário, ele não responde a nenhuma mensagem $(*) ;$

10. Depois de ter se anunciado a um novo $M s s\left(M s s_{n}\right)$ um $M h$ não interage com nenhum outro $M s s$ que não seja $M s s_{n}(*)$;

\subsection{Descrição do Protocolo}

Assim como no protocolo $A M^{2} C$, o $i A M^{2} C$ é também um protocolo $2 \mathrm{PC}$ com uma etapa adicional de coleta de lixo. A seguir, serão descritos os principais eventos e ações em cada uma das fases:

\section{- FASE I:}

Um host móvel, $M h \_S$, envia para o seu $M s s_{M h \_S}$ uma requisição de multicast de uma mensagem $M$ para os destinatários mencionados em M.Dest. O $M s s_{M h_{-} S}$, que doravante chamaremos de $M s s_{\text {init }}$, faz portanto o papel de inicializador do 2PC para esta requisição.

$M s s_{\text {init }}$ difunde a nova requisição para todos os IMSs do sistema. Cada IMS por sua vez, armazena $M$ em um buffer local e a retransmite para todos Msss de seu domínio que tenham algum $M h$ local pertencente a $M$.Dest. Cada $M s s$ que recebe $M$ a retransmite para todo $M h \in$ (M.Dest $\cap$ Mss.LocalMhs) e espera por T1 unidades de tempo por respostas dos Mhs. O Mss acrescenta em seu $\log$ a identificação da mensagem, indicando que a mesma já foi repassada para os $M h s$.

Quando ocorre o time-out T1, o Mss envia uma mensagem OkSet para Mssinit, a qual contém a informação sobre o conjunto de $M h s$ que responderam à mensagem $M$ (com suas respectivas respostas). Ou seja, a mensagem OkSet é um conjunto de pares $\left(M h_{i}, r e s p_{i}\right)$, onde resp $p_{i}=$ 
$\left\{\mathrm{Ok}_{M}, \mathrm{NOk}_{M}\right\}$. Se um $M h$ não responder à mensagem antes do time-out T1, o Mss considera sua resposta como $\mathrm{NOk}_{M}$.

Quando um $M h \in M$.Dest recebe $M$ do seu $M s s_{M h}$, este armazena a mensagem em uma área de trabalho temporária e imediatamente responde ao $M s s_{M h}$ com um $\mathrm{Ok}_{M}$ ou $\mathrm{NOk}_{M}$, dependendo se a mensagem $M$ pode ou não ser processada localmente pela aplicação executada no $M h$.

Caso um $M s s$ se torne responsável por um novo $M h$, digamos $M h_{n e w}$, que tenha migrado para sua célula, então o $M s s$ envia a mensagem LocationUpdate para o IMS correspondente a fim de que este retransmita todas as mensagens para as quais $M h_{n e w}$ seja destinatário e ainda não as tenha recebido. Quando uma mensagem retransmitida chega no Mss, a depender da situação a mensagem pode ser enviada para o $M h$ e o time-out T1 prorrogado. Este caso é detalhado na seção 4.6 .

Após receber as respostas referentes a todos os $M h s \in M$.Dest, Mssinit verifica se todas as respostas recebidas foram $\mathrm{Ok}_{M}$ ou se alguma delas foi $\mathrm{NOk}_{M}$. No primeiro caso, o estado final do multicast é Confirmado (Commited) e caso contrário, Abortado (Aborted).

\section{- FASE II:}

De forma similar à Fase I, Mss $s_{i n i t}$ difunde agora o estado do multicast $M$ para todos os IMSs do sistema, os quais retransmitem a mensagem de status (Commited ou Aborted) somente para aqueles $M s s$ s de seus respectivos domínios que tenham algum Mh local pertencendo a M.Dest. Cada IMS também armazena o estado final de $M$ em Outcomes.

Uma vez recebida a mensagem de status, um Mss a retransmite para todo $M h \in($ M.Dest $\cap$ Mss.LocalMhs) e espera T2 unidades de tempo pela confirmação do recebimento da mensagem de status por parte dos Mhs. Seja C o conjunto de Mhs que responderam. Ocorrido o time-out T2, o Mss envia uma mensagem Ackset com o conjunto C de volta a Mssinit.

Quando o $M h$ recebe o estado Commited, a mensagem $M$ correspondente (armazenada temporariamente numa área de trabalho) é entregue à aplicação, e caso contrário é descartada.

Assim como ocorre na Fase I, quando um Mh migra para a célula de um Mss a mensagem LocationUpdate é enviada para o IMS correspondente, o qual retransmite para o Mss os estados finais de todos os multicasts ainda não finalizados e que têm o $M h$ como destinatário. O Mss por sua vez, repassa os estados finais para o $M h$, independente se o mesmo já os recebeu anteriormente. Neste caso, o Mss poderá aguardar por até mais T2 unidades de tempo pela 
confirmação do recebimento de cada estado pelo $M h$. Se esta confirmação chegar à tempo, o Mss enviará a mensagem AckSet\{Mh\} para $M s s_{\text {init }}$ e, caso contrário, a mensagem não será enviada.

\section{- FASE III:}

Cada vez que $M$ ssinit $_{\text {in }}$ recebe uma mensagem AckSet\{C\} referente a um multicast $M$, este adiciona os elementos contidos em C a uma lista M.Confirmados. Assim que M.Confirmados equivale a M.Dest, então $M s s_{\text {init }}$ difunde uma mensagem $\operatorname{Del}_{M}$ para todos os $I M S s$ a fim de que estes removam o estado final de $M$ armazenado localmente. Ao receber tal mensagem, cada $I M S$ executa a operação solicitada.

A fim de evitar que o $i A M^{2} C$ sofra do problema de um multicast ficar bloqueado indefinidamente devido à falta de resposta de um $M h \in M$.Dest, seja na Fase I ou II, define-se um tempo máximo de execução do protocolo. Isto é, depois de esgotado um tempo de espera T3 (onde T3 é bem maior do que $\max (\mathrm{T} 1, \mathrm{~T} 2))$ o $M s s_{\text {init }}$ decide abortar o multicast ou enviar a mensagem $\mathrm{Del}_{M}$ para cada $I M S$, a fim de completar a Fase I ou a Fase II, respectivamente. Ao mesmo tempo, o Mssinit difunde uma mensagem anunciando a exclusão do(s) $M h(\mathrm{~s})$ não disponível(eis) no sistema.

Vale observar ainda que os Msss não armazenam as mensagens de multicast $M$ ou os estados finais, mas apenas repassam $M$ (ou estado final) recebida do $I M S$, e simplesmente indicam no seus respectivos logs que a mensagem foi enviada. Sempre que se faz necessária uma retransmissão de uma mensagem para um $M h$, o $M s s$ correspondente tem que solicitar o reenvio de tal mensagem ao seu $I M S$.

\subsection{Exemplo de Funcionamento do iA $M^{2} C$}

Na Figura 4.3 são ilustrados os tipos de mensagens transmitidas pelo protocolo $i A M^{2} C$ em um cenário composto por dois $M h s$, três $M s s s$, e um IMS. Neste caso, estamos considerando um único domínio (do $I M S_{1}$ ) composto pelos três Msss. Inicialmente, tanto $M h_{1}$ como $M h_{2}$ estão localizados na célula de $M s s_{1}$. Para simplificar, vamos supor que um dado $M h \_S$ já tenha enviado uma requisição de multicast de uma mensagem $M$ para seu $M s s$ responsável ( $M s s_{i n i t}$ ), e que os destinatários de $M$ sejam apenas $M h_{1}$ e $M h_{2}$.

Ao receber a mensagem, Mssinit difunde $M$ para todos os $I M S s$ do sistema (neste caso apenas um). Quando recebe a mensagem, IMS 1 a armazena em um buffer local e verifica, de acordo com o 


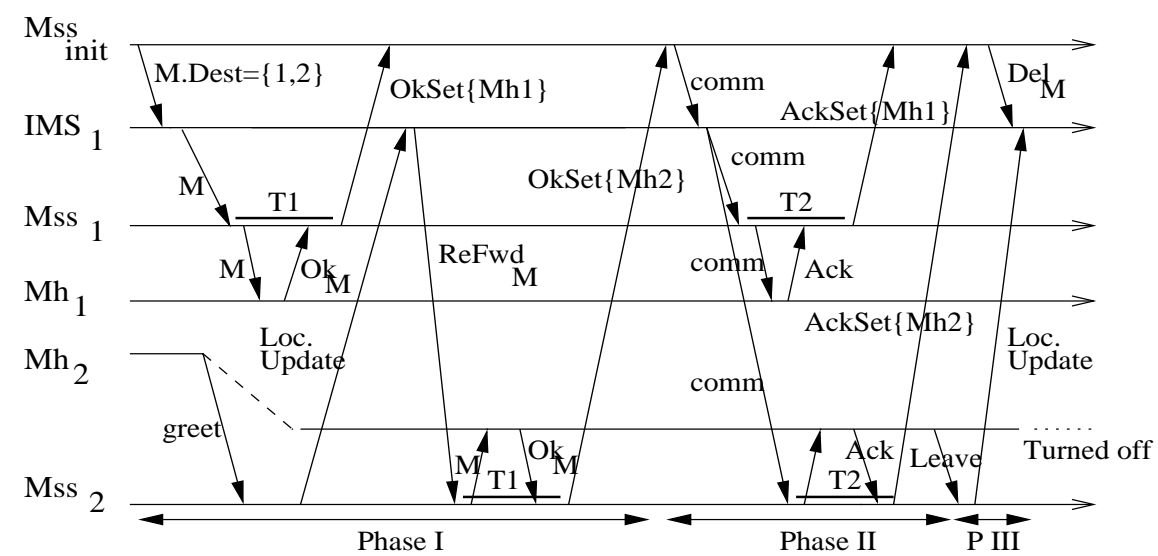

Figura 4.3: Exemplo de Funcionamento do protocolo $i A M^{2} C$

LocMap, quais são os Msss que possuem algum $M h \in M$.Dest. Dessa forma, $M$ é enviada somente para $M s s_{1}$. Uma vez recebida, $M s s_{1}$ envia a mensagem apenas para $M h_{1}$, pois $M h_{2}$ está em processo de migração. $M h_{1}$ responde com um $\mathrm{Ok}_{M}$ para $M s s_{1}$. Após decorrido o tempo T1, $M s s_{1}$ então envia a mensagem OkSet $\left\{\mathrm{Mh}_{1}\right\}$ para $M s s_{\text {init }}$ confirmando a aceitação de $M$ por parte de $M h_{1}$ (a mensagem OkSet sempre carrega a resposta do $M h, \mathrm{Ok}_{M} / \mathrm{NOk}_{M}$, que, neste exemplo, consideramos o primeiro caso).

Quando o hand-off é completado na célula de $M s s_{2}$, este envia a mensagem LocationUpdate para $I M S_{1}$, informando-o sobre a nova localização de $M h_{2}$ e sobre a última mensagem de $M s s_{\text {init }}$ repassada a $M h_{2}$. O IMS por sua vez, atualiza o LocMap $\left(\operatorname{LocMap}\left(M h_{2}\right)=M s s_{2}\right)$ e retransmite $M$ para $M s s_{2}$, já que $M h_{2}$ pertence a $M$.Dest e não recebeu a mensagem. $M s s_{2}$ então envia a mensagem para $M h_{2}$, o qual responde com um $\mathrm{Ok}_{M}$ antes de T1 se esgotar. Passadas T1 unidades de tempo, $M s s_{2}$ então envia a mensagem $0 \mathrm{kSet}\left\{\mathrm{Mh}_{2}\right\}$ para $M s s_{\text {init }}$ informando a aceitação de $M$ pelo $M h_{2}$.

Depois de receber as respostas de todos os $M h s \in M$.Dest, $M s s_{\text {init }}$ verifica que todas são $0 \mathrm{k}_{M}$ e, dessa forma, define o estado final de $M$ como Confirmado (Commited), e envia este para $I M S_{1}$ e para o $M h$ requisitante do multicast. $I M S_{1}$ por sua vez envia o estado final para $M s s_{1}$ e $M s s_{2}$, já que agora ambos os Msss possuem um Mh pertencente ao grupo de destinatários da mensagem original. $M s s_{1}$ e $M s s_{2}$ enviam o estado final do multicast para $M h_{1}$ e $M h_{2}$, respectivamente, que confirmam o recebimento do mesmo antes de T2 se esgotar. Passado o tempo T2, Mss 1 e $M s s_{2}$ enviam as mensagens AckSet $\left\{\mathrm{Mh}_{1}\right\}$ e AckSet $\left\{\mathrm{Mh}_{2}\right\}$, respectivamente, para $M s s_{\text {init }}$, informando sobre a confirmação do recebimento do estado final de $M$ por parte de $M h_{1}$ e $M h_{2}$.

Mssinit então envia a mensagem $\operatorname{Del}_{M}$ para $I M S_{1}$ a fim de que este remova a mensagem $M$ 
armazenada localmente. Esta operação é realizada em qualquer IMS que faça parte do sistema. Finalmente, antes que $M h_{2}$ deixe o sistema, este envia a mensagem Leave para $M s s_{2}$, que por sua vez envia a mensagem LocationUpdate para $I M S_{1}$, o qual atualizará a informação de que $M h_{2}$ não se encontra mais no sistema.

De forma similar à seção 3.4, a tabela 4.1 mostra a equivalência das mensagens do protocolo $i A M^{2} C$ e as mencionadas no exemplo.

\begin{tabular}{|l|l|}
\hline No Exemplo & Na Implementação \\
\hline M.Dest $=\{1,2\}$ & FwdMsgFromMssInit \\
\hline M & FwdMsgFromIMS ou FwdMsgFromMss \\
\hline Ok ${ }_{M}$ & RespFromMh \\
\hline OkSet & RespFromMss \\
\hline LocUpdate & LocationUpdate \\
\hline ReFwd $_{M}$ & ReFwdMsgFromIMS \\
\hline comm $M$ & StatusFromMssInit ou StatusFromIMS \\
\hline Ack & ou StatusFromMss \\
\hline AckSet & AckMh \\
\hline Del ${ }_{M}$ & AckMss \\
\hline Requisição Inicial & Delete \\
\hline Hand-off & MulticastRequested \\
\hline Entrada/Saída Sistema & Goin / Leave \\
\hline
\end{tabular}

Tabela 4.1: Mensagens do protocolo $i A M^{2} C$.

\subsection{Hand-off no $\mathrm{iA} \boldsymbol{M}^{2} \mathrm{C}$}

Esta seção tem o objetivo de apresentar a componente de $h a n d$-off no protocolo iAM ${ }^{2} C$. Todavia, antes de entrarmos nos detalhes relativos ao hand-off, é importante apresentar a estrutura de dados $h \_R E C D$ utilizada no $i A M^{2} C$, que é responsável pela transferência de informações relevantes sobre um $M h$ entre os $M s s$ s envolvidos em uma migração do $M h$. 


\subsection{1 $\quad h \_R E C D$ no $i A M^{2} C$}

A estrutura $h \_R E C D$ no $i A M^{2} C$ é um pouco diferente da utilizada no $A M^{2} C$. A razão desta diferença é a ausência, no $i A M^{2} C$, da garantia da entrega de mensagens em ordem FIFO e somente uma vez (como no MCAST [1]) para os Mhs destinatários. Estes fatos são decorrentes do acréscimo de mais um nível de indireção na entrega de multicasts com a introdução dos IMSs. Devido à ausência destas garantias, uma implementação do $h \_R E C D$ como no $A M^{2} C$ impossibilitaria a entrega confiável de multicasts aos Mhs. Os detalhes de como o acréscimo de mais um nível de indireção no $i A M^{2} C$ implica nos fatos mencionados anteriormente, bem como as conseqüências destes, caso fosse utilizada a mesma implementação do $A M^{2} C$, são explicados na seção 6.2 .

Assim como no $A M^{2} C$, cada $M h$ do sistema possui um array $h \_R E C D$ associado, e que é mantido pelo $M s s$ responsável pelo $M h$. A diferença entre o $h \_R E C D$ do $A M^{2} C$ e do $i A M^{2} C$ é que, neste último, cada posição $h \_R E C D[\mathrm{i}]$ em vez de conter um número de seqüência, contém uma lista com os números de seqüência de todas as mensagens de multicast iniciados por $M s s_{i}$ e já recebidas pelo Mh.

Seja $M$ uma mensagem de multicast difundida por $M s s_{i}$, cujo número de seqüência é $j$. Quando um $M s s$ recebe $M$, a mensagem só será enviada para um $M h$ destinatário se $j \notin h \_R E C D\left[M s s_{i}\right]$. Sempre que um $M h$ responde a uma tal mensagem, o número de seqüência desta é então inserido em $h \_R E C D\left[M s s_{i}\right]$. Se o $M h$ não é destinatário de uma mensagem, nenhuma atualização é feita em seu $h \_R E C D$.

Como também acontece no $A M^{2} C$, quando um $M h$ não responde a $M$ dentro do período de T1 unidades de tempo, $j$ é acrescentado em $h \_R E C D\left[M s s_{i}\right]$ para indicar que o $M s s$ responsável pelo $M h$ já tratou a mensagem (no caso, considerou a resposta do $M h$ como $\mathrm{NOk}_{M}$ ). O mesmo ocorre quando o $M s s$ da nova célula decide não retransmitir uma mensagem para um $M h$ migratório.

Para evitar que a lista presente em $h_{-} R E C D\left[M s s_{i}\right]$ (para qualquer $M s s_{i}$ do sistema) cresça indefinidamente com o envio de novos multicasts, faz-se necessária uma "coleta de lixo". Essa coleta é feita sempre que uma mensagem contendo o estado final de um multicast (mensagem de status) é transmitida pelo IMS aos seus Msss. Assim, além de remover uma mensagem $M$ do buffer de um $I M S$, elimina-se também o número de seqüência correspondente em $h \_R E C D\left[M s s_{i}\right]$, já que o mesmo não será mais usado para verificar se um $M h$ recebeu ou não a mensagem. Como a mensagem de status é difundida para qualquer $M s s$ que possua um $M h \in M$.Dest, e como só existe uma única cópia de $h \_R E C D$ por $M h$, então certamente o número de seqüência de $M$ será removido de todos 
os $h \_R E C D$ s dos Mhs destinatários.

\subsubsection{O Protocolo de Hand-off}

Nesta seção descreveremos o hand-off no $i A M^{2} C$, ressaltando as principais diferenças com relação ao hand-off no $A M^{2} C$. Estamos assumindo que um dado $M h\left(M h_{n e w}\right)$ está em processo de migração da célula de $M s s_{o}$ para a célula de $M s s_{n}$, e que este já enviou a mensagem Dereg para $M s s_{o}$ solicitando o desvinculamento de $M h_{n e w}$ da sua antiga célula. A tabela 4.2 mostra a seqüência de eventos mais importantes que ocorrem em $M s s_{o}$ e $M s s_{n}$ durante o processo de hand-off. As ações tomadas pelos elementos diante da chegada destes eventos são descritas no decorrer desta seção.

\begin{tabular}{|c|l|}
\hline Linha & Seqüência de Eventos \\
\hline$o_{1}$ & Dereg $\prec \mathrm{M}$ \\
$o_{2}$ & $\mathrm{M} \prec$ Dereg $\prec \mathrm{M}+\mathrm{T} 1$ \\
$o_{3}$ & $\mathrm{M} \prec \mathrm{Ok}_{M} \prec$ Dereg \\
$o_{4}$ & $\mathrm{M} \prec \mathrm{NOk}_{M}$ ou $\mathrm{M}+\mathrm{T} 1 \prec$ Dereg \\
\hline$n_{1}$ & $\mathrm{ReFwd}($ Pendentes, Finais $) \prec \mathrm{M}$ \\
$n_{2}$ & $\mathrm{M} \prec \operatorname{ReFwd}($ Pendentes,Finais $) \prec \mathrm{M}+\mathrm{T} 1$ \\
$n_{3}$ & $\mathrm{M}+\mathrm{T} 1 \prec$ ReFwd(Pendentes,Finais) \\
\hline
\end{tabular}

Tabela 4.2: Seqüência de eventos mais relevantes ocorridas em $M s s_{o}$ e $M s s_{n}$.

1. O recebimento da mensagem Dereg por parte de $M s s_{o}$ e o consequente envio da mensagem DeregAck para $M s s_{n}$ ocorre em situações idênticas às descritas na seção 3.5. A diferença está no tratamento dado em relação à estrutura $h \_R E C D$ (que é parâmetro da mensagem DeregAck), e que apresentamos a seguir. Para isso, seja $M$ uma mensagem de multicast difundida por um dado $M s s$ inicializador $\left(M s s_{\text {init }}\right)$, cujo número de seqüência seja $j$.

(a) linha $o_{1}$ da tabela: $M s s_{o}$ envia a mensagem DeregAck para $M s s_{n}$ sem incluir $j$ em $h \_R E C D\left[\mathrm{Mss}_{\text {init }}\right]$;

(b) linha $o_{2}$ : se $M s s_{o}$ já enviou $M$ para $M h_{n e w}$, o qual ainda não respondeu, então $M s s_{o}$

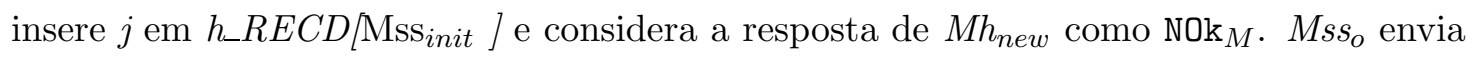
então a mensagem DeregAck para $\mathrm{Mss}_{n}$; 
(c) linha $o_{3}$ : neste caso, o $h \_R E C D$ incluído na mensagem DeregAck contém o número de seqüência $j$ de $M$, uma vez que tal inclusão é feita no momento da chegada da resposta de $M h_{\text {new }}$;

(d) linha $o_{4}$ : a mensagem DeregAck é enviada com o número de seqüência de $M$ incluído em $h \_R E C D$, visto que em ambos os casos $j$ é inserido em $h \_R E C D\left[\mathrm{Mss}_{\text {init }}\right]$;

Se $M s s_{o}$ e $M s s_{n}$ pertencem a domínios diferentes (i.e., o $I M S$ ao qual $M s s_{o}$ está associado não é o mesmo $I M S$ que $M s s_{n}$ está associado), $M s s_{o}$ também envia a mensagem LocationUpdate para o $I M S$ responsável pelo seu domínio, o qual atualizará a informação de que $M h_{n e w}$ não mais se encontra em nenhuma célula dos Msss de seu domínio.

2. Ao receber a mensagem DeregAck $M s s_{n}$ oficializa $M h_{n e w}$ como parte de seu conjunto LocalMhs e armazena o $h \_R E C D$ recebido na mensagem. $M s s_{n}$ envia então a mensagem LocationUpdate para o $I M S$ correspondente, incluindo na mensagem o $h \_R E C D$. Esta mensagem fará o papel de solicitação de atualização de LocMap e de reenvio de mensagens pendentes.

3. Na chegada da mensagem LocationUpdate o IMS atualiza então seu LocMap, o qual indicará agora que $M h_{n e w}$ encontra-se na célula de $M s s_{n}$. Para toda mensagem $M$ armazenada em seu buffer e que tenha $M h_{n e w}$ como destinatário, o IMS verifica se o número de seqüência de $M$ está presente no $h \_R E C D$ transmitido na mensagem recebida. Em caso negativo (ou seja, $M h_{n e w}$ não recebeu a mensagem), o $I M S$ acrescenta $M$ em uma lista Pendentes. Da mesma forma, o IMS acrescenta em uma lista Finais todos os estados finais dos multicasts que tenham $M h_{\text {new }}$ como destinatário. A mensagem ReFwdMsgFromIMS(Pendentes, Finais) é então enviada para $M s s_{n}$.

4. Quando $M s s_{n}$ recebe ReFwdMsgFromIMS (Pendentes, Finais) do IMS, para cada mensagem $M \in$ Pendentes, três situações podem ocorrer. Seja $M$ uma mensagem de multicast difundida por $M s s_{i n i t}$ e com o número de seqüência $=j$. Note-se que $M$ pode chegar em $M s s_{n}$ no intervalo de tempo entre o envio do LocationUpdate e a chegada de ReFwdMsgFromIMS (Pendentes,Finais) (por exemplo, pode existir algum outro $M h$ local e pertencente a M.Dest). Os possíveis casos e correspondentes ações são:

(a) A chegada de ReFwdMsgFromIMS ocorre antes da chegada de $M$ (linha $n_{1}$ da tabela): $M s s_{n}$ envia $M$ para $M h_{\text {new }}$ e inicia o timer com time-out T1, aguardando por uma resposta de $M h_{\text {new }}$; 
(b) ReFwdMsgFromIMS chega em $M s s_{n}$ após a chegada de $M$, mas antes da ocorrência do seu time-out (linha $n_{2}$ ): neste caso, duas ações podem ser tomadas, de acordo com a política de retransmissão de mensagens adotada. Estas políticas são baseadas no $\log$ do $M s s$, e podem ser:

P1) Envio condicional: $M$ só é enviada caso ainda não tenha sido transmitida para nenhum outro $M h \in$ LocalMhs $\cap$ M.Dest (o que é verificado pelo Mss através da consulta a seu $\log$ ). Na situação (b), assume-se que a resposta do novo $M h$ é $\mathrm{NOk}_{M}$ e o $M s s_{n}$ acrescenta $j$ em $h_{-} R E C D\left[\mathrm{Mss}_{\text {init }}\right]$;

P2) Envio incondicional: a mensagem é enviada para o novo $M h$, e o tempo de espera é estendido por mais T1 unidades de tempo.

(c) A mensagem ReFwdMsgFromIMS chega em $M s s_{n}$ após o time-out de $M$ (linha $n_{3}$ ): como de certa forma $M$ já foi descartada por $M s s_{n}$, este responde a $M s s_{i n i t}$ considerando a resposta

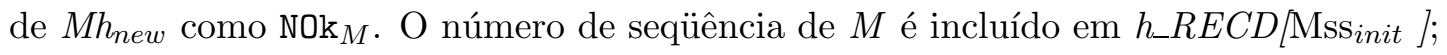

Em relação aos estados finais presentes na lista Finais, estes são retransmitidos para $M h_{\text {new }}$, independente da política adotada.

A política incondicional de envio de mensagens (considerando um $M h$ na situação (b)) tem a vantagem de ser menos pessimista, isto é, o $M s s$ dá uma nova chance ao $M h$ de receber e responder um multicast antes de considerar sua resposta como NOk. Todavia, como nestes casos o time-out é prorrogado, esta política possui a desvantagem de ser mais demorada do que a política condicional.

A Figura 4.4 mostra um exemplo no qual uma mensagem $M$ chega em $M s s_{o}$ no momento em que $M h_{n e w}$ está em processo de migração. Considere que $M h_{n e w} \in M$.Dest e que ainda não tenha recebido a mensagem. Neste caso, como o IMS associado a $M s s_{o}$ (IMS2) não é o mesmo $I M S$ associado a $M s s_{n}(I M S 1)$, depois de enviar a mensagem DeregAck para $M s s_{n}$, $M s s_{o}$ envia a mensagem LocationUpdate para IMS2.

Depois que DeregAck chega em $M s s_{n}$, este acrescenta $M h_{n e w}$ em LocalMhs e também envia a mensagem LocationUpdate para IMS1, informando-o que $M h_{\text {new }}$ agora se encontra em sua célula. Através de $h \_R E C D, I M S 1$ percebe que $M h_{n e w}$ ainda não recebeu $M$ e a retransmite para $M s s_{n}$. Adotando a política de entrega condicional discutida anteriormente, $M s s_{n}$ envia $M$ para o novo $M h$, o qual responde antes de T1 se esgotar. $M s s_{n}$ então envia a mensagem $\operatorname{OkSet}\left\{M h_{n e w}\right\}$ para 


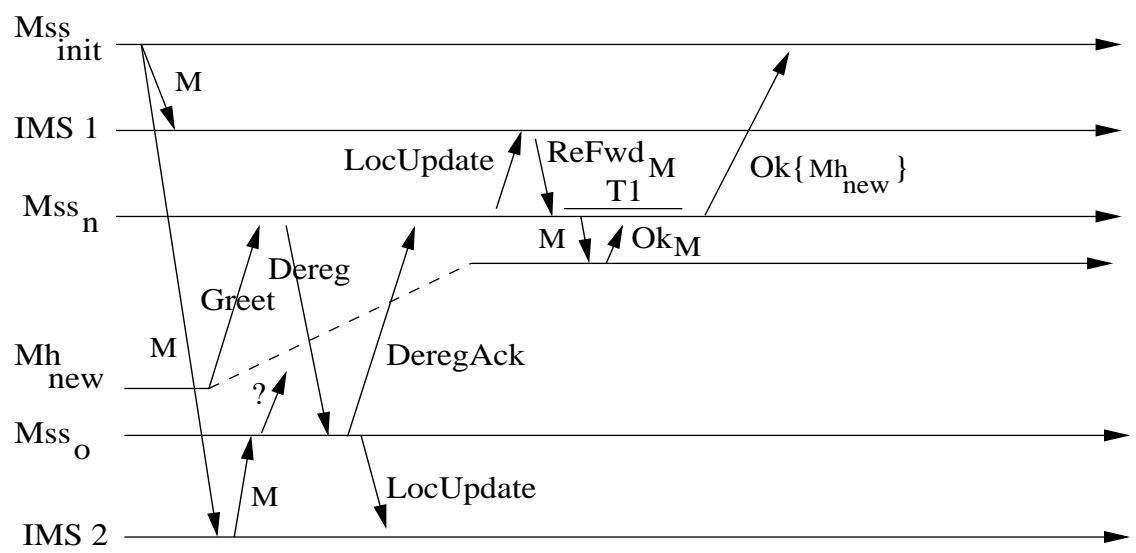

Figura 4.4: Protocolo de Hand-off no $i A M^{2} C$

$M s s_{\text {init }}$ informando-o sobre a aceitação de $M$ por parte de $M h_{n e w}$. Caso fosse adotada a política de entrega incondicional, mesmo que $M s s_{n}$ já tivesse enviado $M$ a outro $M h$ destinatário local, e $\operatorname{ReFwd}_{M}$ tivesse chegado antes do time-out ser processado, o Mss também retransmitiria $M$ para $M h_{\text {new }}$.

\subsection{Discussão}

Nesta seção discutiremos alguns pontos importantes do $i A M^{2} C$, comparando alguns deles com o $A M^{2} C$.

\subsubsection{Consequência do Acréscimo de Mais um Nível de Indireção}

Um ponto importante a ser discutido é a conseqüência do acréscimo de mais um nível de indireção no gerenciamento de localização do $i A M^{2} C$. A introdução dos $I M S s$ como elemento intermediário entre os $M s s$ s (Mss $\leftrightarrow M S \leftrightarrow M s s)$ eventualmente pode causar uma inconsistência da informação sobre a localização de um $M h$ nestes elementos. Isto é decorrente dos elementos envolvidos em um hand-off no $i A M^{2} C\left(M s s_{n}, M s s_{o}\right.$ e $\left.I M S\right)$ serem informados da nova localização do $M h$ em momentos diferentes, que acontece, respectivamente, na chegada da mensagem Greet, Dereg e LocationUpdate. Como estes eventos não ocorrem simultaneamente, a informação sobre a localização de um $M h$ fica inconsistente durante um certo período de tempo.

Assim, consideremos um $M h\left(M h_{n e w}\right)$ que acabou de migrar da célula de $M s s_{o}$ para a célula de $M s s_{n}$. Caso a mensagem LocationUpdate chegue no IMS após a chegada de uma mensagem de 
multicast $M$ que tenha $M h_{n e w}$ como destinatário, então o $I M S$ enviará $M$ para $M s s_{o}$, pois o LocMap do $I M S$ ainda não foi atualizado. Notemos que o envio de $M$, neste caso, é desnecessário, uma vez que $M s s_{o}$ nada pode fazer em relação à transmissão da mensagem para $M h_{n e w}$ (pois este não mais pertence a LocalMhs). Dessa forma, aumenta-se o overhead do protocolo.

Todavia, como assumimos que a comunicação na rede fixa é confiável, em algum momento a inconsistência descrita acima deixará de existir. Ainda, o envio da mensagem LocationUpdate do $M s s_{n}$ (Mss da nova célula) para seu correspondente $I M S$, ocorre imediatamente após o registro de $M h_{\text {new }}$ em sua célula. Dessa forma, espera-se que o delay para a atualização do mapeamento no $I M S$ seja pequeno, evitando que mensagens sejam transmitidas desnecessariamente na rede com fio. Vale observar que mesmo nestes casos, não há nenhuma implicação em termos de corretude do protocolo, visto que o $M s s_{o}$ simplesmente descartará a mensagem. Ainda, o envio de $M$ para $M s s_{o}$ só constituiria um overhead caso $M s s_{o}$ só tivesse $M h_{\text {new }}$ como elemento destinatário da mensagem. Em todos os outros casos, a chegada de $M$ seria processada normalmente por $M s s_{o}$, e não representaria nenhum custo adicional para o protocolo.

\subsubsection{Papel Desempenhado Pelos Msss e IMSs}

Alguns aspectos também merecem atenção quando comparamos o comportamento do $i A M^{2} C$ com o do $A M^{2} C$. Neste último, os $M s s s$ tratam tanto do hand-off (transferência do $h \_R E C D$ ) como do armazenamento das mensagens e estados finais de multicasts. Já no $i A M^{2} C$ estas funções são bem divididas entre os $M s s$ s e os $I M S s$, respectivamente. Esta divisão torna o $i A M^{2} C$ melhor estruturado, mas tem como conseqüência um maior número de mensagens na rede fixa para a transmissão de um multicast/estado final a um $M h$, quando ocorre uma migração.

Apesar de implementações diferentes, a estrutura $h \_R E C D$ tem a mesma finalidade nos dois protocolos: determinar quais os multicasts que já foram recebidos por um $M h$ e permitir decidir quais multicasts devem ser retransmitidos. No $A M^{2} C$ esta decisão é tomada pelos $M s s s$, enquanto que no $i A M^{2} C$ isto é feito pelos IMSs. Por este motivo, após completado um hand-off o $h \_R E C D$ também precisa ser passado para o IMS correspondente (através da mensagem LocationUpdate).

\subsubsection{Semântica de Resposta de um $M s s$}

Outro ponto é a semântica da resposta de um Mss (para o $M s s_{\text {init }}$ correspondente) ao término do tempo T1 (Fase I). No $A M^{2} C$ o Ok/NOk sintetiza um conjunto de respostas (dos $M h s$ locais e destinatários de uma mensagem). Já no $i A M^{2} C$, o OkSet indica cada resposta de um $M h$ explicitamente. 


\subsubsection{Estimativa do Número de Mensagens Transmitidas}

Nesta subseção apresentamos equações que estimam o número de mensagens transmitidas tanto na rede fixa como na rede sem fio, para ambos os protocolos. Em seguida é feita uma avaliação dos resultados obtidos. Antes de iniciarmos, sejam as seguintes considerações:

1. As equações referem-se às mensagens transmitidas em decorrência de uma única requisição de multicast;

2. Consideremos um sistema composto por $M$ Mhs destinatários. Suponhamos também uma rede com I IMSs e $N$ Msss, dos quais apenas $D$ destes possuem algum $M h$ local $\in M$;

3. Sejam mig_1 e mig_2 variáveis que indicam o número de migrações e/ou reconexões dos $M h s$ nas fases I e II, respectivamente, dos protocolos;

4. Estamos desconsiderando a influência de outros parâmetros (como o valor dos time-outs) nas análises seguintes;

5. Os parênteses na primeira linha de cada equação indicam as mensagens transmitidas pelos protocolos nas fases I e II, respectivamente.

\section{Mensagens no $A M^{2} C$}

Mensagens na rede fixa (Wd):

$$
\begin{array}{r}
W d=\left(2 N+2 m i g \_1\right)+\left(2 N+2 m i g \_2+m i g \_2\right)+N \\
W d=5 N+2 m i g \_1+3 m i g \_2
\end{array}
$$

Mensagens na rede sem fio $(\mathrm{Wl})$ :

$$
\begin{array}{r}
W l=(1+2 M)+\left(2 M+2 m i g \_2\right) \\
W l=4 M+2 m i g \_2+1 \\
W l=2\left(2 M+m i g \_2\right)+1
\end{array}
$$

Em se tratando das mensagens na rede com fio, na Fase I do $A M^{2} C$ temos a difusão do multicast para todos os Msss do sistema, as respostas dos mesmos enviadas para o Mss inicializador do multicast, e as mensagens Dereg e DeregAck geradas durante os hand-offs. Este mesmo raciocínio pode ser aplicado à Fase II (a partir da difusão do estado final do multicast), levando-se em consideração 
também o número de mensagens AckMss extras ${ }^{2}$. Na Fase III temos a difusão da mensagem Delete para todos os Msss. Desta forma, a estimativa do número de mensagens trocadas na rede fixa no $A M^{2} C$ é dada através da equação 4.1 .

Com relação às mensagens enviadas pela rede sem fio, na Fase I do $A M^{2} C$, além da requisição do multicast, temos o envio e resposta da mensagem para os $M$ destinatários. Notemos que nesta fase, graças à estrutura $h \_R E C D$ (vide seção 3.5), uma mensagem de multicast é enviada uma única vez para um Mh destinatário. Na Fase II, além do envio e confirmação do estado final do multicast para os $M$ destinatários, temos que levar em conta as retransmissões (e confirmações) do estado final sempre que há uma migração. Assim, na equação 4.2 temos o número estimado de mensagens transmitidas no enlace sem fio do protocolo $A M^{2} C$.

\section{Mensagens no iA $M^{2} C$}

Mensagens na rede fixa $(\mathrm{Wd})$ :

$$
\begin{array}{r}
W d=\left(I+2 D+2 m i g \_1+2 m i g \_1+m i g \_1\right)+ \\
\left(I+2 D+2 m i g \_2+2 m i g \_2+m i g \_2+m i g \_2\right)+I \\
W d=3 I+4 D+5 m i g \_1+6 m i g \_2
\end{array}
$$

Mensagens na rede sem fio (Wl):

$$
\begin{array}{r}
W l=(1+2 M)+\left(2 M+2 m i g \_2\right) \\
W l=4 M+2 m i g \_2+1 \\
W l=2\left(2 M+m i g \_2\right)+1
\end{array}
$$

Considerando as mensagens enviadas na rede fixa durante a Fase I do protocolo $i A M^{2} C$, temos, nesta ordem: difusão do multicast para os I IMSs; envio (e resposta) da mensagem para os D Msss que possuem algum $M h$ local e destinatário do multicast; mensagens Dereg e DeregAck relacionadas aos hand-offs; atualizações de mapeamento com as migrações (notemos que no pior caso as migrações são sempre inter-domínio, o que implica no envio da mensagem LocationUpdate para os Msss da antiga e nova células); e retransmissões de mensagens pendentes por parte dos IMSs. Na Fase II a análise é semelhante, com a diferença de que temos que considerar as mensagens AckMss extras.

\footnotetext{
${ }^{2}$ Mensagem enviada quando uma resposta de um Mh é processada após a ocorrência do time-out T2 - vide seção 3.3 .
} 
Na Fase III temos a difusão da mensagem Delete para os IMSs. Desta maneira, a equação 4.3 apresenta uma estimativa do número de mensagens trocadas na rede fixa no $i A M^{2} C$.

Em se tratando das mensagens transmitidas no enlace sem fio, vale a mesma análise realizada pa-

ra o protocolo $A M^{2} C$, resultando na equação 4.4. É importante observar que estamos considerando, como pior caso, a adoção da política incondicional de retransmissão de mensagens.

\section{Comparação das Equações}

Considerando as equações que estimam o número de mensagens trocadas na rede fixa nos protocolos $A M^{2} C$ e $i A M^{2} C$ (equação 4.1 e 4.3, respectivamente), aparentemente o segundo protocolo possui um custo superior ao do primeiro. Todavia, podemos assumir que $I$ é desprezível, se comparado aos valores de $N$ e $D$ (por suposição, o número de IMSs é bem menor do que o número de $M s s$ ). Além disto, considerando no pior caso que $D=N$, a estimativa do número de mensagens transmitidas na rede fixa do $i A M^{2} C$ pode ser dada por:

$$
W d\left(i A M^{2} C\right)=4 N+5 m i g \_1+6 m i g \_2
$$

Assim, resolvendo a inequação $W d\left(i A M^{2} C\right)<W d\left(A M^{2} C\right)$, chegamos ao resultado que o uso do protocolo $i A M^{2} C$ compensa se $N>3\left(m i g_{-} 1+m i g_{-} 2\right)$. Isto mostra que o $i A M^{2} C$ é mais adequado do que o $A M^{2} C$ em redes com um número grande de $M s s s$, além de indicar que o protocolo é mais sensível à taxa de migração dos Mhs. A seção 5.5 mostra resultados de simulações que comprovam esta conclusão.

Em termos das mensagens transmitidas na rede sem fio, notemos que as equações $4.2\left(A M^{2} C\right)$ e $4.4\left(i A M^{2} C\right)$ são idênticas. Isto mostra que os dois protocolos utilizam estratégias similares para a entrega de mensagens aos seus destinatários. O que vai diferenciar é a escolha da política de transmissão de mensagens adotada no $i A M^{2} C$. 


\section{Capítulo 5}

\section{Implementação e Simulação}

Este capítulo descreve a implementação e simulação dos protocolos $A M^{2} C$ e $i A M^{2} C$. O objetivo da implementação foi testar, validar e comparar os dois protocolos, verificando as vantagens e desvantagens de cada um. Para isso, prototipamos e implementamos os protocolos no simulador MobiCS $[8,7,5,6]$, como veremos adiante. Para cada um dos protocolos efetuamos testes determinísticos e estocásticos, de maneira a verificar o comportamento dos protocolos em situações específicas e em cenários aleatórios. As estruturas de dados e os algoritmos ${ }^{1}$ utilizados na implementação dos protocolos $A M^{2} C$ e $i A M^{2} C$ podem ser encontrados, respectivamente, nos apêndices C e D.

\subsection{Simulador Mobi $C S$}

Ambientes de Computação Móvel se caracterizam principalmente pela topologia dinâmica da rede e a influência da mobilidade sobre o custo implícito da localização e o grau de disponibilidade dos dispositivos móveis. Por este motivo, o uso de simuladores torna-se essencial para a avaliação de protocolos distribuídos para computação móvel, tais como o $A M^{2} C$ e o $i A M^{2} C$.

O Mobi $C S[8,7,5,6]$ é um ambiente para prototipagem e simulação de protocolos distribuídos para computação móvel, que permite o uso de abstrações de programação de alto nível e provê total transparência de simulação para o programador. MobiCS é capaz de emular um ambiente de computação móvel e funcionar em dois modos distintos de simulação: o modo determinístico, no qual o usuário do simulador pode criar e executar um cenário bem específico de teste; e o modo estocástico, no qual os elementos de rede possuem padrões de comportamento probabilísticos definidos pelo usuário. Tais modos de simulação serão discutidos em maiores detalhes adiante.

\footnotetext{
${ }^{1}$ Os algoritmos também foram desenvolvidos durante o trabalho.
} 
O MobiCS foi projetado para simular um ambiente de rede móvel estruturada, tal como descrito na seção 1. O simulador foi projetado para permitir a implementação e simulação de protocolos que realizam algoritmos distribuídos para ambientes de computação móvel. Além do $A M^{2} C$ [13] e o $i A M^{2} C$ [10], o MobiCS também foi usado para implementar protocolos como o MCAST [1], o RDP [12], o Mobile IP [28] e o Mobile IP com Otimizações de Rotas [9]. Estes protocolos levam em consideração a mobilidade e a localização dos dispositivos móveis, tratando explicitamente as desconexões e a topologia dinâmica intrínseca à computação móvel.

\subsubsection{Simulação Determinística}

No modo de simulação determinístico, o Mobi $C S$ executa um script de simulação definido pelo usuário que expressa um cenário específico do ambiente computacional móvel a ser simulado. O script é composto de eventos como, por exemplo, a movimentação dos elementos móveis, o instante de recebimento de mensagens e eventos locais em cada elemento. Apenas o comportamento do protocolo sendo testado não pode ser descrito em um script, pois este é definido por sua implementação. No modo determinístico não existe a noção de tempo. Em vez disso, a simulação ocorre em rodadas definidas no script de simulação. Eventos simulados em uma mesma rodada são tratados como se fossem eventos concorrentes, ou seja, a ordem de execução é não-determinística.

Neste modo de simulação pode-se validar um protocolo através de scripts que retratam situações bem específicas e críticas para as quais o protocolo deve ser testado. Desta maneira, o protocolo pode ser depurado com relação às situações definidas nos scripts, a fim de se ter certeza de que o comportamento do protocolo está pelo menos parcialmente correto. Apesar disto não garantir a corretude do protocolo em todas as possíveis situações, este modo de simulação é uma ferramenta útil para o desenvolvimento de protocolos complexos. Testes bem sucedidos neste modo são um bom indicador de que o protocolo está funcionando adequadamente.

\subsubsection{Simulação Estocástica}

No modo de simulação estocástica, usualmente implementado pela maioria dos simuladores de rede, o MobiCS considera o comportamento dos elementos de rede como sendo aleatório e baseado em padrões probabilísticos definidos na modelagem da simulação. Neste modo, o simulador realiza testes exaustivos do protocolo com o objetivo de avaliar o desempenho dos algoritmos implementados e a complexidade das mensagens. O modelo de execução no modo estocástico é orientado a eventos, como na simulação determinística, e utiliza o conceito de tempo simulado para associar um 
timestamp aos eventos.

A primeira etapa da simulação estocástica é a modelagem do padrão de comportamento de cada elemento a ser simulado, tal como os computadores móveis e as conexões sem fio. Isto é, definese a geração de eventos periódicos como eventos de migração, eventos de desconexão/conexão, de requisição (do serviço implementado pelo protocolo) e o atraso nas conexões de rede. O Mobi $C S$ possibilita a especificação de vários modelos de simulação. Um modelo de simulação tipicamente possui parâmetros como a taxa de mobilidade dos $M h s$, a probabilidade de desconexão/conexão destes, a probabilidade de atração de cada célula durante um hand-off, o atraso da comunicação sem fio em relação à comunicação na rede fixa, entre outros. Para cada um dos elementos de rede simulados definem-se probabilidades associadas a cada parâmetro do modelo de simulação (por exemplo, a probabilidade de migração de um $M h$ ). A maioria dos parâmetros que definem tal modelo são baseados em uma noção de uma unidade de tempo simulada (UT). Ou seja, para cada novo valor de $U T$ o modelo determina, de acordo com uma probabilidade indicada pelo usuário, quais eventos deverão ser gerados e processados pelo simulador.

Durante a simulação, a camada de simulação de cada elemento processa eventos gerados por outros elementos de rede ou pela própria camada (eventos de tempo) e ordenados pelo seu timestamp. Os eventos descrevem mensagens enviadas entre elementos de rede e o comportamento dinâmico dos elementos, em termos de envio de requisições, movimentações e início e fim de períodos de atividade de $M h s$.

O simulador Mobi $C S$ serviu como principal ferramenta para a prototipação, validação e avaliação de desempenho dos protocolos de multicast atômico $A M^{2} C$ e $i A M^{2} C$ para diferentes ambientes de computação móvel.

\subsection{Modelo de Composição}

Na programação de protocolos utilizando o MobiCS, um protocolo é composto de micro-protocolos que implementam uma funcionalidade parcial bem definida do protocolo. Cada micro-protocolo é composto de um estado e de um conjunto de métodos que tratam cada evento que pode ser recebido por ele. Esses eventos são definidos em interfaces Java (vide seção 5.3) para cada um dos elementos de rede a serem simulados (tais como Msss, Mhs e IMSs). Deste modo, cada micro-protocolo implementa uma ou mais interfaces.

Seguindo este padrão, as Figuras 5.1 e 5.2 apresentam, respectivamente, um esquema da compo- 
sição dos protocolos $A M^{2} C$ e $i A M^{2} C$. O micro-protocolo wired é responsável pelo tratamento dado pelos elementos de rede na chegada de uma mensagem pela rede fixa. Dessa forma, o micro-protocolo wired contém interfaces para os elementos de rede que são capazes de receber uma mensagem enviada pela rede com fio (obviamente não há uma interface para os $M h s$ ). De forma similar, as mensagens transmitidas pelo meio sem fio são tratadas pelo micro-protocolo wireless. Já o micro-protocolo de hand-off se encarrega de manipular (por meio dos métodos que fazem parte das interfaces) as mensagens trocadas durante a migração de um $M h$.

Os diagramas com as principais classes (e seus respectivos métodos) que compõem os protocolos $A M^{2} C$ e $i A M^{2} C$ podem ser encontrados, respectivamente, nos apêndices A e B.

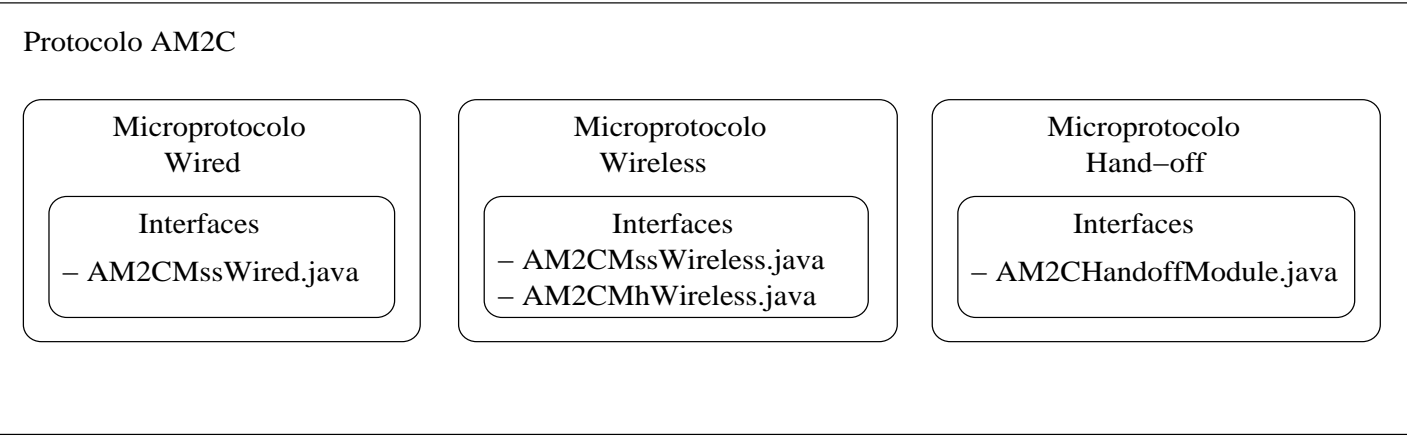

Figura 5.1: Composição do protocolo $A M^{2} C$.

\subsection{Principais Interfaces}

Nesta seção apresentaremos as principais interfaces de cada um dos elementos de rede dos protocolos $A M^{2} C$ e $i A M^{2} C$. Essas interfaces abrangem a comunicação com e sem fio entre os elementos simulados, além do módulo de hand-off. É importante observar que o MobiCS estabelece como convenção que a sintaxe para cada método tratado de um evento Evento seja denominado whenEvento.

\subsubsection{Interfaces no $A M^{2} C$}

\section{AM2CMssWired.java (micro-protocolo wired)}

Define a interface com fio do $M s s$ no protocolo $A M^{2} C$. Contém as mensagens tratadas por um $M s s$ e provenientes de um outro Mss. 
- void whenFwdMsgFromMssInit(Message m) : recebimento de uma mensagem de multicast difundida pelo $M s s$ inicializador do multicast $\left(M s s_{i n i t}\right)$. Faz parte da primeira fase do protocolo.

- void whenRespFromMss(Message m) : recebimento, por parte do Mss $_{\text {init }}$, de uma resposta de um Mss referente a uma mensagem de multicast. Ocorre durante a primeira fase do protocolo.

- void whenStatusFromMssInit(Message $m$ ) : recebimento do estado final de um multicast difundido pelo Mssinit. Faz parte da segunda fase do protocolo.

- void whenAckMss(Message m) : confirmação recebida pelo Mssinit sobre o recebimento do estado final de um multicast por parte dos Mhs locais. Ocorre durante a segunda fase do protocolo.

- void whenDelete(Message $m$ ) : recebimento da solicitação de remoção do estado final de um multicast armazenado localmente. Faz parte da terceira fase do protocolo.

\section{AM2CMssWireless.java (micro-protocolo wireless)}

Define a interface sem fio do $M s s$ no $A M^{2} C$. Contém as mensagens tratadas por um $M s s$ e provenientes de um $M h$ local e os eventos de time-out gerados.

- void whenMulticastRequested(Message $m$ ) : requisição de multicast de uma mensagem feito por um Mh para o seu Mss (que, para efeito do protocolo, será considerado o $M s s_{\text {init }}$ ).

- void whenRespFromMh(Message $m)$ : resposta de um Mh sobre a aceitação ou não de uma mensagem. Ocorre durante a primeira fase do protocolo.

- void whenAckMh(Message m) : Confirmação de um Mh sobre o recebimento do estado final de um multicast. Ocorre durante a segunda fase do protocolo.

- void whenJoin(Message $m$ ) : pedido de entrada no sistema por um $M h$.

- void whenLeave(Message $m$ ) : pedido de saída do sistema por um $M h$.

- void whenWaitingForReply(Timer t) : ocorrência do tempo máximo esperado (time-out) por uma resposta de um $M h$, referente ao envio de uma mensagem durante a primeira fase do protocolo. 
- void whenWaitingForAck(Timer t) : ocorrência do tempo máximo esperado (time-out) por uma confirmação de um $M h$ sobre o recebimento do estado final de um multicast. Ocorre na segunda fase do protocolo.

\section{AM2CMhWireless.java (micro-protocolo wireless)}

Define a interface sem fio de um $M h$ no protocolo $A M^{2} C$. Contém as mensagens que são tratadas por um Mh e provenientes do Mss responsável pelo mesmo.

- void whenFwdMsgFromMssN(Message $m$ ) : recebimento de uma mensagem multicast na primeira fase do protocolo.

- void whenStatusFromMssN(Message $m$ ) : recebimento do estado final de um multicast durante a segunda fase do protocolo.

\section{AM2CHandoffModule.java (micro-protocolo hand-off)}

Define a interface do módulo de hand-off no $A M^{2} C$. Estas mensagens podem ocorrer em qualquer uma das fases do protocolo.

- whenGreet(Message $m$ ) : mensagem recebida pelo Mss quando um Mh entra na célula do Mss ou volta de um período de inatividade.

- void whenDereg(Message $m$ ) : recebimento, por parte do Mss da célula anterior de um Mh migratório, da solicitação de desvinculamento do $M h$, enviada pelo $M s s$ da nova célula.

- void whenDeregAck(Message $m$ ) : recebimento, por parte do Mss da célula para a qual o Mh migrou, da confirmação de desvinculamento do $M h$ de sua antiga célula.

\subsubsection{Interfaces no $\mathrm{iAM} \mathbf{M}^{2} \mathrm{C}$}

Nesta subseção, estaremos apresentando as interfaces do protocolo $i A M^{2} C$. É importante dizer que algumas delas são idênticas às interfaces usadas pelo $A M^{2} C$, e serão indicadas com um $\left(^{*}\right)$. Nestes casos, se o leitor desejar obter alguma explicação sobre a interface, basta consultar a mesma subseção para o protocolo $A M^{2} C$. A idéia principal neste momento é apresentar as principais diferenças em termos de interfaces. Claramente, o tratamento dado por um elemento de rede para uma mesma interface pode (e geralmente é) ser diferente nos dois protocolos (vide apêndices C e D). 

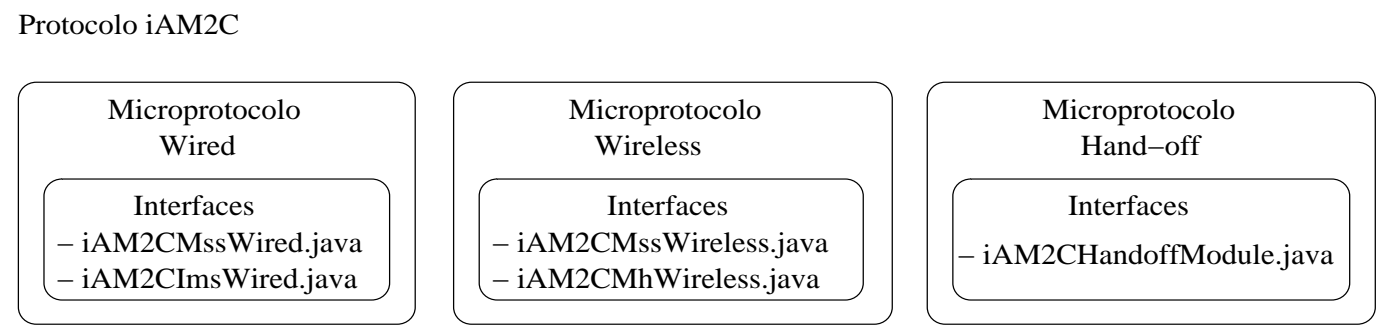

Figura 5.2: Composição do protocolo $i A M^{2} C$.

\section{iAM2CMssWired.java (micro-protocolo wired)}

Define a interface com fio de um Mss. Contém as mensagens recebidas por um Mss e enviadas por outro Mss ou por um IMS.

- void whenFwdMsgFromIms(Message $m$ ) : recebimento de uma mensagem de multicast enviada pelo IMS (relativo ao domínio do Mss) durante a primeira fase do protocolo.

- void whenRespFromMss(Message $m$ ) : recebimento, por parte do Mssinit, de uma mensagem de um Mss com respostas de Mhs locais ao Mss referente a uma determinada mensagem de multicast. Ocorre durante a primeira fase do protocolo.

- void whenStatusFromIms(Message $m$ ) : recebimento do estado final de um multicast enviado pelo $I M S$ durante a segunda fase do $i A M^{2} C$.

- void whenAckMss(Message $m)(*)$

- void whenReFwdMsgFromIms(Message m) : recebimento de uma retransmissão de mensagens (em um único pacote) enviada pelo $I M S$.

\section{iAM2CImsWired.java (micro-protocolo wired)}

Define a interface (com fio) de um $I M S$, isto é, o tratamento de todas as mensagens que são enviadas por um Mss. Apesar de ocorrerem em um $I M S$, o que justifica o texto explicativo, as três primeiras mensagens fazem parte da interface com fio de um $M s s$ no protocolo $A M^{2} C$.

- void whenFwdMsgFromMssInit(Message $m$ ) : recebimento de uma mensagem de multicast

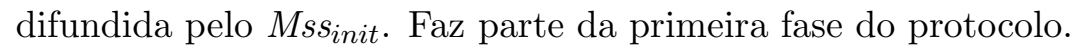


- void whenStatusFromMssInit(Message $m$ ) : recebimento do estado final de um multicast di-

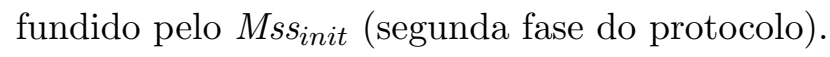

- void whenDelete(Message $m$ ) : recebimento da solicitação de remoção do estado final de um multicast armazenado localmente. Faz parte da terceira fase do protocolo.

- void whenLocationUpdate(Message $m$ ) : solicitação de atualização de mapeamento (e reenvio de mensagens pendentes), enviada de um Mss do domínio do IMS.

\section{iAM2CMssWireless.java (micro-protocolo wireless)}

Interface sem fio do $M s s$ no protocolo $i A M^{2} C$. Contém as mensagens recebidas dos $M h s$ locais e os eventos de time-out gerados.

- void whenMulticastRequested(Message $m)(*)$

- void whenRespFromMh(Message $m)\left({ }^{*}\right)$

- void whenAckMh(Message $m)(*)$

- void whenJoin(Message m)(*)

- void whenLeave(Message $m)(*)$

- void whenWaitingForReply(Timer $t)(*)$

- void when WaitingForAck(Timer $t)(*)$

- void whenTimeIsOver(Timer $t$ ) : ocorrência do tempo máximo esperado (time-out) pelo Mss inicializador de um multicast por respostas de todos os Mhs destinatários de uma mensagem de multicast (como descrito na seção 4.4).

\section{iAM2CMhWireless.java (micro-protocolo wireless)}

Define a interface (sem fio) dos $M h s$ no $i A M^{2} C$. Corresponde às mensagens enviadas pelo Mss responsável pelo $M h$ e tratadas pelo mesmo. Esta interface é a mesma utilizada no protocolo $A M^{2} C$.

- void whenFwdMsgFromMss(Message $m)(*)$

- void whenStatusFromMss(Message m)(*) 


\section{iAM2CHandoffModule.java (micro-protocolo hand-off)}

Interface do módulo de hand-off do protocolo $i A M^{2} C$. Também é a mesma utilizada no protocolo $A M^{2} C$.

- whenGreet(Message $m)(*)$

- void whenDereg(Message $m)(*)$

- void whenDeregAck(Message $m)(*)$

\subsection{Testes}

Aqui encontram-se os principais testes realizados com os protocolos através das simulações determinísticas e estocásticas.

\subsubsection{Testes Determinísticos}

Como mencionado na seção 5.1, os testes determinísticos são importantes no processo de testes e depuração de um protocolo. Nesta etapa focamos em identificar um conjunto de situações críticas e específicas para cada um dos protocolos. Em seguida, definimos e programamos os scripts de simulação correspondentes, a fim de testar o comportamento tanto do $A M^{2} C$ como do $i A M^{2} C$ diante destas situações.

As figuras 5.3 e 5.4 exemplificam dois cenários determinísticos simulados nos protocolos $A M^{2} C$ e $i A M^{2} C$, respectivamente. Para efeito de simplificação da explanação a seguir, deve-se considerar os dois cenários como sendo somente uma parte de uma execução completa dos protocolos. Isto é, deve-se assumir que já foi feita uma solicitação de multicast por parte de algum $M h$ do sistema, e que os protocolos continuarão sendo executados até que a terceira fase dos mesmos seja completada. Além disto, consideramos um único destinatário para o multicast.

No cenário da figura 5.3 está sendo testada a propriedade do protocolo $A M^{2} C$ de abortar um multicast (através do $M s s$ da antiga célula, $M s s_{1}$ ) quando $M h_{1}$ migra sem responder à mensagem enviada (caso $\mathrm{O}_{2}$ da tabela 3.2).

A seguir apresentamos parte do script utilizado para simular o cenário da figura 5.3 em MobiCS. Estamos assumindo que o $M h_{1}$ encontra-se inicialmente na célula de $M s s_{1}$, e que o $M h$ faz parte do grupo de destinatários do multicast. 


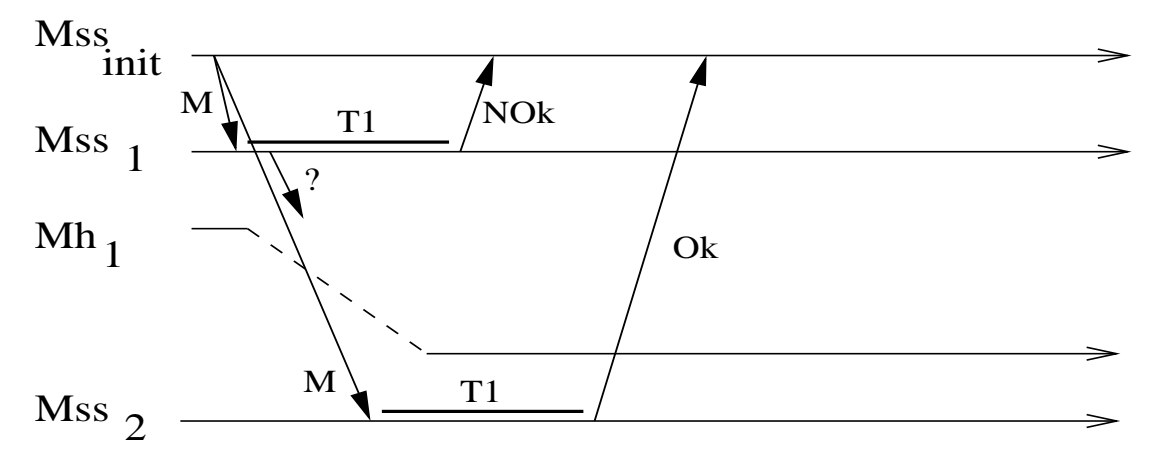

Figura 5.3: Exemplo de cenário determinístico no protocolo $A M^{2} C$.

1. acceptMessageOn (Mss1, false);

2. $\operatorname{next}()$;

3. Mh2.receive (new Start_AM2C( (Group) dest, 100));

4. $\operatorname{next}()$;

5. Mh1.moveTo (cell2);

6. $\operatorname{next}()$;

7. acceptMessageOn (Mss1, true);

8. $\operatorname{next}()$;

No script acima, inicialmente é desligado o processamento de mensagens no $M s s_{1}$ (linha 1), a fim de que o multicast (proveniente da requisição feita por $M h_{2}$ ao $M s_{\text {init }}$ correspondente, linha 3) não seja processado imediatamente pelo Mss. Com o comando moveTo na linha 5, o protocolo de hand-off é iniciado, ou seja, o $M s s$ da célula 2 recebe o Greet de $M h_{1}$ e envia a mensagem Dereg para $M s s_{1}$. No momento em que o processamento de mensagens é reativado em $M s s_{1}$ (linha 7 ), a mensagem de multicast é processada, e então $M s s_{1}$ envia a mensagem para $M h_{1}$. Logo em seguida $M s s_{1}$ processa a mensagem Dereg. Como neste momento o Mss não recebeu nenhuma resposta do $M h_{1}$, então $M s s_{1}$ envia o $\mathrm{NOk}_{M}$ para $M s s_{\text {init }}$. Vale observar que os comandos next() são necessários para estabelecer pontos de sincronização no script, determinando o início de um novo passo de simulação, que só é iniciado quando todos os elementos terminarem a execução das ações do passo anterior.

O segundo cenário (figura 5.4) tem por objetivo testar o envio do estado final do multicast no protocolo $i A M^{2} C$ antes e depois da migração do $M h$. Neste cenário pode-se verificar o envio inicial, por parte do $I M S$, da mensagem de status somente para $M s s_{1}$ (assumindo-se que $M s s_{2}$ não possui nenhum $M h$ local destinatário da mensagem) e a retransmissão do estado final pelo $I M S$ para $M s s_{2}$ 
(após o envio da mensagem LocationUpdate).

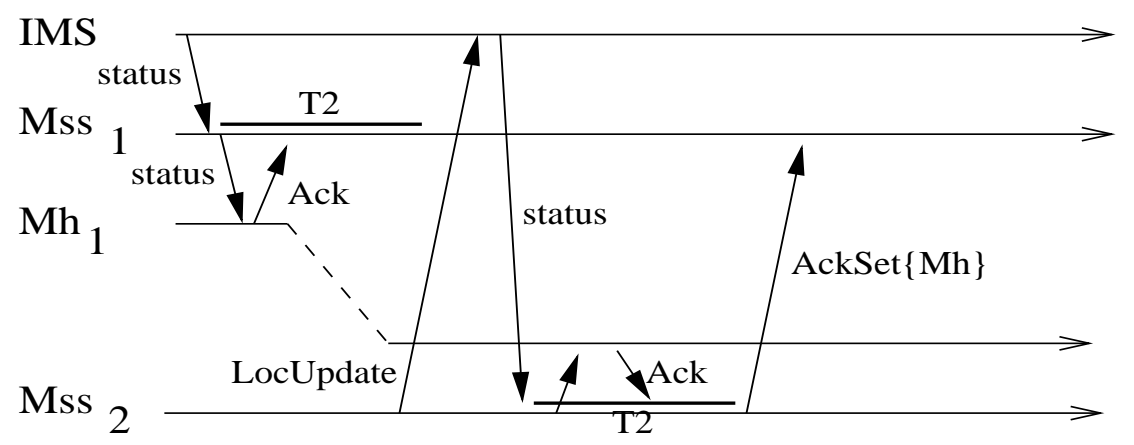

Figura 5.4: Exemplo de cenário determinístico no protocolo $i A M^{2} C$.

O cenário da figura 5.4 pode ser simulado através do trecho de script apresentado abaixo. Estamos considerando que mss1 e mss2 fazem parte do domínio de ims, e que mh1 encontra-se inicialmente na célula de mss1. Embora o foco do cenário esteja na segunda fase do protocolo, abordaremos no script partes da primeira fase, de forma a ajudar no entendimento da fase seguinte.

A fim de que cada time-out possa ser processado através de um comando explícito, inicialmente o processamento de time-outs é desativado no $M s s_{1}$ (linha 1). Em seguida, uma nova requisição de multicast é feita pelo $M h_{2}$ ao $M s s$ correspondente (linha 3), dando início à primeira fase do protocolo. $\mathrm{Na}$ linha 5, é invocado explicitamente o processamento do time-out T1, que indica a conclusão da primeira fase e início da segunda fase do protocolo. Como o processamento do time-out da segunda fase está desligado no $M s s_{1}$, o protocolo é executado até a chegada do Ack (referente ao recebimento do estado final do multicast por parte de $M h_{1}$ ) em $M s s_{1}$. Na linha 7, o comando moveTo desencadeia uma série de eventos definidos pelo protocolo, como o hand-off entre $M s s_{1}$ e $M s s_{2}$ e o conseqüente envio, por parte deste último, da mensagem LocationUpdate para IMS. Ainda no mesmo passo de simulação, o $I M S$ retransmite o estado final do multicast para $M s s_{2}$, que por sua vez o repassa para $M h_{1}$. No passo seguinte, o processamento do time-out T2 é ativado (linha 9) e o protocolo termina a sua execução.

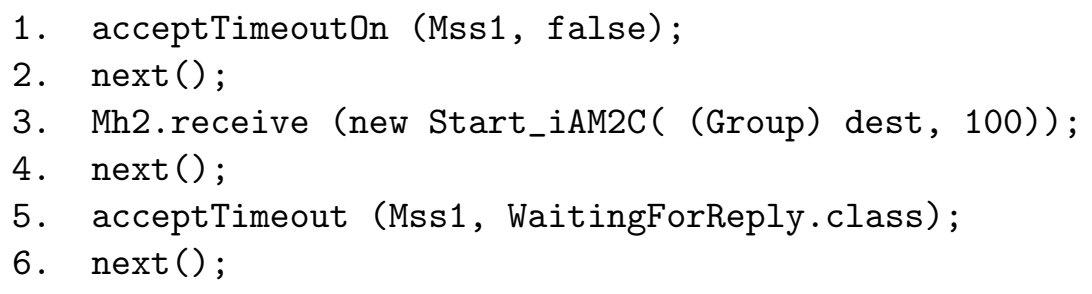


7. Mh1.moveTo (cell2);

8. $\operatorname{next}()$;

9. acceptTimeout (Mss1, WaitingForAck.class); ;

10. $\operatorname{next}()$;

Para verificar se o protocolo executou um script "corretamente", o programador deve analisar o comportamento esperado pelo protocolo antes de sua execução. Em seguida, deve-se comparar os resultados obtidos como $\log$ da execução do script com os resultados esperados.

A execução dos testes determinísticos no processo de simulação, permitiu não só avaliar o comportamento dos protocolos $A M^{2} C$ e $i A M^{2} C$ em diversas situações, mas também foi importante para detectar erros de lógica e uso inadequado de estruturas de dados. A experiência obtida com estes testes será abordada em mais detalhes no capítulo 6 .

Passados os testes determinísticos, cresceu a confiança de que os protocolos possuíam as propriedades básicas necessárias para que funcionassem adequadamente nos cenários aleatórios da simulação estocástica.

\subsubsection{Testes Estocásticos}

A seguir serão apresentados os parâmetros de simulação utilizados nas simulações estocásticas do $A M^{2} C$ e do $i A M^{2} C$, bem como as probabilidades associadas a cada parâmetro neste modelo. Como o objetivo principal foi a comparação do desempenho dos dois protocolos em diferentes cenários, a maioria destes parâmetros foram os mesmos para ambos os protocolos. Aqueles que são específicos de um protocolo serão explicitamente identificados.

\section{Configuração e Características da Rede}

- Número de células $\left(\boldsymbol{N}_{C}\right)$ : na maior parte das simulações usamos uma configuração com 4 ou 8 células. De modo a testar os protocolos em situações mais extremas, realizamos algumas simulações para $N_{C}=\{10,20,30,40,50\}$ e $N_{C}=\{10,15,20,25,30\}$. A topologia utilizada foi de interconexão total. Para cada célula há um Mss responsável pela mesma;

- Número de IMSs: utilizamos uma configuração com dois $I M S s$, de forma que o domínio de cada IMS fosse aproximadamente metade do conjunto total de Msss no sistema. Este parâmetro é exclusivo das simulações do $i A M^{2} C$; 
- Número de $M h s$ : mantivemos sempre o mesmo número de $M h s\left(N_{M h s}=15\right)$ para permitir a comparação dos dois protocolos;

- Posicionamento inicial dos $M h s$ : inicialmente todos os $M h s$ foram "posicionados" nas duas primeiras células. O propósito disto foi verificar se de fato o $i A M^{2} C$ apresenta um desempenho melhor quando há uma distribuição não-uniforme (concentração) de Mhs em algumas células.

- Atraso associado a cada transmissão no meio sem fio: considerando o atraso na rede com fio de 1 unidade de tempo simulada (1 UTs), usamos um atraso 50x maior no meio sem fio. Desta maneira, esta relação equivaleria a uma diferença, por exemplo, entre uma rede com uma taxa de transmissão em torno de 10 Mbps no meio com fio e de 200 kbps no meio sem fio.

\section{Mobilidade}

- Probabilidade de migração $\left(P_{\text {mig }}\right)$ : todos os $M h s$ tinham a mesma probabilidade de migração, ou seja, periodicamente determinava-se se cada $M h$ iria migrar ou não segundo esta probabilidade. Os experimentos foram realizados para $P_{m i g}=0.01$ (quase sem migração), 0.2 , 0.4 , e 0.6 (alta taxa de migração);

- Fator de Atração das células: optou-se pela adoção de atrações iguais para todas as células. Ou seja, cada vez que ocorria uma migração, todas as células tinham a mesma probabilidade de serem a célula-destino da migração. O objetivo não foi modelar uma rede específica, como por exemplo, uma cidade onde as células tipicamente têm diferentes fatores de atração (geralmente dependentes da hora do dia), mas sim testar o desempenho dos protocolos para uma mobilidade aleatória.

\section{Disponibilidade e Requisição}

- Probabilidade de desconexão/reconexão: todos os Mhs tinham a mesma probabilidade $P_{\text {desc }}=0.01$ de ficarem desconectados da rede fixa e a probabilidade $P_{\text {recon }}=0.3$ de se (re)conectarem à rede;

- Probabilidade de requisição de um multicast: cada $M h$ tinha a probabilidade $P_{r e q}=$ 0.1 de requisitar um multicast para seu Mss responsável. Esta probabilidade foi escolhida de 
modo a gerar razões chamada-mobilidade (Call-to-Mobility Ratio) suficientemente distintas, em combinação com os diferentes valores escolhidos para $P_{m i g}$;

- Destinatários dos multicasts: todos os multicasts tinham todos os Mhs como destinatários (pior caso), de forma que possam influenciar os protocolos (tempo de execução, número de mensagens transmitidas, entre outros).

\subsubsection{Dados Medidos}

Nesta seção descrevemos os dados que foram medidos nas simulações estocásticas do $A M^{2} C$ e do $i A M^{2} C$. Para cada combinação distinta de parâmetros de simulação foram realizadas dez rodadas de testes, e as médias dos valores medidos foram então calculadas. Em cada execução foram solicitadas vinte requisições de multicast pelos $M h s$ do sistema.

- Porcentagem de multicasts abortados por requisição: esse dado permite verificarmos o quão "pessimista" é cada um dos protocolos. É importante ressaltar que o valor de T1 na primeira fase dos protocolos tem influência direta sobre as chances de um multicast ser abortado, pois quanto menor for T1, maior a probabilidade de que alguns dos Mhs não respondam a uma mensagem a tempo, causando assim o cancelamento (abort) do multicast. Por este motivo, as simulações foram realizadas para valores de T1/T2 $=\{125,175\}$ UTs.

Os valores de T1/T2 foram selecionados de forma a serem somente um pouco maiores do que duas vezes o atraso na transmissão pelo meio sem fio (50 UTs), que corresponderia ao tempo mínimo necessário para o envio de um multicast e da resposta pelo $M h$ através da interface wireless. A escolha destes valores para T1/T2 foi devido à constatação de que valores muito menores ou maiores do que os escolhidos eram visivelmente menos sensíveis à probabilidade de migração dos $M h s$, isto é, abortavam ou confirmavam a maioria dos multicasts.

- Número de mensagens wireless por $M h$ em uma requisição de multicast: este dado permite compararmos a carga gerada pelo $A M^{2} C$ e pelo $i A M^{2} C$ na rede sem fio para diferentes taxas de migração.

- Sobrecarga na rede fixa: Estamos considerando como sobrecarga na rede com fio algumas das mensagens que são trocadas entre hosts fixos quando ocorre uma migração de um Mh. No $A M^{2} C$, a sobrecarga são todos os acknowledgments enviados de um Mss para o 


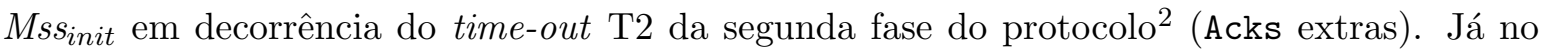
$i A M^{2} C$, além destas mensagens, consideramos também as atualizações de mapeamento (mensagens LocationUpdate) e os reenvios de mensagens pendentes por parte dos IMSs (mensagens ReFwdMsgFromIMS). A medição deste dado permite, além de constatar que o $i A M^{2} C$ possui uma sobrecarga maior que a do $A M^{2} C$, verificar a influência da sobrecarga no número total de mensagens trocadas na rede fixa pelos dois protocolos.

- Número de mensagens na rede fixa por requisição de multicast: um dos problemas do protocolo $A M^{2} C$ é a quantidade de mensagens difundidas na rede fixa e sua aparente ausência de escalabilidade com relação ao número de $M s s$ s no sistema. O iAM ${ }^{2} C$ por outro lado, apesar de introduzir os IMSs na tentativa de ser mais escalável com relação ao número de Msss, possui o overhead causado pelas mensagens do tipo LocationUpdate e ReFwdMsgFromIMS. Dessa forma, os dados medidos aqui permitem a comparação do custo total na rede fixa nos dois protocolos, para diferentes taxas de migração dos Mhs e diversos números de Msss na rede.

- Duração média de um multicast: a duração é definida como o período entre o momento da difusão de uma mensagem de multicast por parte de $M s s_{\text {init }}$ para todos os Msss do sistema (ou para os IMSs), e o instante da difusão da mensagem Delete correspondente, pelo mesmo Mssinit. O objetivo desta medição foi comparar o tempo simulado gasto por cada um dos protocolos, considerando diferentes valores de T1/T2 e das taxas de migração dos $M h s$. Assim, foi possível avaliar, mesmo tendo como base um tempo simulado, qual dos dois protocolos (e para quais parâmetros de simulação) foi mais eficiente.

\subsection{Análise dos Resultados}

Nesta seção faremos uma análise dos gráficos obtidos com os resultados das simulações, referentes aos dados mencionados na subseção anterior. O objetivo principal é comparar os protocolos $A M^{2} C$ e $i A M^{2} C$, porém mostraremos também resultados relevantes de um protocolo específico. Como já mencionado, os resultados aqui apresentados referem-se aos valores médios obtidos em cada uma das simulações realizadas.

\footnotetext{
${ }^{2}$ Uma Ack enviado por um Mss antes de T2 não foi considerado como sobrecarga, visto que faz parte do processamento normal do protocolo (vide seção 4.4).
} 


\subsubsection{Custo Wired Total}

Em primeiro lugar, é importante mencionar que estamos considerando como o custo wired total toda e qualquer mensagem trocada entre dois elementos na rede fixa. Ou seja, o custo wired total engloba, além das mensagens (da rede fixa) inerentes ao funcionamento de cada protocolo, as mensagens Dereg e DeregAck transmitidas durante o protocolo de hand-off, e as mensagens relativas à sobrecarga gerada na rede com fio em cada um dos protocolos (isto será abordado na subseção 5.5.3).

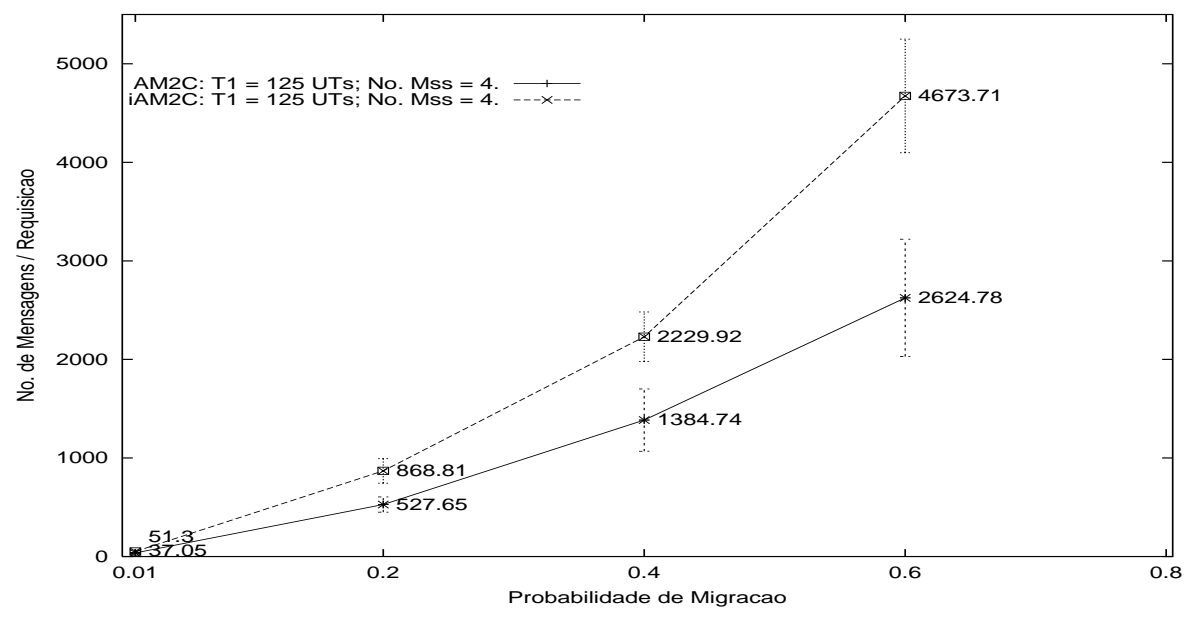

Figura 5.5: Comparação do custo wired total.

Na figura 5.5, analisando cada curva individualmente, é clara a influência da probabilidade de migração, $P_{m i g}$, no número de mensagens transmitidas na rede fixa em ambos os protocolos. Isso se deve principalmente ao número de hand-offs, que aumenta proporcionalmente à $P_{m i g}$ e, no caso do $i A M^{2} C$, também ao número de mensagens do tipo LocationUpdate (vide subseção 5.5.3) que cresce com o aumento da probabilidade de migração.

Outro ponto importante a ser observado é que o $i A M^{2} C$ apresenta um desempenho pior do que o $A M^{2} C$, onde o número de mensagens por requisição na rede com fio no primeiro protocolo é superior ao segundo em torno de 41 a $98 \%$. Isto mostra que para uma rede com quatro $M s s s\left(N_{m s s}=4\right)$, considerando-se os demais parâmetros, o acréscimo de mais um nível de indireção no iAM² C, além do custo das atualizações de mapeamento, representam um aumento no custo wired do protocolo maior do que a redução devido ao menor número de Msss envolvidos.

Considerando as duas curvas na figura $5.6\left(N_{m s s}=8\right)$, fica claro que a introdução dos IMSs no $i A M^{2} C$ (que consequentemente poupa alguns Msss de receberem mensagens desnecessárias) representa um ganho em desempenho deste protocolo em relação ao $A M^{2} C$, para este cenário. 


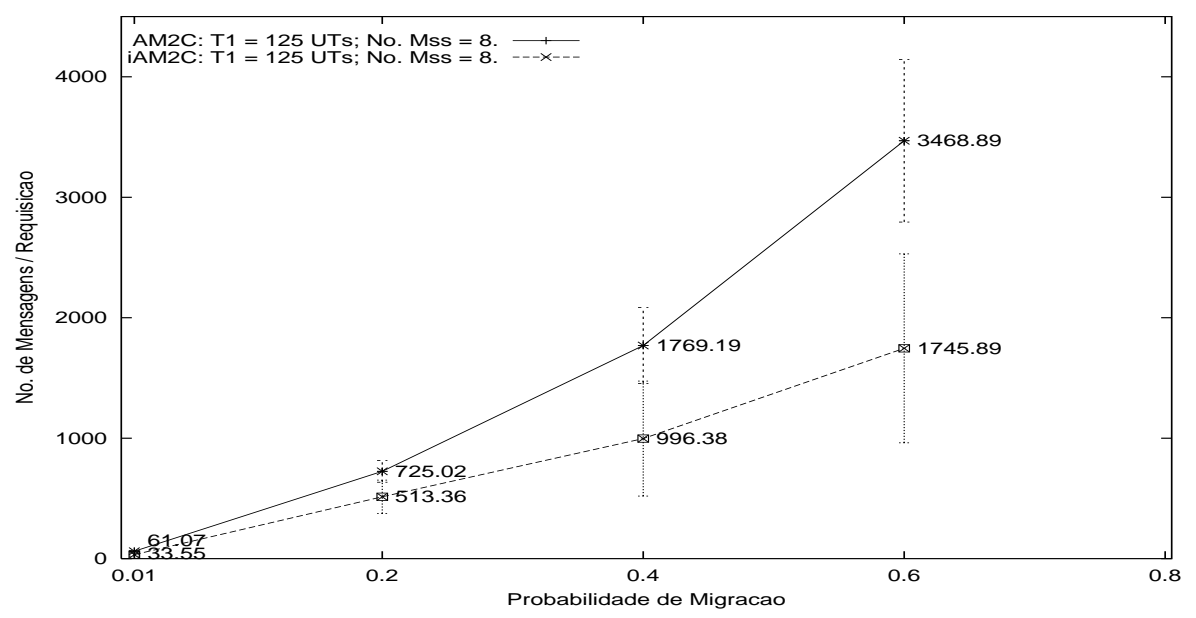

Figura 5.6: Comparação do custo wired total.

Um outro aspecto a ser considerado é que, analisando os valores obtidos em cada gráfico para cada um dos protocolos separadamente, e tomando-se um valor específico de $P_{m i g}$, percebemos que enquanto o número de mensagens por requisição de multicast cresce com o aumento de $N_{m s s}$ no $A M^{2} C$ (curvas contínuas), por outro lado diminui no $i A M^{2} C$ (curvas pontilhadas). Isso já é um indício do problema da falta de escalabilidade do $A M^{2} C$. No caso do $i A M^{2} C$, fica evidente que o protocolo possui um melhor desempenho quando $N_{m s s}=8$. Para que possamos analisar melhor a questão da escalabilidade com relação ao número de $M s s s$, a seguir apresentaremos dois gráficos que retratam melhor esta questão nos protocolos.

\subsubsection{Influência do Número de Msss no Custo Wired Total}

Em outra simulação, variamos o número de $M s s$ s e mantivemos $P_{m i g}$ constante, a fim de avaliar a influência específica do número de Msss no custo wired dos protocolos.

Na figura 5.7, percebemos que enquanto a curva sólida $\left(A M^{2} C\right)$ apresenta um custo proporcional ao aumento de $N_{m s s}$, a curva pontilhada $\left(i A M^{2} C\right)$ mostra que o custo wired é relativamente constante. Concluímos então que neste caso em que $P_{\text {mig }}$ é baixa $\left(P_{m i g}=0.01\right)$, uma vantagem considerável do $i A M^{2} C$ deve-se ao fato de boa parte dos $M s s$ s não precisarem receber o multicast, pois não têm nenhum $M h$ local pertencente ao grupo de destinatários da mensagem. $\mathrm{O} A M^{2} C$, por outro lado, não é beneficiado pelo valor de $P_{m i g}$, uma vez que todos os $M s s$ s recebem um multicast $M$ independente de possuírem ou não algum $M h \in M$.Dest.

A figura 5.8 mostra uma análise similar à da figura 5.7, só que para um valor maior de $P_{m i g}$. As curvas confirmam a forte influência do número de $M s s$ s no protocolo $A M^{2} C$, o que não acontece 


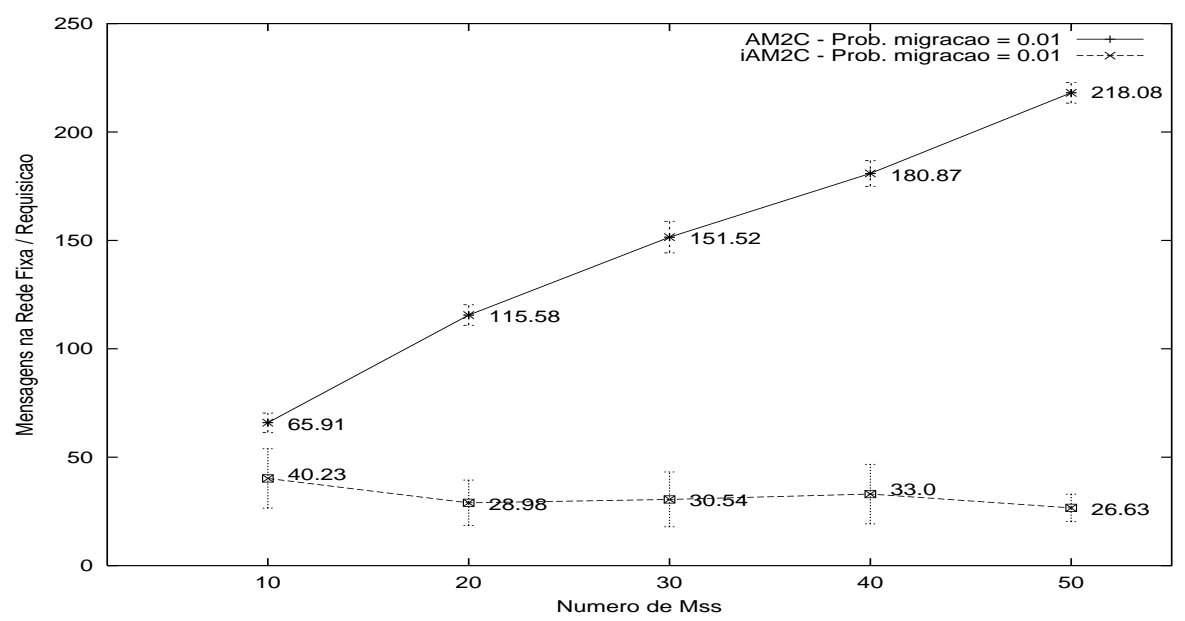

Figura 5.7: Influência do número de Msss no custo wired.

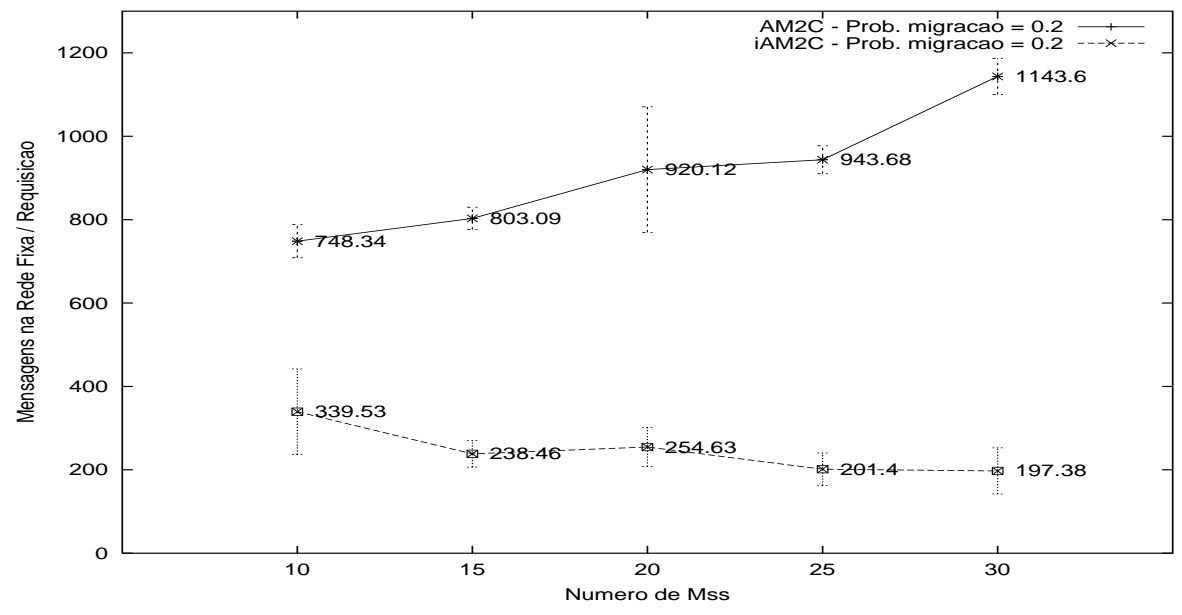

Figura 5.8: Influência do número de Msss no custo wired.

com o $i A M^{2} C$. Como já era esperado, a maior diferença em relação à figura anterior está no fato dos valores absolutos medidos serem maiores, uma vez que $P_{m i g}$ também é maior.

Dessa forma, as figuras 5.7 e 5.8 mostram claramente a escalabilidade do $i A M^{2} C$ com relação ao número de $M s s$ s no sistema. Por outro lado, fica evidente que o custo wired do $A M^{2} C$ é diretamente influenciado pelo valor de $N_{m s s}$.

\subsubsection{Distribuição da Sobrecarga no $i A M^{2} C$}

Como já mencionado na subseção 5.4.3, a sobrecarga na rede fixa do protocolo $i A M^{2} C$ engloba, além dos Acks extras (única sobrecarga do $A M^{2} C$ ), as mensagens de atualização de mapeamento (LocationUpdate) e de reenvio de mensagens pendentes (ReFwdMsgFromIMS), por parte dos IMSs. 
Dessa maneira, procuramos analisar nesta simulação como está dividida a sobrecarga do iAM ${ }^{2} C$, e qual a influência deste dado sobre o custo wired total do protocolo.

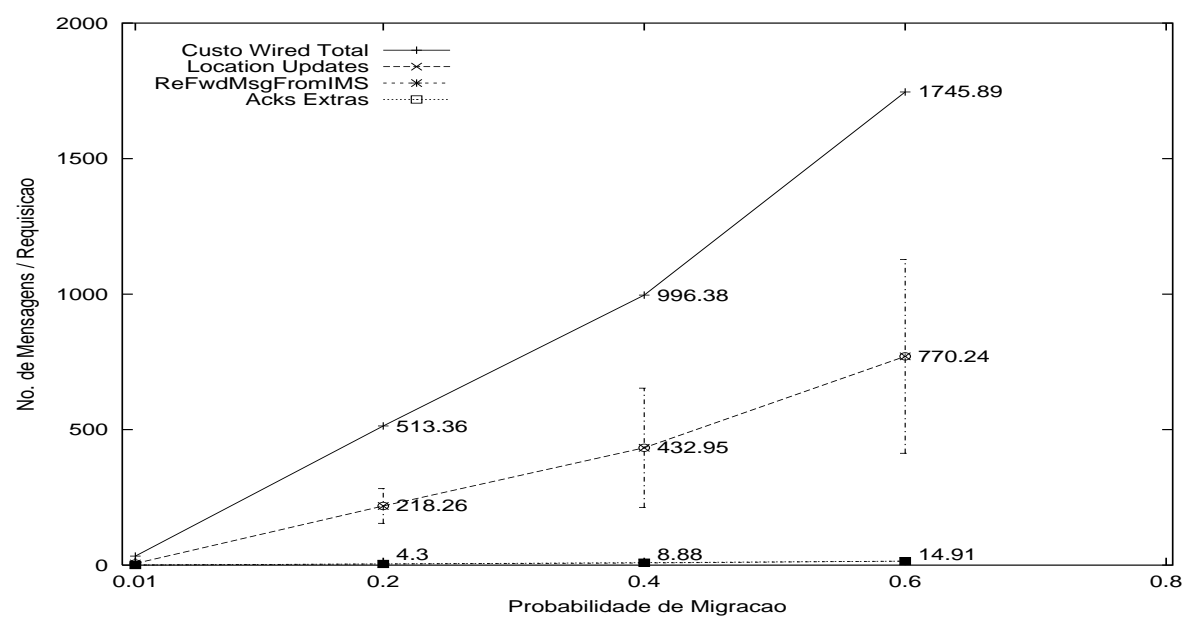

Figura 5.9: Distribuição da sobrecarga no $i A M^{2} C$.

Analisando a distribuição da sobrecarga na figura 5.9 percebe-se duas coisas: a primeira é que as grandes responsáveis pela sobrecarga no $i A M^{2} C$ são as mensagens do tipo LocationUpdate, que representam de 88 a $96 \%$ da sobrecarga total; a segunda é que no $i A M^{2} C$, a sobrecarga (podemos considerar: as mensagens LocationUpdate) na rede com fio é responsável por cerca de $43 \%$ (exceto para $P_{m i g}=0.01$, onde este percentual é de $17 \%$ ) do número total de mensagens enviadas por esse meio de transmissão. É importante mencionar que o $i A M^{2} C$ otimiza as retransmissões de mensagens pendentes (e estados finais) por parte dos IMSs, empacotando todas estas mensagens e fazendo um único envio para o Mss solicitante.

A figura 5.9 também mostra a influência da probabilidade de migração dos $M h s$ em cada um dos tipos de mensagens que compõem a sobrecarga na rede fixa. Quanto maior o valor de $P_{m i g}$, nitidamente maior é o número de mensagens LocationUpdate, o que implica também no aumento do número de retransmissões dos IMSs. Com relação ao número de Acks extras, quanto maior for a probabilidade de migrações dos Mhs, maiores as chances de que em algumas (ou em várias) dessas migrações o time-out T2 já tenha ocorrido no Mss responsável pela célula para a qual o Mh migrou, fazendo com que uma nova mensagem AckMss seja enviada para o Mss inicializador do multicast.

Vale ressaltar ainda que no caso do protocolo $A M^{2} C$ a sobrecarga na rede fixa (que, como dito anteriormente, consiste apenas do número de Acks adicionais) é da mesma ordem de grandeza das mensagens AckMss extras medidas nas simulações do $i A M^{2} C$. Em outras palavras, ao contrário do que ocorre com o $i A M^{2} C$, no $A M^{2} C$ a sobrecarga pouco influencia o custo wired total na rede com 
fio.

\subsubsection{Custo Wireless}

Nos protocolos $A M^{2} C$ e iAM ${ }^{2} C$ há um custo fixo, por requisição de multicast, de quatro transmissões na rede sem fio, para cada $M h$ destinatário. Este custo envolve a transmissão, por parte de um $M s s$, de uma mensagem multicast e recebimento da resposta de um $M h$ (Fase I), e o envio do estado final do multicast e recebimento do acknowledgment (Fase II). Todavia, em ambos os protocolos os estados finais são retransmitidos quando um $M h$ migra para uma nova célula, além de que no $i A M^{2} C$ existe a possibilidade de retransmissão wireless na Fase I (este caso poderá ser percebido na seção 6.2). Desta forma, estamos interessados em medir o impacto gerado pela probabilidade de migração dos Mhs no custo wireless total, em cada protocolo.

Notemos que os valores dos time-outs T1/T2 exercem influência sobre a quantidade de mensagens transmitidas na rede sem fio. Por exemplo, para um valor de T2 muito baixo, talvez o tempo para um $M h$ confirmar o recebimento do estado final de um multicast seja insuficiente. Como os estados finais são retransmitidos após uma migração, o valor escolhido para T2 causaria um maior número de mensagens wireless transmitidas. Entretanto, a influência deste parâmetro não foi percebida nas simulações devido à escolha de valores próximos para os time-outs.

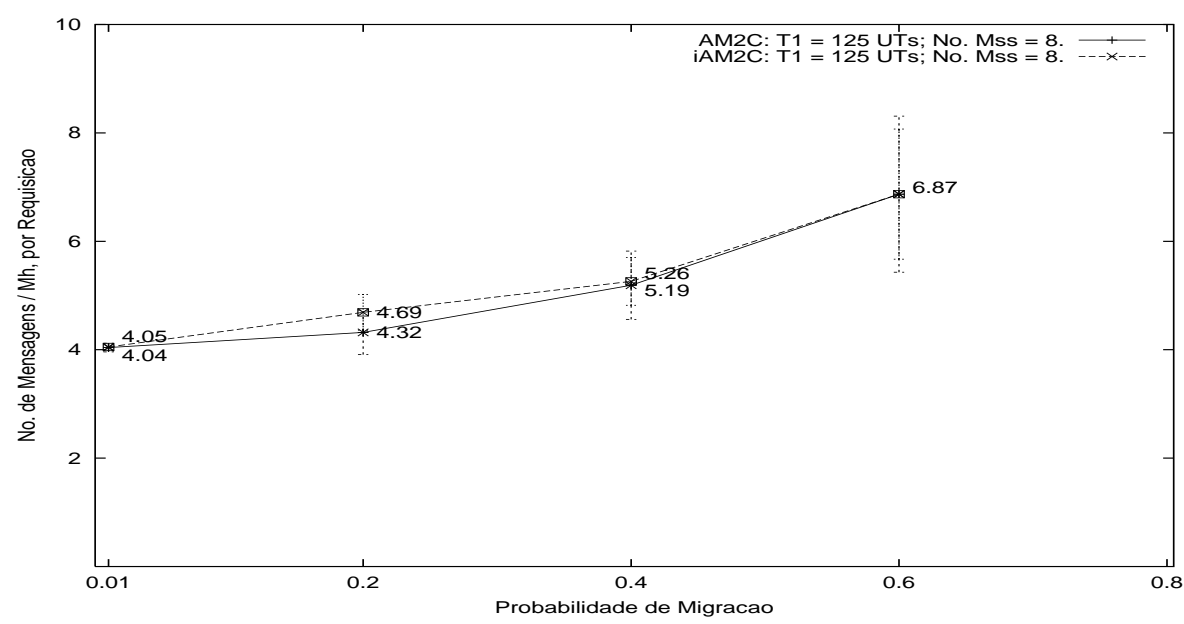

Figura 5.10: Comparação do custo wireless nos protocolos.

Analisando as duas curvas, percebemos que tanto o $A M^{2} C$ como o $i A M^{2} C$ possuem um custo wireless baixo (75\% dos valores obtidos apresentam um custo excedente ${ }^{3}$, por requisição, não superior a 1.26), e muito próximos para um mesmo valor de $P_{\text {mig }}$. Esta proximidade se deve ao fato

\footnotetext{
${ }^{3}$ Custo superior às quatro mensagens, por $M h$, para envio e resposta de um multicast e do seu estado final.
} 
da semelhança comportamental entre os dois protocolos (de uma forma geral), onde a diferença principal está na maneira como as mensagens chegam aos seus destinatários (através da rede fixa).

Deve-se mencionar ainda que adotamos a política incondicional de retransmissão de mensagens, como descrito na seção 4.6. Caso optássemos pela política condicional, muito provavelmente o $i A M^{2} C$ apresentaria um custo wireless ainda menor, visto que esta política causaria menos retransmissões (com a provável conseqüência de uma porcentagem maior de multicasts abortados).

\subsubsection{Porcentagem de Multicasts Abortados}

Os gráficos a seguir comparam os protocolos $A M^{2} C$ e $i A M^{2} C$ com relação à porcentagem média de multicasts abortados. Analisaremos os gráficos de três formas: evidenciando a influência da probabilidade de migração $\left(P_{m i g}\right)$ dos $M h s$ sobre o dado medido; mostrando a influência do timeout T1 (primeira fase de ambos os protocolos); e analisando a porcentagem de multicasts abortados nos dois protocolos em cada gráfico.

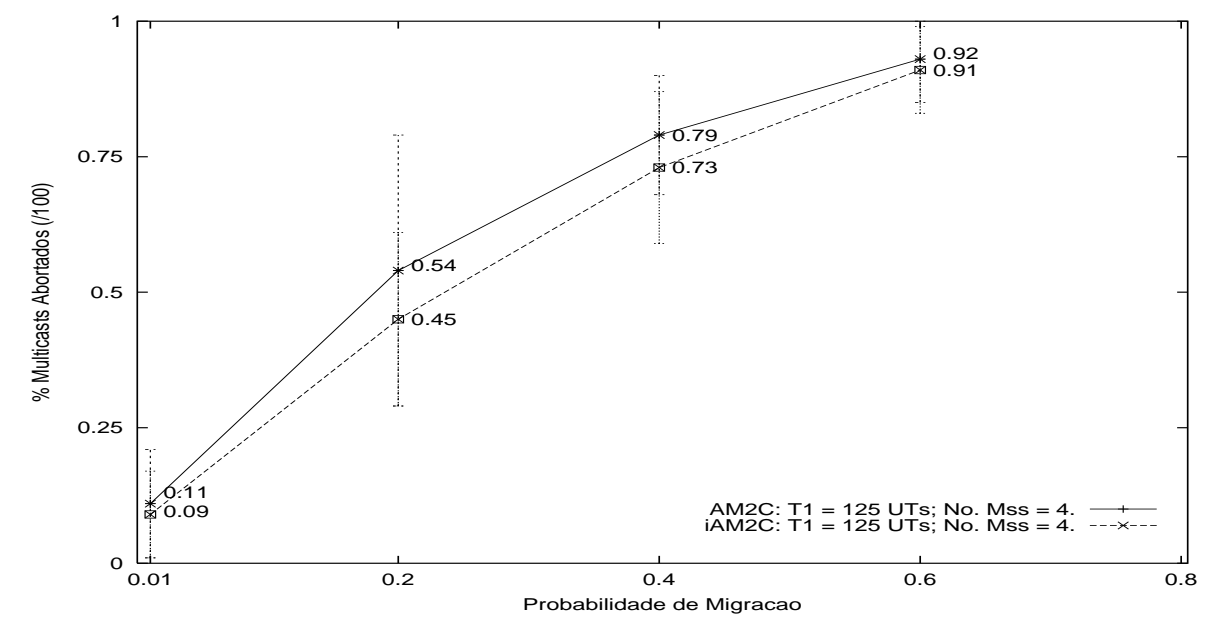

Figura 5.11: Comparação da porcentagem de multicasts abortados.

As figuras 5.11 e 5.12 (para T1 = 125 e 175 UTs, respectivamente) deixam claro a influência de $P_{m i g}$ na porcentagem de multicasts abortados (\%Abort) em ambos os protocolos. Vale ressaltar o aumento brusco de \%Abort (de até cinco vezes na figura 5.11, e até sete vezes na figura 5.12) quando $P_{\text {mig }}$ passa de 0.01 para 0.2 . Isso reflete a visão pessimista dos protocolos, onde o $M s s$ da antiga célula opta por abortar um multicast diante da incerteza sobre a transmissão do multicast por parte do novo $M s s$ para o $M h$ que está migrando (conforme seção 3.5 para o $A M^{2} C$ e seção 4.6 para o $\left.i A M^{2} C\right)$.

Se analisarmos as curvas de cada protocolo separadamente nos dois gráficos, podemos perceber 


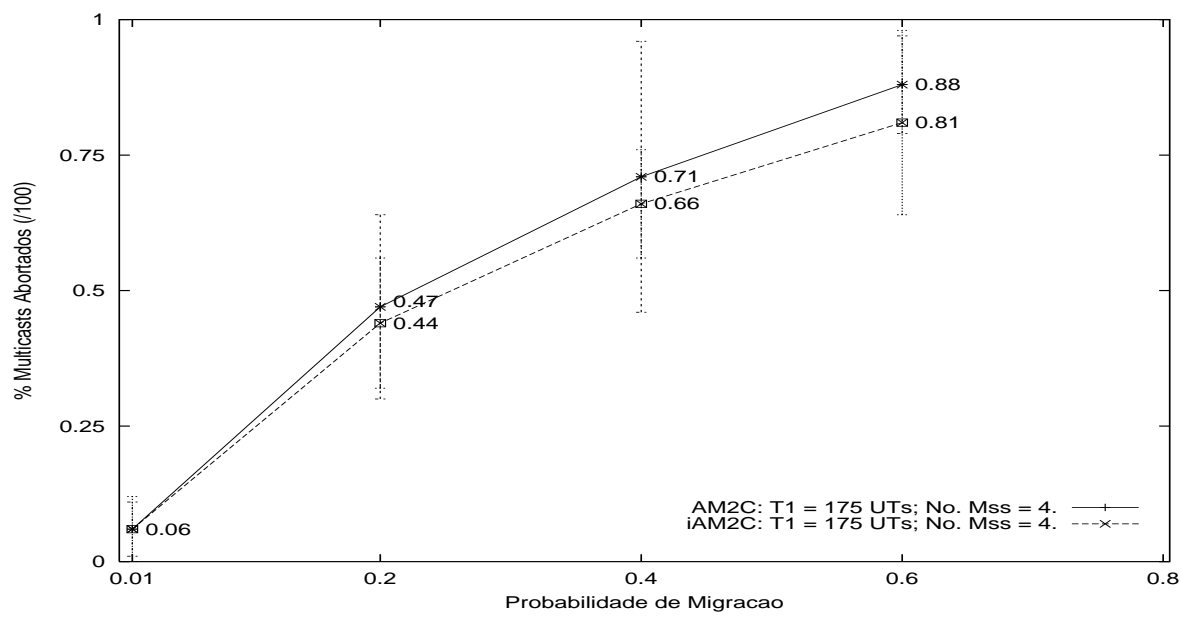

Figura 5.12: Comparação da porcentagem de multicasts abortados.

que a curva do respectivo protocolo na figura 5.11 (onde T1 = 125 UTs) possui valores mais elevados que a mesma curva (e valor de $P_{m i g}$ ) na figura 5.12 (T1 = $175 \mathrm{UTs}$ ). Ou seja, quando o tempo de espera por respostas dos Mhs destinatários nos Msss é menor, maior é o valor de \%Abort. Isto acontece porque quanto menor o time-out T1, maiores são as chances de que neste tempo nem todos os Mhs locais e destinatários tenham respondido a uma determinada mensagem, fazendo com que o multicast seja abortado.

Comparando o $A M^{2} C$ e o $i A M^{2} C$ em ambos os gráficos, podemos observar a proximidade dos valores obtidos para cada valor de $P_{m i g}$ (a diferença máxima é de apenas 0.07 ponto percentual), bem como o aumento proporcional de \%Abort com o incremento da probabilidade de migração dos Mhs. A explicação para isso está na similaridade comportamental dos protocolos no que se refere às situações que geram um cancelamento (abort) de um multicast, que são: (a) quando nem todos os Mhs locais e destinatários de uma mensagem respondem dentro do tempo T1; (b) quando um $M h$ migra sem responder a uma mensagem que lhe foi enviada; e (c), quando um novo $M h$ se registra na célula de um Mss sem ter recebido ainda uma determinada mensagem, mas o time-out desta já foi processado pelo Mss.

Como o envio do NOk pelo $M s s$ no $A M^{2} C$, bem como o envio do OkSet (com o NOk relativo ao $M h$ correspondente) no $i A M^{2} C$, ocorrem nas mesma condições, apesar das curvas do $i A M^{2} C$ estarem um pouco abaixo das curvas do $A M^{2} C$, a diferença entre a média dos valores medidos nos dois protocolos não foi significativa. O fato é que ambos os protocolos implementam uma visão pessimista, que pode acarretar em uma alta porcentagem de multicasts abortados, especialmente em redes onde a taxa de migração dos Mhs é alta. 


\subsubsection{Duração Média de um Multicast}

Seguindo a mesma abordagem da subseção anterior, primeiramente analisaremos a influência de $P_{m i g}$ na duração média de um multicast nos dois protocolos. Em seguida discutiremos a influência dos time-outs (T1/T2) neste dado medido, concluindo com a comparação dos protocolos.

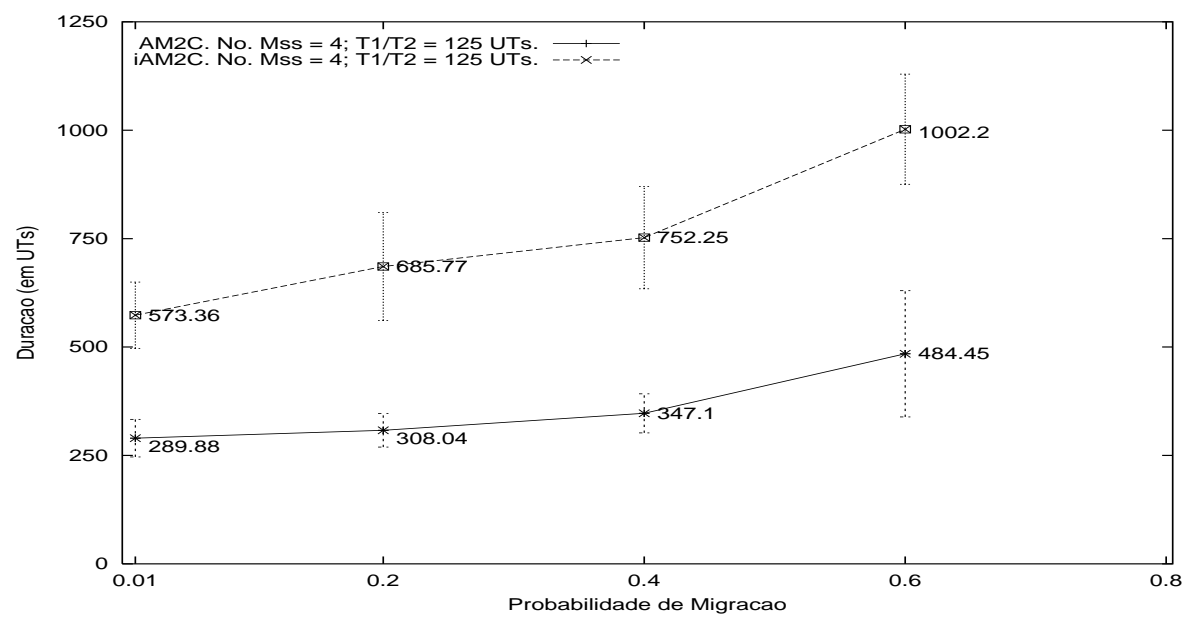

Figura 5.13: Comparação da duração média de um multicast.

De forma geral, nota-se que a duração média de um multicast nas figuras 5.13 e 5.14 (com os time-outs $\mathrm{T} 1 / \mathrm{T} 2=125$ e $175 \mathrm{UTs}$, respectivamente) aumenta conforme a probabilidade de migração dos Mhs. Isso é causado principalmente pela Fase II dos protocolos, onde o estado final de um multicast é sempre retransmitido quando um $M h$ migra, fazendo com que o tempo de espera seja prolongado por mais T2 unidades de tempo. Na Fase I, a prorrogação da espera por respostas dos Mhs (um novo período de time-out T1) pode acontecer, mas este caso é bem mais raro do que na Fase II, devido à visão pessimista do $M s s_{o}$, que quase sempre opta por abortar o multicast.

Como já era esperado, percebemos também que a duração média de um multicast é proporcional ao valor dos time-outs (basta comparar as curvas individualmente para cada protocolo nos dois gráficos).

Comparando o $A M^{2} C$ e o $i A M^{2} C$, temos três pontos importantes a serem destacados. O primeiro é o comportamento parecido das duas curvas em ambos os gráficos. Isto nos mostra que a essência dos dois protocolos é a mesma, havendo algum detalhe que torna o tempo de execução médio (em unidades de tempo simuladas) do $i A M^{2} C$ maior. E este detalhe, que se refere à distância entre as curvas nos gráficos (segundo ponto), está ligado à inclusão dos IMSs como elementos intermediários entre os $M s s s$ no $i A M^{2} C$, acrescentando assim mais um nível de indireção no fluxo das mensagens. Além disto, o $i A M^{2} C$ gasta um tempo adicional, quando comparado com o $A M^{2} C$, com os envios 


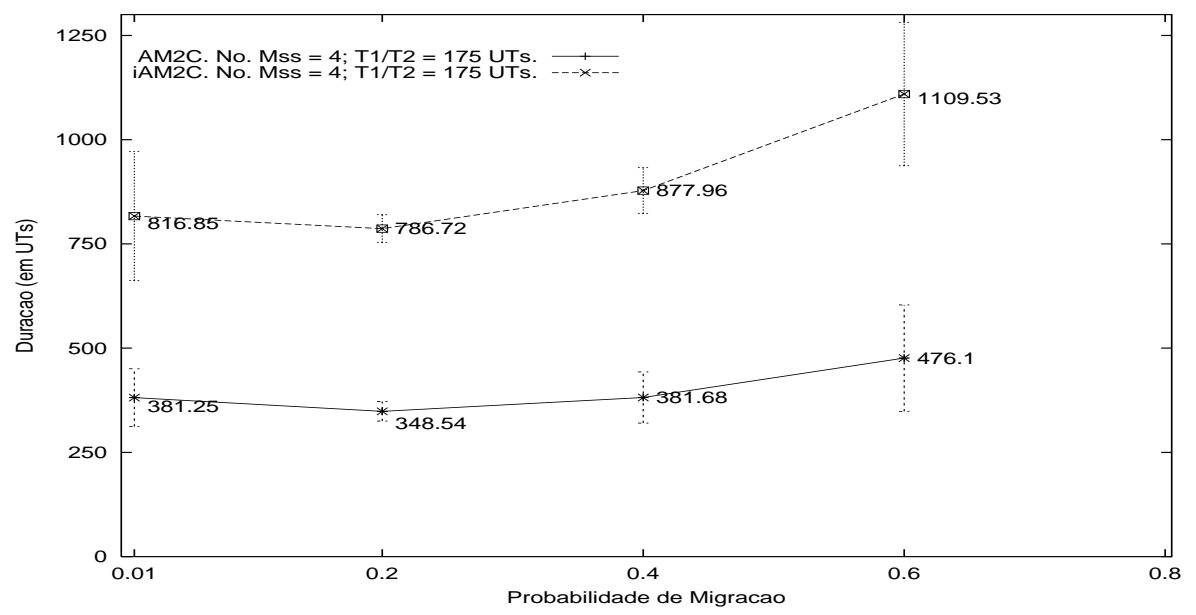

Figura 5.14: Comparação da duração média de um multicast.

das mensagens LocationUpdate e ReFwdMsgFromIMS que, como vimos anteriormente, representam o principal overhead do protocolo.

O terceiro e último ponto está no fato de que, se calcularmos a diferença entre o maior e o menor valor da duração média de um multicast em cada um dos protocolos (considerando os dois gráficos), percebemos que esta diferença é de aproximadamente 187 UTs para o $A M^{2} C$ e de 536 UTs para o $i A M^{2} C$. Assim, concluímos que a variação dos parâmetros de configuração (tais como $P_{\text {mig }}$ e T1/T2) influencia bem menos o $A M^{2} C$ do que o $i A M^{2} C$, que nitidamente é mais demorado que o primeiro.

\subsubsection{Avaliação Geral}

As simulações dos dois protocolos mostraram que o $i A M^{2} C$ apresenta uma sobrecarga na rede fixa bem maior que a do $A M^{2} C$, e que o grande responsável por isto são as mensagens LocationUpdate. Todavia, observamos que, exceto para redes onde o número de $M s s s\left(N_{m s s}\right)$ é pequeno, a redução do número de mensagens transmitidas na rede fixa (custo wired) com a introdução dos IMSs compensa o custo da sobrecarga no $i A M^{2} C$. Assim, o desempenho deste protocolo em termos do custo total na rede com fio quando $N_{m s s}$ é grande, é consideravelmente melhor do que o desempenho do $A M^{2} C$. Além disto, foi constatado que para uma mesma probabilidade de migração dos $M h s$, o custo wired do $A M^{2} C$ é diretamente proporcional ao número de $M s s s$ no sistema. Já no $i A M^{2} C$ este custo permanece "constante", mesmo quando o número de Msss é grande.

Os resultados dos testes também mostraram que ambos os protocolos apresentam um baixo custo na rede sem fio (custo wireless) e uma alta porcentagem de multicasts abortados em redes onde a 
taxa de migração dos $M h s$ é acentuada. Este último dado confirma a abordagem conservadora dos protocolos para multicasts confiáveis, uma vez que requer a disponibilidade de todos os destinatários de um multicast para que o mesmo seja confirmado (commited). No entanto, ao contrário de outros 2PC, o $i A M^{2} C$ não sofre do problema de bloqueio indefinido, devido a dois fatores:

a) A suposição de que os hosts da rede fixa são altamente confiáveis, fazendo com que o estado do 2PC esteja sempre disponível e possa sempre ser retransmitido para os Mhs destinatários, independente de sua localização (esta suposição também é valida para o $A M^{2} C$ );

b) A decisão unilateral de abortar um multicast quando o tempo de validade do mesmo estiver esgotado, e da exclusão forçada dos Mhs inacessíveis.

\begin{tabular}{|l|c|c|}
\hline & $\mathbf{A M}^{2} \mathbf{C}$ & iAM $^{2} \mathbf{C}$ \\
\hline Escalabilidade em Relação a $N_{m s s}$ & não & sim \\
\hline Sobrecarga na Rede Fixa & baixa & alta \\
\hline Custo Wired Total & $\begin{array}{c}\text { menor quando } N_{m s s} \\
\text { é pequeno }\end{array}$ & $\begin{array}{c}\text { menor quando } N_{m s s} \\
\text { é grande }\end{array}$ \\
\hline Custo na Rede sem Fio & baixo & baixo \\
\hline$\%$ Multicast Abortados & alta para taxas de & alta para taxas de \\
migração acentuadas & migração acentuadas \\
\hline Tempo de Execução Médio & baixo & alto \\
\hline Passível de Bloqueio Indefinido & sim & não \\
\hline
\end{tabular}

Tabela 5.1: Resumo comparativo dos protocolos $A M^{2} C$ e $i A M^{2} C$.

Também pudemos concluir através das simulações que uma vantagem do protocolo $A M^{2} \mathrm{C}$ em relação ao $i A M^{2} C$ é o tempo de execução médio de um multicast (em unidades de tempo simuladas, UTs). As atualizações de mapeamento e retransmissões de mensagens pendentes, bem como o acréscimo de mais um nível de indireção no $i A M^{2} C$ aumentam o tempo de execução do protocolo, que em média é aproximadamente 400 UTs a mais que o tempo gasto pelo $A M^{2} C$.

A tabela 5.1 apresenta um resumo da comparação entre os protocolos $A M^{2} C$ e $i A M^{2} C$ em termos dos dados e parâmetros avaliados nas simulações.

Como podemos observar, nenhum dos protocolos é melhor que o outro em todos os aspectos. O que de fato ocorre é que o $A M^{2} C$ se enquadra melhor em redes onde o número de $M s s s$ é pequeno, 
visto que sua sobrecarga na rede com fio é baixa e o seu tempo de execução é melhor que o do $i A M^{2} C$. Este, por outro lado, é mais adequado para redes com um grande número de $M s s s$, onde a quantidade de mensagens difundidas na rede fixa é bem menor se comparada com o $A M^{2} C$. Esta redução é ressaltada especialmente quando a probabilidade de migração dos $M h s$ é baixa, pois, nestes casos, o $i A M^{2} C$ se beneficia do uso dos IMSs como filtros dos Msss que devem receber uma mensagem de multicast.

Em redes onde a taxa de migração dos $M h s$ é alta, o $i A M^{2} C$ só é adequado quando o número de Msss é significativamente grande. Assim, o custo da sobrecarga gerado pelas atualizações de mapeamento é compensado pela redução das mensagens difundidas na rede fixa. 


\section{Capítulo 6}

\section{Experiência Adquirida e Dificuldades Encontradas}

Neste capítulo primeiramente descreveremos a experiência adquirida na implementação dos protocolos $A M^{2} C$ e $i A M^{2} C$ utilizando o simulador MobiCS [5]. Em seguida, apresentaremos as principais dificuldades encontradas durante os processos de implementação e validação dos protocolos, que em alguns casos levaram à tomadas de decisões de projeto.

\subsection{Implementação Utilizando o MobiCS}

Depois de implementar e simular os protocolos $A M^{2} C$ e $i A M^{2} C$ usando o simulador MobiCS, algumas conclusões puderam ser extraídas:

- O MobiCS é uma ferramenta simples e de fácil uso, onde a possibilidade de se ter abstrações de alto nível permite que protocolos sejam prototipados rapidamente;

- A simulação determinística é essencial para a detecção de erros. Apesar deste modo de simulação não garantir a corretude do protocolo, a elaboração de scripts de simulação simples mas com um objetivo bem definido, permite que o protocolo seja testado em situações bem específicas e controladas, escolhidas pelo programador. Dessa forma, esta etapa de testes é fundamental para descobrir se há erros no protocolo e para pensar nas mudanças necessárias para que o protocolo execute conforme o esperado. Note que se o projetista/programador do protocolo for capaz de identificar as principais situações "críticas" em que o mesmo precisa ser 
testado, existem boas chances de que após a conclusão dos testes determinísticos o protocolo esteja de fato funcionando corretamente;

- Para uma simulação estocástica, basicamente são necessárias três coisas: a configuração da rede, o modelo de simulação dos elementos de rede (neste trabalho, apenas dos $M h s$ ) e o protocolo em si. Assim, a depender da complexidade do protocolo e do que se deseja analisar (em termos de desempenho), bastante atenção deve ser dada à definição e implementação destas partes. Erros de lógica ou parâmetros não inicializados de forma correta podem provocar erros na simulação do protocolo, que podem demandar um tempo considerável para detecção do problema;

É importante observar que o alto nível de abstração permitido pelo MobiCS faz com que vários aspectos relativos à implementação de um protocolo em um ambiente real sejam desconsiderados, permitindo que o projetista se concentre nos aspectos algorítmicos relevantes de seu protocolo. Devido a esta característica e à possibilidade de submeter o protocolo tanto à simulações controladas (determinísticas), como à simulações estocásticas, o MobiCS é uma ferramenta bastante útil e eficaz para a validação e avaliação do desempenho de protocolos para redes móveis.

\subsection{Principais Dificuldades}

Uma das dificuldades encontradas foi a programação do gerenciamento dos time-outs, dado que em MobiCS o controle da execução/prorrogação ou não dos mesmos é de total responsabilidade do programador. Além disto, na época do início da programação dos protocolos, o processamento de time-outs acabara de ser incorporado à biblioteca do MobiCS, de forma que não haviam outros usuários do simulador com um conhecimento sobre o uso deste recurso, e com os quais fosse possível a troca de experiências.

Além do controle da execução dos time-outs, durante a etapa de programação dos protocolos percebemos a necessidade de gerenciar a ocorrência ou não de determinadas situações. Por exemplo, ações diferentes deveriam ser tomadas caso um time-out T1 (ou T2) já tivesse ocorrido; se a mensagem Delete já tivesse ou não sido enviada; caso o estado final de um multicast já tivesse sido definido, entre outras. Dessa maneira, decidimos criar uma estrutura de dados que armazenasse informações para o controle da ocorrência de situações como as exemplificadas anteriormente, considerando cada um dos multicasts em processamento. Denominamos esta estrutura objMsgManager (vide apêndices $\mathrm{C}$ e $\mathrm{D}$ ). 
Assim, para cada multicast difundido na rede seria criado no Mss um objMsgManager. Com esta estrutura (que contém apenas atributos booleanos), o Mss é capaz de gerenciar as ações que devem ser tomadas na chegada de determinadas mensagens do protocolo (por exemplo, na chegada da mensagem RespFromMh ou AckMh). Ainda, com o objMsgManager foi possível determinar se no momento da geração de um evento de time-out pelo MobiCS, este deveria ou não ser processado ou prorrogado pelo protocolo.

Em termos de simulação, inicialmente encontramos dificuldades em identificar a causa de algumas saídas da simulação estocástica aparentemente não estarem de acordo com o esperado. O código referente ao tratamento dado às mensagens recebidas pelos elementos de rede foi depurado e verificou-se que o mesmo estava coerente com a especificação. Então, percebemos que o problema era decorrente de erros de lógica no modelo de simulação dos $M h s$, onde várias características do comportamento destes elementos são definidas. Um erro encontrado foi a migração forçada dos Mhs, independente da taxa de migração especificada.

Muitas das dificuldades encontradas durante a implementação e simulação do $A M^{2} C$ não foram encontradas durante estas fases no $i A M^{2} C$. Isto aconteceu devido à similaridade dos dois protocolos e à experiência adquirida com a implementação do $A M^{2} C$. Todavia, um aspecto da implementação do $i A M^{2} C$ causou certa dificuldade. Através das simulações determinísticas detectamos que a estrutura $h \_R E C D$, que até então era idêntica a do $A M^{2} C$, não era adequada ao $i A M^{2} C$, fazendo com que o protocolo não executasse corretamente certos cenários de testes neste modo de simulação.

A necessidade de uma estrutura de dados diferente para o $h \_R E C D$ foi detectada a partir de dois tipos de situações: (a) quando não era possível determinar a ordem de entrega de mensagens provenientes de um mesmo Mss inicializador; e (b), quando uma mesma mensagem era entregue mais de uma vez para um mesmo $M h$ destinatário. Para ilustrar a necessidade de uma estrutura $h \_R E C D$ diferente no protocolo $i A M^{2} C$, apresentamos a seguir dois exemplos que ilustram as situações mencionadas anteriormente. Para isso, vamos supor que $h \_R E C D$ é um vetor de inteiros, como em $A M^{2} C$, que qualquer posição $h \_R E C D[\mathrm{i}]$ contém inicialmente o valor "0", e que um $M h$ é destinatário de qualquer mensagem de multicast difundida na rede.

Situação (a): Imaginemos que o $M h$ migre antes que seu $M s s_{M h}$ tenha recebido uma mensagem de multicast $M_{1}$ (cujo número de seqüência seja "1" e que tenha sido difundida por $M s s_{i}$ ). Ao se registrar na nova célula (sob a responsabilidade de $M s s_{n}$ ), a mensagem LocationUpdate é enviada para o $I M S$ correspondente solicitando também a retransmissão da mensagem $M_{1}$. Suponhamos que após o envio de LocationUpdate $M s s_{n}$ receba uma mensagem $M_{2}$, proveniente do mesmo 
Mss inicializador. Suponhamos que $M_{2}$ é enviada logo em seguida para o $M h$, o qual responde ao $M s s_{n}$. Neste momento, $h \_R E C D[\mathrm{i}]$ passaria a ter o valor "1", correspondente ao incremento após o recebimento da resposta do $M h$. Desta forma, quando a mensagem $M_{1}$ chegasse em $M s s_{n}$ (retransmissão do $I M S$ ), esta não seria repassada para o $M h$, uma vez que $h \_R E C D[\mathrm{i}]=1$, indicando que a mensagem já havia sido recebida.

Situação (b): Imaginemos a mesma situação descrita anteriormente até o envio da mensagem LocationUpdate para o IMS correspondente. Suponhamos, no entanto, que neste caso a mesma mensagem $M_{1}$ chegue em $M s s_{n}$ (via difusão) após o envio de LocationUpdate (ou seja, existe em $M s s_{n}$ algum outro $M h \in M_{1}$.Dest). Desta maneira, como o $M h$ que migrou já faz parte do grupo LocalMhs e também pertence a $M_{1}$. Dest, então a mensagem é enviada para o $M h$, provocando o incremento de $h \_R E C D[\mathrm{i}]$ no momento da sua resposta. Suponhamos que quando o $M s s_{n}$ recebe a retransmissão de $M_{1}$ do $I M S$, o time-out para $M_{1}$ não ocoreu, e que a resposta do $M h$ ainda não chegou em $M_{s s}$. Assim, a mesma mensagem seria enviada novamente para o $M h$. Notemos que, neste caso, duas respostas (do mesmo $M h$ ) seriam processadas por $M s s_{n}$, o que implica no incremento duplo de $h \_R E C D[\mathrm{i}]$, que passaria a ter o valor "2". Desta forma, na chegada da próxima mensagem $\left(M_{2}\right)$ difundida por $M s s_{i}$, o $M h$ não receberia tal mensagem, pois também nesta situação seu $h \_R E C D$ estaria indicando que a mensagem $M_{2}$ já teria sido recebida.

Além dos casos apresentados anteriormente, certamente outras situações poderiam ocorrer em que a estrutura $h \_R E C D$ no protocolo $i A M^{2} C$ como a do $A M^{2} C$ não fosse adequada, gerando erros na execução do protocolo. Desta maneira, a adoção de uma estrutura de dados mais apropriada para o $i A M^{2} C$ (vide seção 4.6.1) tornou-se essencial. 


\section{Capítulo 7}

\section{Conclusões}

Nesta dissertação foram desenvolvidos e comparados dois protocolos de multicast atômico, o $A M^{2} C$ [13] e o iAM ${ }^{2} C$ [10]. Estes protocolos são do tipo Two-Phase Commit (2PC) [14] com uma etapa adicional de coleta de lixo. O primeiro é uma extensão do protocolo MCAST [1], enquanto que o segundo é uma variante do primeiro que utiliza um gerenciamento hierárquico de localização de unidades móveis (Mhs) [25] para difundir mensagens na rede fixa. Os protocolos podem servir de suporte à ações coordenadas entre grupos de dispositivos móveis, que precisem manter uma visão consistente dos dados.

No início deste trabalho o protocolo $A M^{2} C$ já havia sido especificado e sua corretude comprovada analiticamente. Todavia, percebeu-se a necessidade de avaliar seu desempenho para diferentes taxas de mobilidade e outros parâmetros de configuração de rede. Ao mesmo tempo, chegou-se à conclusão de que o $A M^{2} C$ sofria do problema de falta de escalabilidade em relação ao número de estações de suporte à mobilidade $(M s s)$, o que serviu de motivação para o desenvolvimento de um protocolo similar que fosse escalável.

Diante destes objetivos, este trabalho foi iniciado com a implementação e avaliação do protocolo $A M^{2} C$ e o projeto do $i A M^{2} C$ em paralelo, concluindo com a implementação e avaliação deste último e a comparação dos dois protocolos. O $A M^{2} C$ e o $i A M^{2} C$ foram avaliados e validados através de simulações, usando o ambiente de prototipação e simulação MobiCS [5].

No protocolo $A M^{2} C$ uma mensagem de multicast é difundida na rede para todos os $M s s$ do sistema, independente se há ou não algum host móvel local ao Mss que seja destinatário da mensagem. Dessa forma, em redes onde o número de Msss é grande o número de mensagens na rede fixa é expressivo, o que pode comprometer o desempenho do sistema. O $A M^{2} C$ ainda apresenta 
um desperdício de memória, visto que todos os Msss armazenam cada mensagem de multicast, em alguns casos desnecessariamente.

Para solucionar a falta de escalabilidade do $A M^{2} C$ em relação ao número de $M s s s$, o protocolo iAM ${ }^{2} C$ conta com um tipo especial de servidor denominado Intermediate Multicast Server, ou IMS, que tem como função armazenar e retransmitir mensagens multicast para as estações de suporte à mobilidade da rede móvel. Neste protocolo uma mensagem só é enviada pelo IMS caso o Mss possua algum $M h$ destinatário da mensagem. Os IMSs são elementos mais simples do que os Msss, pois não tratam dos hand-offs e, consequentemente, não precisam interagir entre si, como os Msss. $\mathrm{O} i A M^{2} C$ parte do pressuposto de que o conjunto de $I M S s$ é muito menor do que o conjunto dos Msss, tornando o multicast escalável para redes com muitos Msss.

Todavia, a propriedade de atomicidade garantida pelos dois protocolos faz com que tanto o $A M^{2} C$ como o $i A M^{2} C$ não sejam escaláveis em relação ao número de $M h s$ no sistema. Em redes com muitos clientes móveis, torna-se "caro" chegar a um consenso, uma vez que são necessárias muitas mensagens na rede fixa para se chegar a uma decisão sobre o processamento conjunto de uma ação.

Também foi visto que no $i A M^{2} C$ a gerência de localização de unidades móveis (desempenhada pelos IMSs) representa um custo adicional para o protocolo. Desta forma, a depeder da taxa de migração dos Mhs e do número de $M s s s$, a redução no número de mensagens difundidas na rede fixa não compensa o custo das atualizações de mapeamento.

As simulações mostraram que nenhum dos protocolos é mais eficiente do que o outro em todas as situações, e que os cenários é que determinam qual dos protocolos é mais ou menos adequado. De forma geral, o $A M^{2} C$ se adequa melhor a redes com poucos $M s s s$, enquanto que o $i A M^{2} C$ é mais indicado para redes com muitos Msss. Ambos os protocolos possuem um baixo custo na rede sem fio e uma porcentagem relativamente alta de multicasts abortados quando a taxa de migração dos $M h s$ é alta. Durante as simulações não houve a preocupação em determinar uma taxa (probabilidade) realista de migração para os $M h s$, mas sim apenas comparar o desempenho dos protocolos para situações hipotéticas.

\subsection{Trabalhos Futuros}

Imaginamos que multicast confiável/atômico para redes sem fio continua sendo uma área para muitas pesquisas, e que MobiCS pode ser uma ferramenta valiosa para a prototipação e análise de 
vários protocolos.

Como trabalho futuro, pensamos em extensões dos protocolos $A M^{2} C$ e $i A M^{2} C$ que tornem possível o ajuste dinâmico do tempo máximo esperado por um Mss por respostas de seus Mhs locais. Desta forma, como o valor dos time-outs influencia diretamente no número de multicasts abortados, a depender da carga da rede ou da aplicação, este valor poderia ser mais ou menos estendido.

Outro possível trabalho futuro consiste no desenvolvimento de uma variante do $i A M^{2} C$ onde os Msss possam manter as mensagens de multicasts em seus caches por um período determinado de tempo. Com isso, procuramos diminuir a sobrecarga na rede fixa do protocolo, mantendo sua escalabilidade em relação ao número de Msss no sistema.

Além disto, algumas possíveis direções do trabalho podem ser: adaptação de protocolos para multicast confiável em redes convencionais para redes sem fio, analisar sua complexidade e comparála com o $i A M^{2} C$; definir protocolos para multicast com garantias de entrega menos rigorosas, como por exemplo, entrega para pelo menos $k$ membros do grupo, dentre outras possibilidades; multicasts em redes ad-hoc. 


\section{Apêndice A}

\section{Diagrama de Classes no $\boldsymbol{A} \boldsymbol{M}^{2} \boldsymbol{C}$}

A seguir apresentamos o diagrama de classes (com os respectivos métodos públicos) do protocolo $A M^{2} C$.

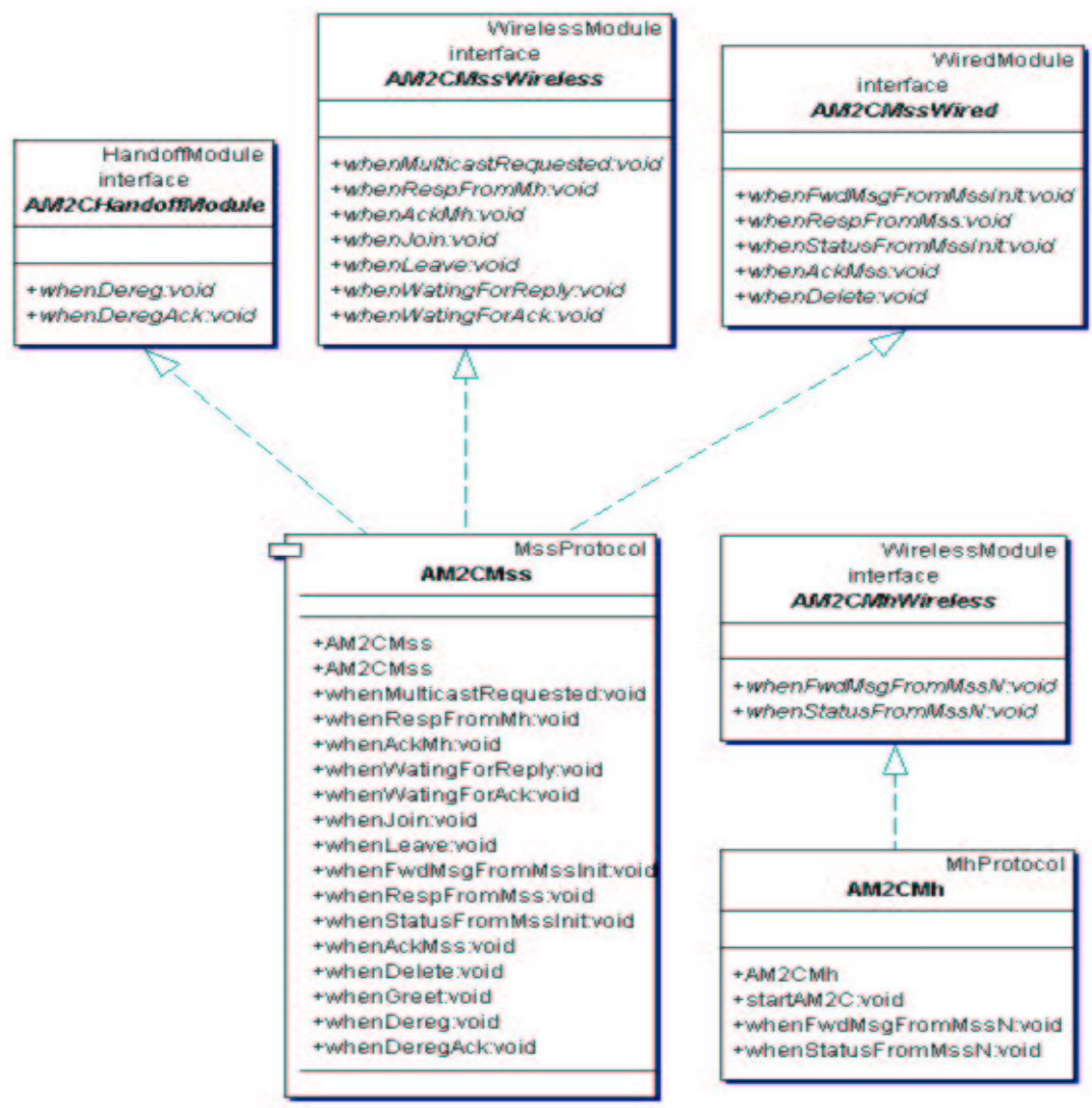

Figura A.1: Diagrama de Classes do $A M^{2} C$. 


\section{Apêndice B}

\section{Diagrama de Classes no iAM $\mathbf{M}^{2} C$}

A seguir apresentamos o diagrama de classes (com os respectivos métodos públicos) do protocolo $i A M^{2} C$.

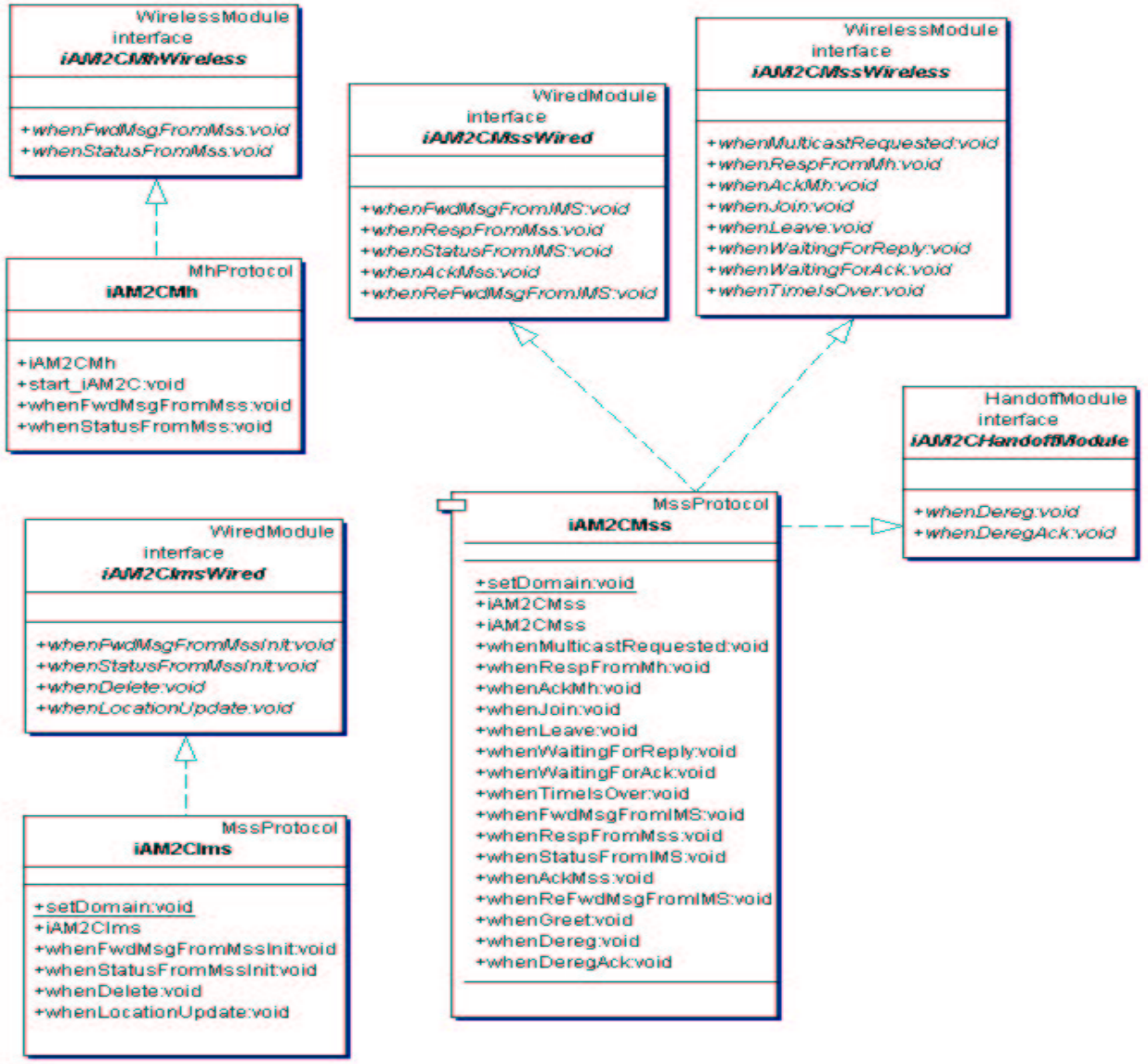

Figura B.1: Diagrama de Classes do $i A M^{2} C$. 


\section{Apêndice C}

\section{Estruturas de Dados e Tratamento de Mensagens no $\boldsymbol{A} \boldsymbol{M}^{2} \boldsymbol{C}$}

\section{C.1 Introdução}

O funcionamento de um protocolo prototipado no simulador MobiCS $[5,6]$ se dá basicamente através

de trocas de mensagens. É por meio do tratamento dado a cada uma dessas mensagens que é definido o comportamento do protocolo. Neste documento apresentamos as estruturas de dados que foram utilizadas e os algoritmos desenvolvidos para o funcionamento do protocolo de multicast atômico $A M^{2} C[13]$.

É importante dizer que estamos considerando dois tipos de elemento de rede, que são os $M h$ s e os Msss. Entretanto, para um melhor entendimento do funcionamento do protocolo, dividimos logicamente os Msss em Mssinit e Mss part, de acordo com o papel que um mesmo Mss assume no sistema. O primeiro refere-se ao Mss inicializador de uma mensagem de multicast; o segundo refere-se a um Mss participante no processamento de uma mensagem.

Dessa forma, a próxima seção define algumas estruturas de dados utilizadas pelo protocolo. Na seção C.3 encontram-se as definições e o conteúdo de todas as mensagens enviadas durantes as três fases do $A M^{2} C$, bem como durante os hand-offs. Por fim, a seção C.4 apresenta o tratamento dado (algoritmo) pelo protocolo para cada uma das mensagens descritas na seção C.3. 


\section{C.2 Estruturas de Dados}

Nesta seção encontram-se as principais estruturas de dados, juntamente com seus respectivos significados, utilizadas pelo protocolo $A M^{2} C$. Considere $M$ como uma mensagem em processo de difusão iniciada por $M s s_{\text {init }}$ para um conjunto de $M s s_{\text {part }}$ (no caso do $A M^{2} C$, todos os $M s s$ s do sistema). Cada mensagem desse tipo possui um grupo de destinatários que chamaremos de M.Dest.

Vale ressaltar ainda que algumas dessas estruturas estão relacionadas, independentemente, a cada mensagem de multicast difundida, ficando isso subtendido. São elas:

\section{C.2.1 Estruturas de Dados Gerais}

1. MsgId: Uma mensagem é identificada unicamente através de um objeto da classe MsgId. Este objeto contém dois atributos: o endereço do $M s s$ inicializador do multicast $\left(M s s_{\text {init }}\right)$ e um número de seqüência gerado pelo mesmo.

2. ObjReply: Esta classe implementa um objeto-resposta composto pelo endereço do elemento de rede responsável pela resposta e pela resposta em si (0k/NOk).

3. ObjMsgManager: Esta classe implementa um objeto da estrutura MsgManager (vide seção Estruturas de Dados em $M s s_{\text {part }}$ ), que serve para um Mss gerenciar as ações que devem ser tomadas em relação à chegada de uma mensagem. Um ObjMsgManager é composto por sete atributos booleanos:

- podeProcessar: indica se um evento de time-out na primeira fase do protocolo e associado a uma determinada mensagem $M$ pode ou não ser processado;

- tmoutF1Proc: indica se um evento de time-out associado a uma mensagem já foi ou não processado na primeira fase do protocolo;

- tmoutF2Proc: o mesmo, só que para a segunda fase do protocolo;

- deleteEnviado: indica se a mensagem Delete referente a um multicast $M$ já foi ou não enviada;

- statusDefinido: indica se o estado final de um multicast já foi ou não definido pelo Mssinit; - tmoutT1Iniciado: indica se o time-out relacionado a uma mensagem de multicast na primeira fase do protocolo já foi ou não iniciado;

- tmoutT2Iniciado: o mesmo especificado no item anterior, só que vale para a segunda fase do protocolo; 


\section{C.2.2 Estruturas de Dados em Mss init :}

1. mseq: variável inteira que armazena o número de seqüência da próxima mensagem de multicast a ser difundida por um dado $M s s$ inicializador $\left(M s s_{\text {init }}\right)$. O mseq é um dos atributos que compõem um objeto MsgId, como descrito na seção C.2.1.

2. RepliesFromMss: tabela hash contendo as respostas dos Msss referentes às mensagens de multicast difundidas. Seja $M$ uma tal mensagem e $i d$ sua identificação (um objeto $M s g I d$ ). Cada posição RepliesFromMss $[$ M.id] retorna um conjunto de respostas (0k/NOk) referentes à mensagem $M$.

Obs.: Utilizaremos no restante deste apêndice o termo M.id (ou equivalente) para indexar a posição referente a uma mensagem de multicast $M$ em uma estrutura de dados como uma tabela hash ou vetor. Todavia, deve-se ter em mente que este índice (tal como outros atributos de uma mensagem) é, na verdade, obtido por um método get, tal como getMsgId(). De forma similar, deve-se considerar um método put para atribuir um valor em uma certa posição de uma estrutura (por exemplo em RepliesFromMss $[$ M.id] := valor). Estas simplificações também serão bastante utilizadas nos algoritmos da seção C.4.

3. DestM: tabela hash onde cada posição DestM $[M . i d]$ armazena o grupo de destinatários da mensagem $M$.

4. GConfirmados: tabela hash indexada pelo id da mensagem. Cada posição da tabela contém o conjunto de Mhs que confirmaram o recebimento do estado final de uma mensagem multicast.

\section{C.2.3 Estruturas de Dados em $M s s_{\text {part }}$ :}

1. LocalMhs: grupo de $M h s$ pertencentes à célula que está sob a responsabilidade de $M s s_{\text {part }}$.

2. h_RECD: Esta estrutura (hash) é única para cada $M h$ do sistema e está presente no Mss responsável pela célula na qual o $M h$ se encontra. Contém $n$ posições, onde $n$ corresponde ao número total de $M s s$ s no sistema. Cada posição $i, 0 \leq i<n$, onde $h \_R E C D[\mathrm{i}]=j$, corresponde à $j$-ésima mensagem $(m s e q=j)$ recebida pelo $M h$ e difundida por $M s s_{i}$.

3. Buffer: fila que armazena as mensagens de multicast difundidas por um Mss inicializador $\left(M s s_{\text {init }}\right)$. Só é usada durante a primeira fase do protocolo. 
4. Outcomes: tabela hash que armazena o estado final de cada mensagem de multicast difundida até então. É indexado por M.id.

5. RepliesFromMhs: tabela hash de respostas (Ok/NOk) dos Mhs locais à Mss part referente a todas as mensagens já transmitidas pelo Mss. Seja $M$ uma tal mensagem. Cada posição RepliesFromMhs $[$ M.id $]$ retorna um vetor que contém um conjunto de objetos do tipo ObjReply. Cada objeto desse tipo é composto pelo endereço do $M h$ e por sua resposta à mensagem $M$.

6. AckMhs: tabela hash usada para armazenar o grupo de Mhs locais e destinatários de uma mensagem que confirmaram o recebimento do estado final do multicast. O M.id é utilizado como índice.

7. MsgManager: tabela hash onde cada posição indexada por M.id (para uma mensagem de multicast $M$ ) contém um objeto do tipo ObjMsgManager. É por meio desta estrutura que o Mss gerencia diversas ações relativas a uma mensagem, tais como o processamento ou não da mensagem, do evento de time-out a ela associado, entre outras (como poderá ser observado no tratamento das mensagens na seção C.4).

8. DestMLocal: conjunto de $M h s$ locais e destinatários de uma determinada mensagem de multicast.

\section{C.3 Definição das Mensagens}

Nesta seção encontram-se as definições e o conteúdo das mensagens segundo o elemento de rede que as processa. Considere $M$ como sendo genericamente qualquer uma das mensagens a seguir. $M$ contém sempre uma identificação $(M . i d)$ e um conteúdo que, de forma geral, é alguma informação relevante para o sistema.

É importante observar que quando utilizamos uma variável $M^{\prime}$ ( ou $M$ ") no lugar da variável $M$ para referenciar uma mensagem, deve-se ao fato de que $M$ e $M^{\prime}$ (ou $M^{\prime \prime}$ ) são sintaticamente diferentes. Todavia, $M^{\prime} / M^{\prime}$ "sempre conterá a mesma identificação de $M\left(M^{\prime} . i d=M . i d\right)$. Ou seja, todas as mensagens referem-se a uma mesma mensagem original, só que contêm atributos diferentes. Esta observação também é valida para a seção C.4.

\section{C.3.1 Mensagens Tratadas por $M s s_{\text {init }}$ :}

1. $\mathbf{M}=$ MulticastRequested(Mh mh, Group dest, int content): 
Mensagem de multicast requisitada por um Mh. Sempre enviada para o Mss responsável pela célula a qual o $M h$ se encontra no momento do envio da mensagem $\left(M s s_{M h}\right)$. Contém o identificador do $M h$ requisitante, o grupo de destinatários (M.dest) e o conteúdo da mensagem.

2. $\mathbf{M}=\operatorname{RespFromMss}(M s g I d$ id, int reply):

Resposta proveniente de um Mss a respeito de uma determinada mensagem $M^{\prime}$. Esta resposta refere-se à disponibilidade e aceitação de $M^{\prime}$ por todos os $M h$ s locais ao Mss e que pertencem a $M^{\prime}$.Dest. Contém a identificação da mensagem (onde $M . i d=M^{\prime} . i d$ ) e a resposta, M.reply (Ok/NOk).

3. $\mathbf{M}=\operatorname{AckMss}($ MsgId id, Group $C)$ :

Mensagem enviada de um $M s s$ para o $M s s_{\text {init }}$ de uma determinada mensagem $M^{\prime}$. É composta pela identificação da mensagem $\left(M . i d=M^{\prime}\right.$ 'id $)$ e pelo grupo de $M h$ s locais e pertencentes a $M^{\prime}$.Dest que confirmaram o recebimento do estado final de $M^{\prime}$.

\section{C.3.2 Mensagens Tratadas pelo $M s s_{\text {part }}$ :}

1. $\mathbf{M}=\mathbf{F w d M s g F r o m M s s}_{\text {init }}($ MsgId id, Group dest, int content $)$ :

Recebimento de uma mensagem de multicast $M$ inicializada por um $M s s_{\text {init }}$. $M$ deve ser retransmitida para todo $M h \in(M s s . L o c a l M h s \cap M . D e s t)$. Contém o identificador da mensagem (M.id), o grupo de destinatários (M.Dest) e o conteúdo (M.content).

2. $\mathbf{M}=\operatorname{RespFromMh}(M h m h$, MsgId id, int reply):

Resposta de um $M h$ para seu $M s s_{M h}$ sobre a aceitação ou não de uma mensagem recebida (chamemos de $M^{\prime}$ ). Contém a identificação do $M h$, da mensagem (onde $M . i d=M^{\prime}$.id) e a resposta, M.reply (Ok/NOk).

\section{3. $\mathbf{M}=$ WaitingForReply(Timer T1):}

Ocorrência do evento de time-out no Mss. Refere-se ao término do tempo máximo esperado pelo $M s s_{\text {part }}$ por respostas de seus $M h s$ locais e destinatários de uma mensagem (associada ao timer T1) enviada durante a primeira fase do protocolo.

4. $\mathbf{M}=$ StatusFromMss $_{\text {init }}($ MsgId id, Group dest, char Status):

Recebimento do estado final de um multicast enviado pelo Mss inicializador $\left(M_{s s_{i n i t}}\right)$ para todos os Msss do sistema. Contém a identificação da mensagem (M.id), o grupo de $M h s$ destinatários (M.dest) e o estado final ("A" = "Aborted"; "C" = "Commited"). 
5. $\mathbf{M}=\operatorname{AckMh}(M s g I d i d, M h m h)$ :

Recebimento da confirmação de um $M h$ sobre o recebimento do estado final de um multicast. Contém o identificador da mensagem e do $M h$.

6. $\mathbf{M}=$ WaitingFor Ack(Timer T2):

Ocorrência do evento de time-out no Mss. Refere-se ao término do tempo máximo esperado pelo $M s s_{\text {part }}$ por confirmações de seus $M h s$ locais e destinatários de uma mensagem (associada ao timer T2) enviada durante a segunda fase do protocolo. Essas confirmações dizem respeito ao recebimento do estado final de um multicast.

\section{7. $\mathbf{M}=\operatorname{Delete}(M s g I d i d)$ :}

Recebimento da solicitação do $M s s$ inicializador de um multicast $M$ ' para que todos os $M s s s$ removam $M^{\prime}$ de seus respectivos Outcomes. Contém apenas a identificação da mensagem $\left(M^{\prime} \cdot i d\right)$.

8. $\mathbf{M}=\operatorname{Greet}\left(M h m h, M s s \mathrm{Mss}_{o}\right)$ :

Mensagem enviada por um $M h$ a um $M s s_{\text {part }}$ toda vez que o $M h$ entra na célula que está sob a responsabilidade de $M s s_{\text {part }}$, inicializando assim o protocolo de hand-off. Contém a identificação do $M h$ e do $M s s$ responsável pela célula da qual o $M h$ migrou $\left(M s s_{o}\right)$.

9. $\mathbf{M}=\operatorname{Dereg}\left(\right.$ Mh $\left.m h, M s s \mathrm{Mss}_{n}\right)$ :

Solicitação de desvinculação de um $M h$ de sua antiga célula. É enviada do $M s s$ responsável pela célula para a qual o $M h$ está migrando, para o $M s s$ responsável pela célula da qual o $M h$ migrou. Contém a identificação do $M h$ e do novo $M s s\left(M s s_{n}\right)$. Esta mensagem faz parte do protocolo de hand-off.

10. $\mathbf{M}=\operatorname{Dereg} \operatorname{Ack}\left(M h\right.$ mh, hashtable $\mathrm{h} \_$RECD $)$:

Confirmação de desvinculação de um $M h$ de sua antiga célula. Enviada do $M s s$ da antiga célula para o $M s s$ responsável pela nova célula. Contém a identificação do $M h$ e o $h \_R E C D$ relacionado ao $M h$. Também faz parte do protocolo de hand-off.

11. $\mathbf{M}=\operatorname{Join}(M h m h)$ :

Solicitação de entrada no sistema por parte de um $M h$. Contém a identificação do $M h$.

12. $\mathbf{M}=$ Leave $(M h m h)$ :

Solicitação de saída do sistema de um $M h$ para seu $M s s_{M h}$. Contém a identificação do $M h$. 


\section{C.3.3 Mensagens Tratadas por um Mh:}

1. $\mathbf{M}=\mathbf{F w d M s g F r o m M s s}_{n}($ MsgId id, int content $)$ :

Recebimento de uma mensagem de multicast enviada pelo $M s s$ responsável pelo $M h\left(M s s_{M h}\right)$. Armazena a identificação da mensagem (M.id) e o conteúdo.

2. $\mathbf{M}=\mathbf{S t a t u s F r o m M s s}_{n}($ MsgId $i d$, char status $)$ :

Recebimento do estado final de um multicast enviado pelo $M s s$ responsável pelo $M h\left(M s s_{M h}\right)$. Contém a identificação da mensagem $(M . i d)$ o estado final ("C" = "Commited"; "A" = "Aborted").

\section{C.4 Tratamento das Mensagens}

Esta seção apresenta um pseudo-código referente ao tratamento de cada uma das mensagens descritas na seção anterior. Entretanto, antes de iniciarmos faremos algumas considerações:

1. Mais uma vez faremos uma abordagem por elemento de rede envolvido;

2. Faz parte da sintaxe do MobiCS [5,6] o uso da palavra "When" antes do nome da mensagem, indicando o tratamento que é dado a uma mensagem quando esta é recebida por um elemento de rede como um Mss ou $M h$.

3. Considere as tabelas C.1 e C.2 que indicam os principais métodos utilizados no tratamento das mensagens.

4. Os eventos de time-out WhenWaitingForReply $(<$ timer - event $>$ ) e WhenWaitingForAck $(<$ timer-event $>$ ) indicam o término do tempo máximo esperado por um Mss por uma resposta referente a uma mensagem $M$ (associada à < timer - event $>$ ) de seus respectivos $M h$ s t.q. $M h \in($ LocalMhs $\cap$ M.Dest). No primeiro caso, espera-se uma resposta do tipo Ok/NOk e, no segundo, um acknowledgment de um Mh. As principais ações tomadas quando um evento como estes ocorre estão indicadas na tabela C.3. 


\begin{tabular}{|l|l|}
\hline Método & Significado \\
\hline New (<MsgType>) & Criação de uma nova mensagem do tipo <MsgType>. \\
\hline send(elemento, M) & Envio da mensagem M para elemento. \\
\hline M.bcast & Difusão da mensagem M para todos os Msss. \\
\hline Object [Mid] .put(anObject) & $\begin{array}{l}\text { Insere o objeto anObject na posição indexada por Mid do objeto } \\
\text { Object. }\end{array}$ \\
\hline Object [Mid] .add(anObject) & Adiciona o objeto anObject ao objeto Object [Mid]. \\
\hline Object [Mid] .remove() & Remove o objeto da posição indexada por Mid. \\
\hline Object.size() & Retorna o número de posições (tamanho) de Object. \\
\hline msgNotHandled(Mh, Mid) & \begin{tabular}{l} 
Retorna TRUE caso uma mensagem M não tenha sido recebida pelo \\
Mh e nenhum $M s s$ considerou sua resposta como NOk. Retorna \\
FALSE no caso contrário. Esse teste é feito de acordo com o \\
número de seqüência armazenado em $h \_R E C D[M . M s s I n i t]$ para o \\
$M h$ em questão ( o Mss inicializador pode ser obtido pelo objeto \\
\hline Mid).
\end{tabular} \\
\hline Inc-hRECD(Mh, Mid) & $\begin{array}{l}\text { Indica que a mensagem já foi recebida (ou tratada) pelo Mh. Isto } \\
h \_R E C D[M . M s s I n i t] \text { para o Mh em questão. }\end{array}$ \\
\hline
\end{tabular}

Tabela C.1: Principais Métodos Utilizados no Tratamento das Mensagens no $A M^{2} C$.

5. Existem alguns eventos tais como: connect, disconnect, move, leave e join que podem ocorrer em um Mh. Os dois últimos são ações voluntárias do usuário que estaria desligando/ligando seu dispositivo móvel. A ocorrência destes eventos é determinada por probabilidades ou por comandos explícitos do usuário.

6. Para uma melhor compreensão dos algoritmos, as variáveis serão expressas da seguinte forma: parâmetros, estruturas de dados ou mensagens serão expressos da mesma forma como descritos nas seções anteriores, porém em itálico (ex. "Par1","LocalMhs"); variáveis temporárias serão escritas em minúsculo (ex. "aux").

7. Considere TOTAL-MSSs como uma variável que armazena o número total de Msss no sistema.

8. O termo owner corresponde a uma referência para o $M s s / M h$ que está processando a mensa- 


\begin{tabular}{|c|c|}
\hline Método & Significado \\
\hline timerEvent.getMsg() & Retorna a mensagem associada à timerEvent. \\
\hline $\begin{array}{l}\text { MsgManager [Mid] . setInfo- } \\
\text { AboutDelete- } \\
\text { Sent (TRUE/FALSE) }\end{array}$ & $\begin{array}{l}\text { Indica se a mensagem Delete referente a uma mensagem cujo } \\
\text { identificador é Mid já foi ou não enviada. Este método é utilizado } \\
\text { pela estrutura MsgManager. }\end{array}$ \\
\hline $\begin{array}{l}\text { setTimer (<timer-event>, } \\
<\text { repeat-order }>\text {, <time- } \\
\text { to-elapsed }>)\end{array}$ & $\begin{array}{l}\text { Inicia um temporizador para uma mensagem associada à <timer- } \\
\text { event>. <repeat-order> ("ONCE" ou "REPEATING") indica se } \\
\text { o evento será gerado apenas uma vez ou repetidamente. <time- } \\
\text { to-elapsed> refere-se ao tempo (em UTs) no qual o evento deverá } \\
\text { ser gerado ou o período de repetição. }\end{array}$ \\
\hline $\begin{array}{l}\text { MsgManager }[\text { Mid }] \text {.getPermis- } \\
\text { sionToProcess }()\end{array}$ & $\begin{array}{l}\text { Retorna TRUE caso o evento de time-out associado à mensagem } \\
\text { M pode ser processado. Retorna FALSE no caso contrário. }\end{array}$ \\
\hline $\begin{array}{l}\text { MsgManager [Mid] . setPermis- } \\
\text { sionToPro- } \\
\text { cess (TRUE/FALSE) }\end{array}$ & $\begin{array}{l}\text { Indica se o evento de time-out associado a uma mensagem cujo } \\
\text { identificador é Mid pode ou não ser processado. Este método é } \\
\text { utilizado pela estrutura MsgManager. }\end{array}$ \\
\hline $\begin{array}{l}\text { MsgManager }[\text { Mid] .getInfo- } \\
\text { AboutEventProcessedIn- } \\
\text { F1/F2() }\end{array}$ & $\begin{array}{l}\text { Devolve TRUE se o evento de time-out da Fase I/II referente à } \\
\text { mensagem indexada por Mid já foi processado. Retorna FALSE } \\
\text { no caso contrário. }\end{array}$ \\
\hline $\begin{array}{l}\text { MsgManager }[\text { Mid }] \text {.setInfo- } \\
\text { AboutEventProcesse- } \\
\text { dInF1/F2 (TRUE/FALSE) }\end{array}$ & $\begin{array}{l}\text { Indica que o evento de time-out associado à mensagem M na Fase } \\
\text { I/II do protocolo já foi ou não processado. }\end{array}$ \\
\hline
\end{tabular}

Tabela C.2: Principais Métodos Utilizados no Tratamento das Mensagens no $A M^{2} C$. gem.

9. Nas próximas subseções, considere $M$ como sendo cada uma das mensagens tratadas;

\section{C.4.1 Mensagens Tratadas por Mssinit:}

1. WhenMulticastRequested (Mh, Dest, Content):

(a) $m s e q:=m s e q+1$;

(b) mid := New MsgId (owner, mseq); /* Identificador da mensagem. */

(c) $M^{\prime}:=$ New FwdMsgFromMssinit (mid, Dest, Content);

(d) DestM $[\mathrm{mid}]:=$ Dest; 


\begin{tabular}{|c|c|}
\hline Evento & $\begin{array}{l}\text { Ações (Seja } M \text { uma mensagem associada a }<\text { timer }- \\
\text { event }>\text { ) }\end{array}$ \\
\hline WhenWatingForReply $(<$ timer - event $>)$ & $\begin{array}{l}\text { Se LocalMhs } \cap M . \text { Dest }=\emptyset \text { ou } \forall M h \in \text { (LocalMhs } \cap \\
M . \text { Dest), a resposta referente à } M \text { é } 0 \mathrm{k} \text {, então envie } \\
\text { um } 0_{k} \text { para } M s s_{\text {init }} \text {. Senão envie um } \operatorname{NOk}_{M} \text {. }\end{array}$ \\
\hline WhenWatingForAck $(<$ timer - event $>)$ & $\begin{array}{l}\text { Seja C o grupo de } M h s \text { locais que confirmaram o re- } \\
\text { cebimento de } M \text {. Envie um acknowledgment }\left(\operatorname{Ack}_{M}\right) \\
\text { com o grupo C para o } M s s_{\text {init }} \text { relativo à } M \text {. }\end{array}$ \\
\hline
\end{tabular}

Tabela C.3: Eventos ocorridos em um $M s s$ no $A M^{2} C$.

(e) GConfirmados [mid] := \{\} ;

(f) M'.bcast; /* Difusão para todos os Msss. */

2. WhenRespFromMss(Mid, Reply):

Seja resp uma resposta do tipo "OK"/"NOK".

(a) RepliesFromMss [Mid] . add (reply);

(b) Se RepliesFromMss [Mid].size() = TOTAL-MSSs então

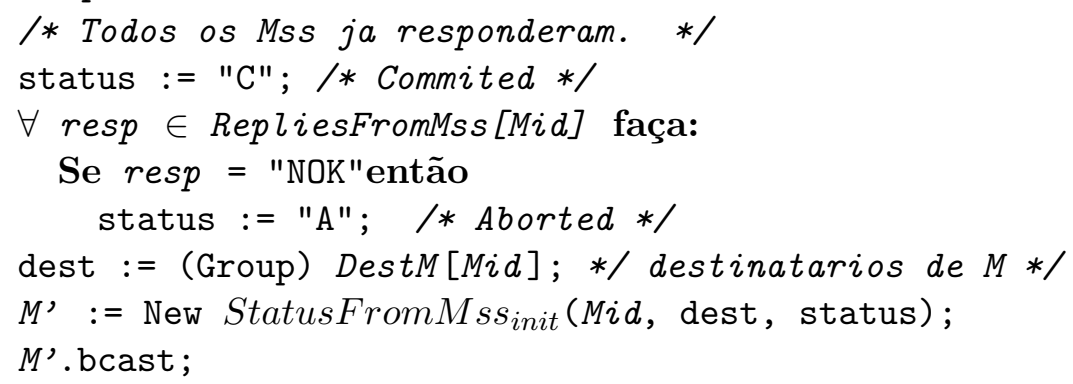

3. WhenAckMss (Mid, C):

(a) $\forall$ Mh $\in C$ faça:

GConfirmados [Mid] . add $(M h)$;

(b) Se GConfirmados [Mid].size ( ) = DestM[Mid].size() então

I* Todos os Mhs $\in$ M.Dest ja confirmaram o recebimento do status de $M *$ /

MsgManager [Mid] . setInfoAboutDeleteSent (TRUE);

$M^{\prime}:=$ New Delete $(M i d)$;

$M^{\prime} \cdot$ bcast;

\section{C.4.2 Mensagens Tratadas por $M s s_{\text {part }}$ :}

1. WhenFwdMsgFromMss ${ }_{\text {Init }}($ Mid, Dest, Content):

Seja $M$ a $i$-ésima mensagem difundida por uma dado Mssinit.

(a) Buffer.add $(M)$; 
(b) Seja $N=\{$ Mh t.q. $M h \in$ (LocalMhs $\cap$ M.Dest) $\}$

Se $N=\emptyset$ então

$M^{\prime}:=$ New RespFromMss (Mid,"Ok");

send (M.Mssinit, $\left.M^{\prime}\right)$;

Senão

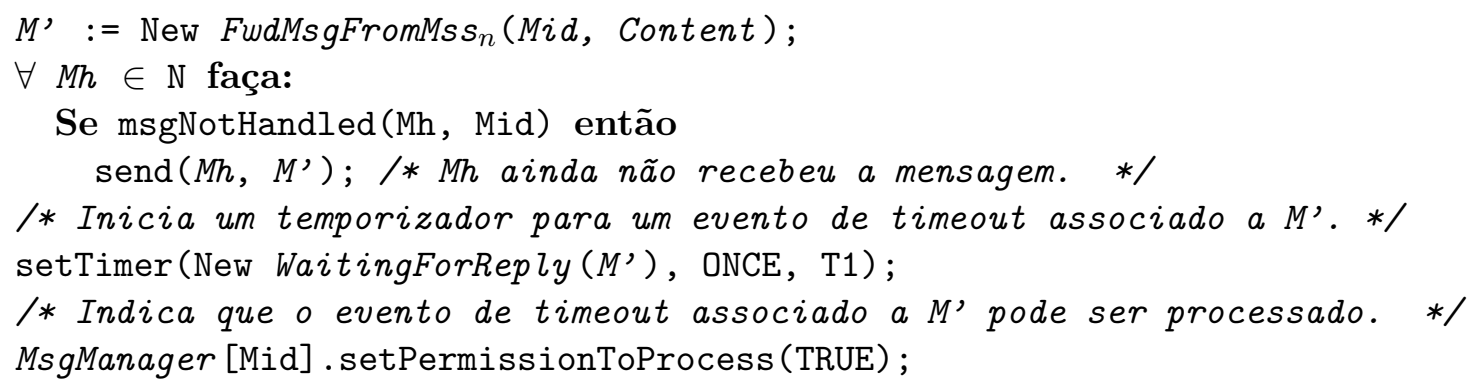

2. WhenRespFromMh(Mh, Mid, Reply):

/*Verifica se o evento de time-out na 1a.fase para a mensagem ainda nao foi processado. *I

(a) Se MsgManager [Mid].getInfoAboutEventProcessedInF1( ) = FALSE então

/* Guarda a resposta do Mh. *I

RepliesFromMhs [Mid] . add (Reply);

(b) $\operatorname{Inc}-h R E C D(M h, M i d)$;

3. WhenWaitingForReply (TimerEvent):

Seja resp uma resposta de um Mh do tipo "Ok"/"NOk".

(a) M':= TimerEvent.getMsg();/* Mensagem associada ao time-out. */

(b) Se MsgManager [M'.id].getPermissionToProcess() então

Seja $N=\{$ Mh t.q. Mh $\in$ (LocalMhs $\cap$ M.Dest) $\}$

Se $N=\emptyset$ então

reply := "OK";

senão

/* Testa se TODOS os Mhs ja responderam. */

Se RepliesFromMhs [M'.id].size() = N.size() então

reply := "Ok";

$\forall$ resp $\in$ RepliesFromMhs [M'.id] faça:

Se $\operatorname{resp}=$ "NOk"então

reply := "NOK";

\section{Senão}

reply := "NOk";

$M^{\prime \prime}:=$ New RespFromMss (M'.id, reply);

send ( $\left.M^{\prime} . M s s_{\text {init }}, M^{\prime \prime}\right)$;

/* Indica que o time-out ja foi processado na fase I. */

MsgManager. setInfoAboutEventProcessedInF1 (TRUE);

\section{Senão}

/* Proximo evento de time-out deve ser processado. */
MsgManager [M'.id].setPermissionToProcess(TRUE);

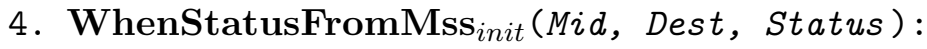

Seja $M$ a $i$-ésima mensagem de status difundida por um Mssinit. 
(a) Outcomes $[$ Mid] := Status;

(b) Buffer.remove(Mid);

(c) $M^{\prime}:=$ New StatusFromMss $s_{n}$ (Mid, Status);

$\forall M h \in$ (LocalMhs $\cap$ M.Dest) faça: send $\left(M h, M^{\prime}\right)$;

(d) /* Inicia um temporizador para um evento de timeout associado a M'. */ setTimer(New WaitingForAck (M'), ONCE, T2);

5. WhenAckMh $(M i d, M h)$ :

/* Testa se o evento de time-out ja foi processado. Neste caso, a mensagem AckMss $\{M h\}$ (Ack extra) deve ser enviada para o Mss inicializador do multicast. *I

(a) Se MsgManager [Mid] .getInfoAboutEventProcessedInF2() = TRUE então M': : New AckMss (Mid, Mh); send (M.Mssinit, $\left.\mathrm{M}^{\prime}\right)$;

senão

/* Adiciona o Mh no grupo de Mhs que ja enviaram um acknowledjment para M. */ $A c k M h s[M i d] . \operatorname{add}(M h)$;

6. WhenWaitingForAck (TimerEvent) :

(a) $M^{\prime}:=$ TimerEvent.getMsg();

(b) $M^{\prime \prime}:=$ New AckMss (M'.id, AckMhs $\left.\left[M^{\prime}, i d\right]\right)$;

(c) send (M'.Mssinit, $\left.M^{\prime \prime}\right)$;

(d) /* Remocao do Mhs que ja responderam a M'. */ $\forall M h \in A c k M h s\left[M^{\prime}, i d\right]$ faça AckMhs $\left[M^{\prime} . i d\right] . \operatorname{remove}(M h)$;

(e) MsgManager[M',id].setInfoAboutEventProcessedInF2(TRUE);

7. WhenDelete $(M i d)$ :

(a) Outcomes [Mid].remove(); /* Remocao de M de Outcomes. *I

8. WhenGreet $\left(M h_{n e w}, \operatorname{Mss}_{o}\right)$ :

(a) /* Testa se o Mh esta entrando agora no sistema. */

Se $M s s_{O} \neq$ null então

/* Testa se o Mh nao voltou de um periodo de inativacao. */

Se $M s s_{o} \neq$ owner então

I* Envio da mensagem Dereg do Mss responsavel pela celula atual para Mss solicitando o desligamento de $M h_{n e w}$ de sua antiga celula. *I

$M^{\prime}:=$ New Dereg $\left(M h_{n e w}\right.$, owner $)$; send $\left(M s s_{O}, M^{\prime}\right)$;

\section{Senão}

/* Varredura do Buffer. */

$\forall M^{\prime} \in$ Buffer faça:

Se MsgManager [M',id].getInfoAboutEventProcessedInF1( $)=$ FALSE então

Se $M h_{n e w} \notin M^{\prime}$. Dest e msgNotHandled $\left(M h_{n e w}, M^{\prime} . i d\right)$ então 


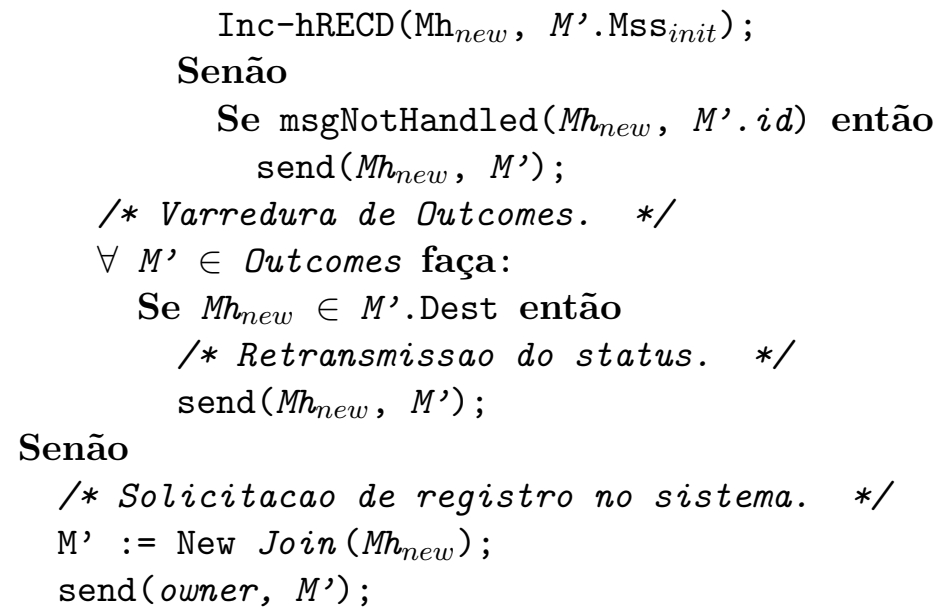

9. WhenDereg $\left(M h_{\text {new }}, \operatorname{Mss}_{n}\right)$ :

Esta mensagem é processada em $\mathrm{Mss}_{O}$.

(a) /* Remocao de Mhnew do grupo LocalMhs. */

LocalMhs.remove $\left(M h_{n e w}\right)$;

(b) /* Aborta (indiretamente) todas as mensagen que o Mh e destinatario e ainda nao respondeu. */

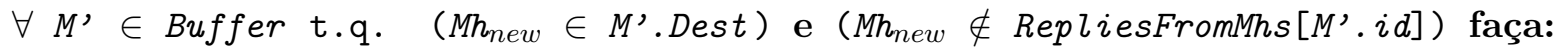

$M^{\prime \prime}:=$ New RespFromMss (M'.id, "NOk");

send (M'.Mssinit, $\left.M^{\prime \prime}\right) ; / *$ Mss inicializador de $M^{\prime}$. */

Inc-hRECD $\left(\right.$ Mh $_{\text {new }}, M^{\prime}$. Mssinit $\left._{\text {int }}\right)$; /* Indicara que $M^{\prime}$ ja foi tratada. */

/* Indica que o proximo evento de time-out nao deve ser processado. */

MsgManager [M', $i d]$.setPermissionToProcess (FALSE);

(c) /* Envio da confirmacao de desvinculacao do Mh para Mss ${ }_{n}$. */ $M^{\prime}:=$ New DeregAck $\left(M h_{\text {new }}\right.$, gethRECD $\left(M h_{\text {new }}\right)$; send $\left(M s s_{n}, M^{\prime}\right)$;

10. When DeregAck $\left(M h_{n e w}, h R E C D\right)$ :

(a) LocalMhs. add $\left(M h_{\text {new }}\right)$;

(b) $\forall M^{\prime} \in$ Buffer faça:

Se $M h_{\text {new }} \in M^{\prime}$.Dest então

/* Testa se o evento de time-out associado a M' ja foi processado. */

Se MsgManager [M'.id].getInfoAboutEventProcessedInF1( $)$ FALSE) então

Se msgNotHandled $\left(M h_{n e w}, M^{\prime} . i d\right)$ então

I* Retransmissao de M' para o Mh. */

send $\left(M h_{\text {new }}, M^{\prime} . i d\right)$;

/* Prorrogacao do time-out. */ setTimer(New WaitingForReply(M'), ONCE, T1);

/* Indica que o evento de time-out anterior nao deve ser processado.*/ MsgManager.setPermissionToProcess (FALSE);

\section{Senão}

Se msgNotHandled $\left(M h_{n e w}, M^{\prime} . i d\right)$ então I* Envio do "NOk"por parte do Mss. *I 


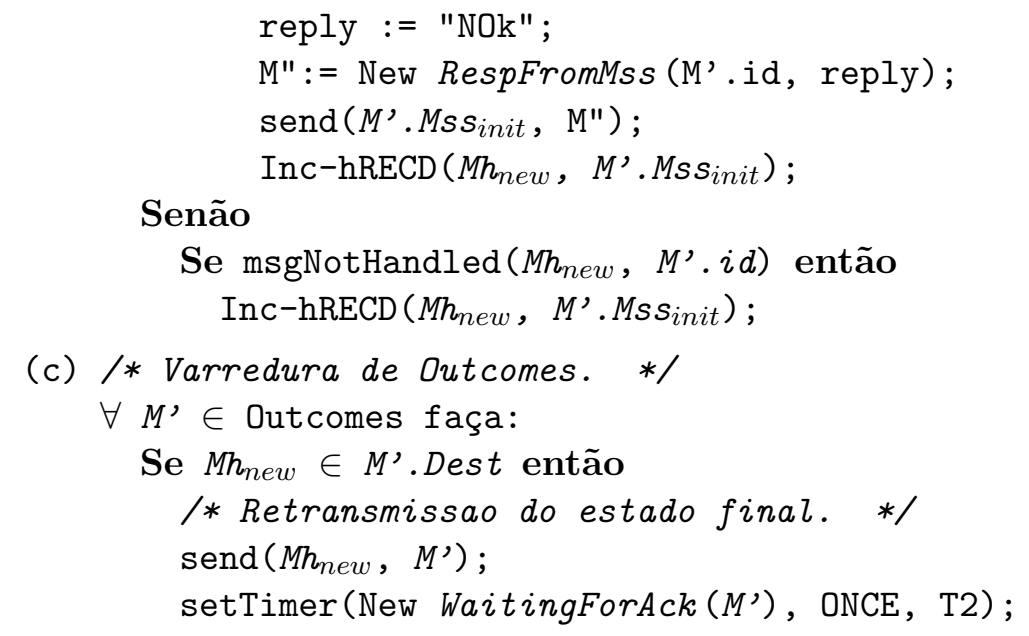

11. WhenJoin $\left(M h_{\text {new }}\right)$ :

(a) LocalMhs.add $\left(M h_{\text {new }}\right)$; /* Adiciona Mh new no grupo de Mhs locais. */

12. WhenLeave $(M h)$ :

(a) LocalMhs.remove(Mh); /* Remove Mh do grupo de Mhs locais. */

\section{C.4.3 Mensagens Tratadas no Mh:}

1. WhenFwdMsgFromMss ${ }_{n}($ Mid, Content):

(a) Se a aplicacao e capaz de processar a mensagem então reply := "Ok";

Senão reply := "NOk";

(b) $M^{\prime}:=$ New RespFromMh (owner, Mid, reply);

(c) /* Envia resposta para o Mss resposavel pelo Mh.*/ send (Mssowner, $\left.M^{\prime}\right)$;

2. WhenStatusFromMss ${ }_{n}$ (Mid, Status):

/* Acknowledgment enviado para Mss responsável pelo Mh confirmando o recebimento do estado final de uma mensagem. */

(a) $M^{\prime}:=$ New AckMh (owner, Mid);

(b) send (Mss owner, $\left.M^{\prime}\right)$; 


\section{Apêndice D}

\section{Estruturas de Dados e Tratamento de Mensagens no iAM $M^{2} C$}

\section{D.1 Introdução}

Este apêndice tem como objetivo apresentar as estruturas de dados, mensagens e o tratamento dado a estas pelos elementos de rede envolvidos durante o funcionamento do protocolo $i A M^{2} C[10]$, através do uso do simulador MobiCS [5,6].

Estamos considerando três tipos de elementos de rede, que são os Mhs, os Msss e os IMSs. Assim como fizemos no apêndice C, dividimos logicamente os $M s s s$ em $M s s_{\text {init }}$ e $M s s_{\text {part }}$, de acordo com o papel que um mesmo Mss assume no sistema.

A próxima seção define as principais estruturas de dados utilizadas pelo protocolo. A seção D.3 apresenta e define o conteúdo de todas as mensagens enviadas durantes as três fases do $i A M^{2} C$, bem como durante os hand-offs. Finalmente, na seção D.4 encontra-se o tratamento dado pelo protocolo para cada uma das mensagens descritas na seção D.3.

\section{D.2 Estruturas de Dados}

Nesta seção encontram-se as principais estruturas de dados, juntamente com suas respectivas utilidades, usadas pelo protocolo $i A M^{2} C$. Seja $M$ uma mensagem de multicast difundida por um $M s s$ inicializador $\left(M s s_{\text {init }}\right.$ ) para um conjunto de $M s s_{\text {part }}$. Cada mensagem desse tipo possui um grupo de destinatários que chamaremos de M.Dest.

Muitas das estruturas de dados que serão apresentadas são as mesmas utilizadas pelo protocolo $A M^{2} C$ (e que já foram vistas). Nestes casos, indicaremos com um (*) tais estruturas, apresentando apenas um resumo das mesmas. 


\section{D.2.1 Estruturas de Dados Gerais}

1. MsgId (*): identificador de uma mensagem composto pelo endereço do Mss inicializador do multicast e de um número de seqüência gerado pelo mesmo.

2. ObjReply (*): Resposta de um elemento de rede referente a uma mensagem de multicast.

3. ObjMsgManager (*): Classe que implementa um objeto da estrutura MsgManager (vide seção D.2.3) e que contém sete atributos booleanos. Estes atributos, que estão relacionados a uma mensagem de multicast, permitem que o Mss gerencie as ações que devem ser tomadas na chegada de uma mensagem.

4. IMSAddress: vetor com os endereços de todos os IMSs do sistema.

\section{D.2.2 Estruturas de Dados em Mss $_{\text {init }}$ :}

1. mseq $\left(^{*}\right)$ : número de seqüência da próxima mensagem de multicast a ser difundida pelo Mss inicializador $\left(M s s_{\text {init }}\right)$.

2. RepliesMhSet: tabela hash indexada pelo identificador de uma mensagem $M$ (M.id - objeto MsgId). Cada posição RepliesMhSet[M.id] retorna um vetor de objetos do tipo ObjReply com o conjunto de $M h s$ (e suas correspondentes respostas) que responderam à $M$.

3. DestM (*): tabela hash que armazena, para cada posição indexada por M.id, o grupo de destinatários de um multicast $M$.

4. GConfirmados $\left(^{*}\right)$ : tabela hash que contém o conjunto de Mhs que confirmaram o recebimento do estado final de um multicast. Também é indexado pelo $i d$ da mensagem.

\section{D.2.3 Estruturas de Dados em $M s s_{\text {part }}$ :}

1. RespIms: endereço do $I M S$ ao qual o Mss está associado.

2. LocalMhs $(*)$ : grupo de $M h s$ pertencentes à célula que está sob a responsabilidade de Mss $s_{\text {part }}$.

3. h_RECD $\left(^{*}\right)$ : estrutura (tabela hash) semelhante à descrita na subseção C.2.3 no sentido de que está relacionada a cada $M h$ do sistema e é mantida no $M s s$ responsável pelo $M h$ no momento. Contém $n$ posições, onde $n$ corresponde ao número total de Msss no sistema. A principal diferença está no fato de que cada posição $h \_R E C D[\mathrm{i}](i, 0 \leq i<n)$ contém uma 
lista com os números de seqüência de todas as mensagens já recebidas pelo $M h$ e difundidas por $M s s_{i}$.

4. MsgLog: vetor que guarda em cada posição um objeto MsgId referente a uma mensagem multicast enviada para um dos elementos do grupo LocalMhs e que é destinatário da mensagem.

5. RepliesFromMhs (*): tabela hash semelhante à RepliesMhSet descrita na subseção anterior. Cada posição RepliesFromMhs $[$ M.id] retorna um vetor que com as respostas dos Mhs locais e destinatários da mensagem $M$.

6. AckMhs (*): tabela hash indexada pelo identificador da mensagem (M.id), onde cada posição AckMhs $[$ M.id $]$ retorna o grupo de $M h s$ que confirmaram o recebimento do estado final de $M$.

7. MsgManager (*): hash de objetos do tipo ObjMsgManager que auxilia, para cada mensagem $M$, o $M s s$ no gerenciamento das ações que devem ser tomadas em relação à mensagem $M$.

8. DestMLocal: tabela hash onde cada posição indexada por $M . i d$ devolve o conjunto de $M h s$ locais e destinatários de uma determinada mensagem $M$.

\section{D.2.4 Estruturas de Dados no IMS:}

1. Buffer $(*)$ : fila que armazena as mensagens de multicast difundidas por um Mss inicializador. É usado durante a primeira fase do protocolo.

2. Outcomes $(*)$ : tabela hash que armazena o estado final das mensagens de multicast difundidas até o momento.

3. Domain: grupo de $M s s s$ que fazem parte do domínio do $I M S^{1}$.

4. MappingTable: tabela hash indexada pelo endereço de um Mss (seja $M s s_{n}$ ) que pertença a Domain. Cada posição MappingTable[Mssn ] devolve o grupo LocalMhs de Mss $n$. Desta forma, esta estrutura é responsável pelo mapeamento $M h \leftrightarrow M s s$ no IMS.

\section{D.3 Definição das Mensagens}

Esta seção contém as definições e o conteúdo das mensagens segundo o elemento de rede que as processa. Mais uma vez, indicaremos com um $\left(^{*}\right)$ as mensagens que são comuns ao $A M^{2} C$ e ao

\footnotetext{
${ }^{1}$ Esta informação é replicada nos Msss, ou seja, dado que um Mss pertence a um domínio A, o Mss sabe quais os demais Msss pertencentes a A.
} 
$i A M^{2} C$ e que não sofreram nenhuma modificação em sua estrutura ${ }^{2}$. Considere $M$ como qualquer uma das mensagens a seguir, a qual possui uma identificação (M.id).

\section{D.3.1 Mensagens Tratadas por $M s s_{\text {init }}$ :}

1. $\mathbf{M}=\operatorname{MulticastRequested}(M h m h, \text { Group dest, int content })^{*}$ :

Mensagem de multicast requisitada por um Mh. Sempre enviada para o Mss responsável pela célula na qual o $M h$ se encontra no momento do envio da mensagem $\left(M s s_{M h}\right)$. Contém o identificador do $M h$ requisitante, o grupo de destinatários (M.Dest) e o conteúdo.

2. $\mathbf{M}=\operatorname{RespFromMss}(M s g I d$ id, Vector replySet):

Recebimento da resposta de um Mss a respeito de uma determinada mensagem $M^{\prime}$. replySet contém um conjunto de objetos do tipo ObjReply com as respostas de todos os Mhs pertencentes a DestMLocal referentes à mensagem $M^{\prime}$ '

3. $\mathbf{M}=\operatorname{AckMss}(M s g I d i d, \text { Group } C)^{*}$ :

Mensagem enviada de um Mss para o $M s s_{\text {init }}$ de uma determinada mensagem $M^{\prime}$. É composta pela identificação da mensagem (onde $M . i d=M^{\prime} . i d$ ) e pelo grupo de $M h s$ locais e pertencentes a $M^{\prime}$.Dest que confirmaram o recebimento do estado final de $M^{\prime}$.

4. $\mathbf{M}=$ TimeIsOver(Timer T3):

Tempo máximo esperado pelo Mss inicializador de um multicast por respostas de todos os Mhs destinatários da mensagem. O timer T3 está associado uma mensagem do tipo FwdMsgFromMssInit difundida por Mssinit para todos os IMSs do sistema.

\section{D.3.2 Mensagens Tratadas pelo $M s s_{\text {part }}$ :}

1. $\mathbf{M}=\mathbf{F w d M s g F r o m I M S}(M s g I d$ id, Group dest, int content):

Mensagem enviada do $I M S$ ao qual $M s s_{\text {part }}$ está associado. Contém a identificação da mensagem, o grupo de destinatários e o conteúdo.

2. $\mathbf{M}=\operatorname{RespFromMh}(\text { Mh mh, MsgId id, int reply })^{*}$ :

Resposta de um $M h$ para seu $M s s_{M h}$ sobre a aceitação ou não de uma mensagem recebida (chamemos de $\left.M^{\prime}\right)$. Contém a identificação do $M h$, da mensagem $\left(M . i d=M^{\prime} . i d\right)$ e a resposta (Ok/NOk).

\footnotetext{
${ }^{2} \mathrm{O}$ que pode mudar nestes casos é o fluxo dessas mensagens no protocolo.
} 


\section{3. $\mathbf{M}=$ WaitingForReply(Timer T1)*:}

Evento de time-out ocorrido em um Mss. Neste caso, o time-out corresponde ao término do tempo máximo esperado por um $M s s_{\text {part }}$ por respostas de seus Mhs locais e destinatários da mensagem (Fase I). Contém um timer ao qual está associada uma mensagem $M^{\prime}$ do tipo FwdMsgFromMss, que é enviada do Mss para todo $M h \in($ LocalMhs $\cap$ M'.Dest).

4. $\mathbf{M}=\mathbf{S t a t u s F r o m I M S}($ MsgId id, Group dest, char status):

Estado final de um multicast recebido do $I M S$ ao qual o Mss está associado. Contém a identificação da mensagem, o grupo de destinatários e o status ("C" = Commited; "A" = Aborted).

5. $\mathbf{M}=\operatorname{AckMh}(M s g I d i d, M h m h)^{*}$ :

Aviso de um $M h$ a seu $M s s_{M h}$ sobre o recebimento de uma mensagem de status (chamemos de $M^{\prime}$ ). Contém o identificador da mensagem (onde $M . i d=M^{\prime}$.id) e do $M h$.

\section{6. $\mathbf{M}=$ WaitingForAck(Timer T2)*:}

Evento de time-out ocorrido em um Mss. Neste caso, o time-out corresponde ao término do tempo máximo esperado por um $M s s_{\text {part }}$ por confirmações de seus Mhs locais e destinatários de uma mensagem sobre o recebimento do estado final do multicast (Fase II). Contém um timer ao qual está associada uma mensagem $M^{\prime}$ do tipo StatusFromMss, que é enviada do Mss para todo $M h \in\left(\right.$ LocalMhs $\cap M^{\prime}$.Dest $)$.

7. $\mathbf{M}=\operatorname{Greet}\left(M h m h, M s s \operatorname{Mss}_{o}\right)^{*}$ :

Mensagem recebida por $M s s_{\text {part }}$ quando um $M h$ está entrando na sua célula (inicializando assim o protocolo de hand-off) ou volta de um período de inatividade. Contém a identificação do $M h$ e do $M s s$ da antiga célula $\left(M s s_{o}\right)$.

8. $\mathbf{M}=\operatorname{Dereg}\left(M h m h, M s s \operatorname{Mss}_{n}\right) *$ :

Solicitação de desvinculamento de um $M h$ de sua antiga célula enviada do $M s s$ responsável pela nova célula $\left(M s s_{n}\right)$. Contém a identificação do $M h$ e do novo $M s s$.

9. $\mathbf{M}=\operatorname{Dereg} \operatorname{Ack}\left(M h m h \text {, hashtable h_RECD, Mss } \mathrm{Mss}_{o}\right)^{*}$ :

Recebimento da confirmação de desvinculamento de um $M h$ de sua antiga célula (sob a responsabilidade de $M s s_{o}$ ). Contém a identificação do $M h$, o $h \_R E C D$ relacionado ao $M h$ e o endereço do $M s s_{o}$. 
10. $\left.\mathbf{M}=\mathbf{R e F w d M s g F r o m I M S ( V e c t o r ~ P e n d e n t e s , ~ V e c t o r ~ F i n a i s , ~ M h ~ m h , ~ M s s ~} \mathrm{Mss}_{o}\right)$ :

Recebimento de uma retransmissão de mensagens pendentes (que é uma resposta ao envio de uma mensagem do tipo LocationUpdate) do IMS ao qual o Mss está associado. Contém um vetor (Pendentes) com todas as mensagens ainda não recebidas por $m h$ (desde que seja destinatário) e um vetor (Finais) com os estados finais de todos os multicasts ainda armazenados no $I M S$ (onde o $M h$ é destinatário). O parâmetro $M s s_{o}$ indica o endereço do $M s s$ responsável pela célula da qual o $M h$ migrou (e que gerou o envio da mensagem LocationUpdate - vide seção 4.4).

11. $\mathbf{M}=\operatorname{Join}(M h m h)^{*}$ :

Solicitação de entrada no sistema por parte de um $M h$. Contém a identificação do $M h$.

12. $\mathbf{M}=$ Leave $(M h m h)^{*}$ :

Solicitação de saída do sistema de um $M h$ para seu $M s s_{M h}$. Contém a identificação do $M h$.

\section{D.3.3 Mensagens Tratadas por um IMS:}

1. $\mathbf{M}=$ FwdMsgFromMssInit(MsgId id, Group Dest, int content $)^{*}$ :

Mensagem recebida do $M s s$ inicializador do multicast $\left(M s s_{\text {init }}\right)$ e que deve ser enviada para todo $M s s \in$ Domain e que tenha algum $M h \in($ M.Dest $\cap$ Mss.LocalMhs). Armazena o identificador da mensagem (M.id), o grupo de destinatários (M.Dest) e o conteúdo.

2. $\mathbf{M}=$ StatusFromMssInit(MsgId id, Group Dest, char Status $)^{*}$ :

Recebimento do status de uma mensagem enviado pelo respectivo Mssinit para todos os IMSs do sistema. Contém a identificação da mensagem (M.id), o grupo de Mhs destinatários (M.dest) e o status ("A" = "Aborted"; "C" = "Commited").

3. $\mathbf{M}=\operatorname{Delete}(M s g I d i d)^{*}$ :

Mensagem que foi enviada pelo Mss inicializador do multicast ( $M s s_{\text {init }}$ ) para todos os $I M S s$ a fim de que estes removam o estado final de $M$ de seus respectivos Outcomes. Contém apenas a identificação da mensagem $(M . i d)$.

4. $\mathbf{M}=\operatorname{LocationUpdate}\left(M h m h\right.$, Vector $h_{-} R E C D, M s s \mathrm{Mss}_{n}, M s s \mathrm{Mss}_{o}$, int opcao):

Mensagem que foi enviada de um Msspart (e que faz parte do domínio do IMS) responsável pela célula-destino de um $M h$ em processo de hand-off ou que está voltando de um período de inatividade. É composta pelos endereços do $M h$, do $M s s$ da nova célula $\left(M s s_{n}\right)$ e do $M s s$ 
da antiga célula $\left(M s s_{o}\right)$, respectivamente. Ainda, as ações são tomadas de acordo com o parâmetro opcao, o qual pode assumir os seguintes valores:

0: Solicitação de Atualização de Mapeamento (registro do $M h$ no sistema);

1: Solicitação de Reenvio de Mensagens Pendentes (baseado nos valores contidos em $h \_R E C D$ );

2: Ambos os itens anteriores;

3: Solicitação de Remoção de Mapeamento (caso de migração inter-domínio);

\section{D.3.4 Mensagens Tratadas por um Mh:}

1. $\mathbf{M}=\mathbf{F w d M s g F r o m M s s}(M s g I d \text { id, int content })^{*}$ :

Recebimento de uma mensagem de multicast enviada pelo $M s s$ responsável pelo $M h\left(M s s_{M h}\right)$. Armazena a identificação da mensagem e o conteúdo.

2. $\mathbf{M}=\mathbf{S t a t u s F r o m M s s}(\text { MsgId id, char status })^{*}$ :

Recebimento do estado final de um multicast enviado pelo $M s s$ responsável pelo $M h\left(M s s_{M h}\right)$. Contém a identificação da mensagem e o estado final.

\section{D.4 Tratamento das Mensagens}

Esta seção apresenta um pseudo-código para o tratamento dado pelos elementos de rede na chegada das mensagens descritas na seção anterior. Sejam as seguintes considerações:

1. A abordagem será por elemento de rede envolvido;

2. As tabelas D.1 e D.2 apresentam os principais métodos utilizados no tratamento das mensagens no $i A M^{2} C$.

3. Sendo T1 e T3, respectivamente, os tempos (em UTs) dos eventos de time-out WaitingForReply e TimeIsOver, como T3 >> T1, se o estado final do multicast ainda não foi definido ao término de T1, então existe algum $M h$ que, por algum motivo, não permanece em uma célula durante um tempo suficiente para que lhe seja enviada a mensagem (por exemplo, um Mh numa região de transição constante). Caracterizamos isso como um caso "patológico" que dificilmente ocorre, mas que o protocolo deve levar em consideração. 


\begin{tabular}{|l|l|}
\hline Método & Significado \\
\hline New(<MsgType>) & Criação de uma nova mensagem do tipo <MsgType>. \\
\hline $\begin{array}{l}\text { setTimer(<timer-event>, } \\
\text { <repeat-order>, <time- } \\
\text { to-elapsed>) }\end{array}$ & $\begin{array}{l}\text { Inicia um temporizador para uma mensagem associada atimer- } \\
\text { event>. <repeat-order> "ONCE" ou "REPEATING") indica se } \\
\text { o evento será gerado apenas uma vez ou repetidamente. <time- } \\
\text { to-elapsed> refere-se ao tempo (em UTs) no qual o evento deverá } \\
\text { ser gerado ou o período de repetição. }\end{array}$ \\
\hline $\begin{array}{l}\text { MsgManager [Mid] .getInfoAb- } \\
\text { outEventProcesse- } \\
\text { dInF1/F2() }\end{array}$ & $\begin{array}{l}\text { Devolve TRUE se o evento de time-out da Fase I/II referente à } \\
\text { mensagem indexada por Mid já foi processado. }\end{array}$ \\
\hline $\begin{array}{l}\text { MsgManager [Mid] .setInfoAb- } \\
\text { outEventProcessedInF1/F2 } \\
\text { (TRUE/FALSE) }\end{array}$ & $\begin{array}{l}\text { Indica que o evento de time-out associado à mensagem M na Fase } \\
\text { I/II do protocolo já foi ou não processado. }\end{array}$ \\
\hline $\begin{array}{l}\text { MsgManager [Mid] .getInfo- } \\
\text { AboutDeleteSent() }\end{array}$ & $\begin{array}{l}\text { Retorna TRUE caso a mensagem Delete referente à mensagem } \\
\text { indexada por Mid já foi enviada para os IMSs. Retorna FALSE } \\
\text { no caso contrário. }\end{array}$ \\
\hline $\begin{array}{l}\text { MsgManager [Mid] .setInfoAb- } \\
\text { outDelete- } \\
\text { Sent(TRUE/FALSE) }\end{array}$ & $\begin{array}{l}\text { Indica se a mensagem Delete referente a uma mensagem cujo } \\
\text { identificador é Mid já foi ou não enviada. }\end{array}$ \\
\hline $\begin{array}{l}\text { MsgManager [Mid] .getPermis- } \\
\text { sionToProcess() }\end{array}$ & $\begin{array}{l}\text { Retorna TRUE caso o evento de time-out associado à mensagem } \\
\text { M (cujo identificador é Mid) pode ser processado. Retorna FALSE } \\
\text { no caso contrário. }\end{array}$ \\
\hline $\begin{array}{l}\text { MsgManager [Mid] .setPermis- } \\
\text { sionToPro- } \\
\text { cess (TRUE/FALSE) }\end{array}$ & $\begin{array}{l}\text { Indica se o evento de time-out associado a uma mensagem cujo } \\
\text { identificador é Mid pode ou não ser processado. }\end{array}$ \\
\hline $\begin{array}{l}\text { MsgManager [Mid] .getInfoAb- } \\
\text { outStatusDefined() }\end{array}$ & $\begin{array}{l}\text { Retorna TRUE se o estado final de uma mensagem } M \text { já foi defi- } \\
\text { nido. Retorna FALSE no caso contrário. }\end{array}$ \\
\hline $\begin{array}{l}\text { MsgManager [Mid] .setInfoAb- } \\
\text { FALSE) }\end{array}$ & $\begin{array}{l}\text { Indica se o estado final de uma mensagem indexada por Mid já foi } \\
\text { ou não definido. }\end{array}$ \\
\hline gethRECD(Mh) & Devolve o $h$ RECD relacionado ao Mh. \\
\hline
\end{tabular}

Tabela D.1: Principais Métodos Utilizados no Tratamento das Mensagens no $i A M^{2} C$.

Dessa forma, considere a tabela D.3 que indica as principais ações tomadas quando um evento de time-out ocorre no protocolo $i A M^{2} C$.

4. Nos algoritmos, os parâmetros, estruturas de dados ou mensagens serão expressos utilizando-se a mesma notação do $A M^{2} C$.

5. O termo owner corresponde a uma referência para o Ims/Mss/Mh que está processando a mensagem. 


\begin{tabular}{|c|c|}
\hline Método & Significado \\
\hline $\begin{array}{l}\text { allMhsHaveReplied } \\
\text { (RepliesMhSet [Mid], } \\
\text { DestM }[\text { Mid]) }\end{array}$ & $\begin{array}{l}\text { Testa se todos os Mhs destinatários de uma mensagem } M \\
(\text { DestM[Mid]) já responderam. RepliesMhSet[Mid] é um subcon- } \\
\text { junto de DestM[Mid] correspondente ao conjunto (LocalMhs } \cap \\
\text { M.Dest) que responderam à mensagem } M \text {. }\end{array}$ \\
\hline $\begin{array}{l}\text { allMhsHaveConfirmed } \\
(\text { AckMhs }[\text { Mid] } \\
\text { DestM }[\text { Mid]) }\end{array}$ & $\begin{array}{l}\text { Testa se todos os Mhs destinatários de uma mensagem } \\
M(\text { DestM[Mid]) já confirmaram o recebimento do estado final da } \\
\text { mensagem. AckMhs[Mid] é um subconjunto de DestM[Mid] cor- } \\
\text { respondente ao conjunto (LocalMhs } \cap \text { M.Dest) que confirmaram o } \\
\text { recebimento do estado final de } M \text {. }\end{array}$ \\
\hline msgNotHandled (Mh, Mid) & $\begin{array}{l}\text { Retorna TRUE caso a mensagem M (cujo identificador é Mid) não } \\
\text { tenha sido recebida pelo Mh e nenhum } M s s \text { considerou sua res- } \\
\text { posta como "NOk". Retorna FALSE no caso contrário. Esse teste } \\
\text { é feito de acordo com os números de seqüência armazenados em } \\
h \_R E C D[M . M s s I n i t] \text { para o } M h \text { em questão (o } M s s \text { inicializador } \\
\text { pode ser obtido pelo objeto Mid). }\end{array}$ \\
\hline $\begin{array}{l}\text { msgNotReceived (Mh, Mid, } \\
\text { hRECD) }\end{array}$ & $\begin{array}{l}\text { Este método tem a mesma finalidade do método MsgNotHan- } \\
\text { dled (Mh, M.id), onde a única diferença está no parâmetro adicio- } \\
\text { nal hRECD. É por meio deste parâmetro, que é passado pelo Mss no } \\
\text { envio da mensagem LocationUpdate, que o IMS correspondente é } \\
\text { capaz de saber quais mensagens já foram tratadas/recebidas pelo } \\
\text { Mh em questão. }\end{array}$ \\
\hline atualizaHRECD (Mh, Mid) & $\begin{array}{l}\text { Acrescenta o número de seqüência de } M \text { na estrutura } \\
h \_R E C D[M . M s s I n i t] \text { (onde o } M s s \text { inicializador pode ser obtido } \\
\text { através do identificador da mensagem) para o } M h \text { em questão. }\end{array}$ \\
\hline removeFromHRECD (Mh, Mid) & $\begin{array}{l}\text { Remove o número de seqüência da mensagem } M \text { presente na es- } \\
\text { trutura } h R E C D[M . M s s I n i t] \text { para o } M h \text { em questão. }\end{array}$ \\
\hline Object [Mid].put (anObject) & $\begin{array}{l}\text { Insere o objeto anObject na posição indexada por Mid do objeto } \\
\text { Object. }\end{array}$ \\
\hline Object [Mid] .add (anObject) & Adiciona o objeto anObject em Object [Mid]. \\
\hline Object [Mid].remove() & Remove o objeto da posição indexada por Mid. \\
\hline send (elemento, M) & Envio da mensagem M para elemento. \\
\hline
\end{tabular}

Tabela D.2: Principais Métodos Utilizados no Tratamento das Mensagens no $i A M^{2} C$.

6. Seja $M$ uma das mensagens descritas na seção D.3. Assim como ocorreu com o $A M^{2} C$, quando utilizamos uma variável $M^{\prime}$ (ou $M$ ") no lugar da variável $M$ para referenciar uma mensagem, temos que tais mensagens possuem a mesma identificação $\left(M^{\prime} \cdot i d=M \cdot i d\right)$. Ou seja, $M^{\prime} / M^{\prime \prime}$ refere-se a mesma mensagem original $(M)$ só que contém atributos diferentes.

\section{D.4.1 Mensagens Tratadas por $M s s_{\text {init }}$ :}

1. WhenMulticastRequested (Mh, Dest, Content):

(a) $m s e q:=m s e q+1$;

(b) mid := New MsgId (owner, mseq); /* Identificador da mensagem. */ 


\begin{tabular}{|c|c|}
\hline Evento & $\begin{array}{l}\text { Ações (Seja } M \text { uma mensagem associada a }<\text { timer }- \\
\text { event }>\text { ) }\end{array}$ \\
\hline WhenWaitingForReply $(<$ timer - event $>)$ & $\begin{array}{l}\text { Seja } A \text { o conjunto de } M h s \text { formado por (LocalMhs } \cap \\
M . D e s t) \text {. Seja } B \text { um subconjunto de } A \text { composto por } \\
\text { todos aqueles } M h s \text { que responderam à mensagem } M \text {, e } \\
\text { o conjunto } C=A-B . \forall M h \in C \text { considere a resposta } \\
\text { como sendo "NOk } M \text { ". Envie tais respostas, juntamen- } \\
\text { te com as respostas dos } M h s \text { pertencentes a } A \text {, para } \\
M s s_{\text {init }} \text {. }\end{array}$ \\
\hline WhenWaitingForAck $(<$ timer - event $>)$ & $\begin{array}{l}\text { Seja } C \text { o grupo de } M h s \text { locais que confirmaram o rece- } \\
\text { bimento de } M \text {. Envie um acknowledgment com o grupo } \\
C \text { para o } M s s_{\text {init }} \text {. }\end{array}$ \\
\hline WhenTimeIsOver $(<$ timer - event $>)$ & $\begin{array}{l}\text { Se o estado final de } M \text { ainda não foi definido então } \\
\text { defina tal estado como "Aborted". Difunda o estado } \\
\text { final para todos os } I M S s \text { do sistema. }\end{array}$ \\
\hline
\end{tabular}

Tabela D.3: Eventos ocorridos em um Mss.

(c) $M^{\prime}:=$ New FwdMsgFromMssInit (mid, Dest, Content);

(d) DestM [mid] := Dest;

(e) /* Difusao para todos os IMSs do sistema. */

$\forall$ ims $\in$ IMSAddress faça

send (ims, $M^{\prime}$ ) ;

(f) /* Inicia um temporizador para um evento de timeout associado a M'. */ setTimer(New TimeIsOver ( $\left.M^{\prime}\right)$, ONCE, T3);

2. WhenRespFromMss (Mid, ReplySet):

Considere que ReplySet contém um conjunto de objetos do tipo ObjReply com as respostas dos Mhs $\in$ LocalDestM[Mid].

(a) $\forall$ objReply $\in$ ReplySet faça

RepliesMhSet [Mid] .add (objReply);

(b) Se allMhsHaveReplied(RepliesMhSet [Mid], DestM[Mid]) então

*/ Definição do estado final do multicast. */

status := "C"; /* Commited */

$\forall$ objReply $\in$ RepliesMhSet [Mid] faça:

reply := objReply.getReply();

Se reply = "NOk"então

status := "A"; /* Aborted *I

break;

M':= New StatusFromMssInit (Mid, DestM[Mid], status);

MsgManager [Mid] . setInfoAboutStatusDef ined (TRUE);

*I Difusao para todos os IMSs. *I

$\forall$ ims $\in$ IMSAddress faça

send (ims, $M^{\prime}$ ) ;

3. WhenAckMss $(M i d, C)$ : 
(a) $\forall M h \in C$ faça:

GConfirmados [Mid] .add (Mh);

(b) Se allMhsHaveConfirmed(GConfirmados [Mid], DestM[Mid]) então MsgManager [Mid] . setInfoAboutDeleteSent (TRUE);

$M^{\prime}:=$ New Delete $($ Mid);

*/ Difusão para todos os IMSs. */

$\forall$ ims $\in$ IMSAddress faça send (ims, $M^{\prime}$ ) );

4. WhenTimerIsOver (TimerEvent) :

(a) $M^{\prime}:=$ TimerEvent.getMsg(); /* Mensagem associada ao time-out. */

(b) Se MsgManager[M'.id].getInfoAboutStatusDefined() = FALSE então

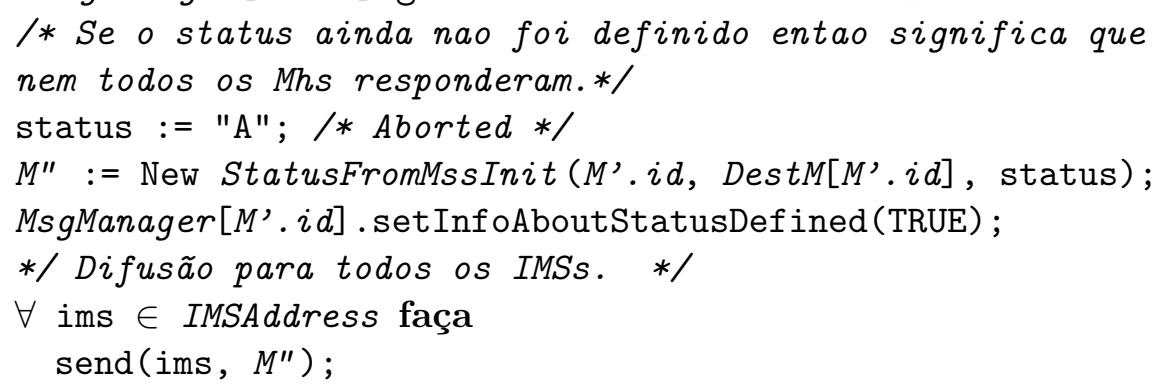

\section{D.4.2 Mensagens Tratadas por $M s s_{\text {part }}$ :}

1. WhenFwdMsgFromIMS (Mid, Dest, Content):

Seja $M$ a $i$-ésima mensagem difundida por um dado $M s s_{i n i t}$.

(a) /* Filtro dos Mhs locais e que pertencem a M.Dest. */

$\forall M h \in$ LocalMhs faça:

Se $M h \in$ Dest e msgNotHandled (Mh, Mid) então

DestMLocal [Mid] .add (Mh);

(b) M':= New FwdMsgFromMss (Mid, Content);

(c) Envio da mensagem para os Mhs locais e destinatarios. *I

$\forall M h \in$ DestMLocal [Mid] faça:

send $\left(M h, M^{\prime}\right)$;

(d) /* Inicia um temporizador para um evento de timeout associado a M'. */ setTimer(New WaitingForReply ( $\left.M^{\prime}\right)$, ONCE, T1);

(e) /* Indica que o evento de timeout associado a M' pode ser processado. *I MsgManager $[M i d]$. setPermissionToProcess (TRUE);

(f) /* Indica no Log que a mensagem ja foi transmitida. */ MsgLog $[$ Mid] . add (Mid);

2. WhenRespFromMh(Mh, Mid, Reply):

/*Verifica se o evento de time-out na 1a.fase para a mensagem ainda nao foi processado. *I

(a) Se MsgManager [Mid].getInfoAboutEventProcessedInF1( ) = FALSE então objAux := New ObjReply(Mh, Reply); 
RepliesFromMhs [Mid].add (objAux);

/* Apenas aqui ha a atualizacao de $h_{-} R E C D$, pois se o time-out ja foi processado entao $h_{-} R E C D$ ja foi atualizado. */

atualizaHRECD (Mh, Mid);

\section{WhenWaitingForReply (TimerEvent):}

(a) $M^{\prime}:=$ TimerEvent.getMsg();/* Mensagem associada ao time-out. */

(b) Se MsgManager [M'.id].getPermissionToProcess() então

*I Verifica quais Mhs nao responderam. *I

$\forall M h \in$ DestMLocal[M'.id] faça

Se $M h \notin R e p l i e s F r o m M h\left[M^{\prime} . i d\right]$ então

*I Considera a resposta do Mh como "Nok". *I

objAux := New ObjReply(Mh, "Nok");

RepliesFromMh [M'.id] .add (objAux);

*/ Indica que a mensagem ja foi tratada. */

atualizaHRECD (Mh, M'.id);

M": = New RespFromMss (M'.id, RepliesFromMh[M'.id]);

*/ Envio da resposta para Mssinit. */

send (M'.MssInit(), M") ;

MsgManager. setInfoAboutEventProcessedInF1 (TRUE);

Senão

/* Proximo evento de time-out deve ser processado. */

MsgManager $\left[M{ }^{\prime}, i d\right]$. setPermissionToProcess (TRUE);

4. WhenStatusFromIMS(Mid, Dest, Status):

(a) M' := New StatusFromMss (Mid, Status);

(b) $\forall M h \in$ (LocalMhs $\cap$ M. Dest) faça:

send (Mh, M');

/* Remove o numero sequencia da mensagem de $h_{-}$RECD[M.MssInit] para o Mh em questao, uma vez que esta ja esta obsoleta. *I

removeFromHRECD (Mh, Mid);

(c) /* Inicia um temporizador para um evento de time-out associado a M'. */ setTimer(New WaitingForAck $\left(M^{\prime}\right)$, ONCE, T2);

5. WhenAckMh (Mid, Mh):

/* Testa se o evento de time-out ja foi processado. Neste caso, a mensagem AckMss(Mh) deve ser enviada para o Mss inicializador do multicast. */

(a) Se MsgManager $[$ Mid] .getInfoAboutEventProcessedInF2( ) = TRUE então

$M^{\prime}:=$ New $\operatorname{AckMss}(M i d$, New $\operatorname{Group}(M h))$;

send(M.MssInit, $\left.M^{\prime}\right)$; /* Ack extra enviado. */

Senão

/* Adiciona o Mh no grupo de Mhs que ja enviaram um acknowledjment para M. */ AckMhs $[M i d]$.add $(M h)$;

6. WhenWaitingForAck (TimerEvent) : 
(a) $M^{\prime}:=$ TimerEvent.getMsg();

(b) $M^{\prime \prime}:=$ New AckMss (M'.id,AckMhs [M'.id]);

(c) send (M'.MssInit, M") ;

(d) $\forall M h \in A c k M h s\left[M^{\prime} . i d\right]$ faça

/* Remocao do Mhs que ja responderam a M'. */

AckMhs $\left[M^{\prime}, i d\right]$. remove $(M h)$;

(e) MsgManager.setInfoAboutEventProcessedInF2(TRUE);

7. WhenGreet $\left(M h_{n e w}, \operatorname{Mss}_{o}\right)$ :

(a) /* Testa se o Mh esta entrando agora no sistema. */

Se $M s s_{O} \neq$ null então

/* Testa se o Mh nao voltou de um periodo de inativacao. */

Se $M s s_{o} \neq$ owner então

/* Envio da mensagem Dereg do Mss responsavel pela celula atual para Mss $_{o}$ solicitando o desligamento de $M h_{n e w}$ de sua antiga celula. */

M' := New Dereg $($ Mhnew, owner $)$;

send $\left(\operatorname{Mss}_{O}, M^{\prime}\right)$;

\section{Senão}

1* O Mh esta voltando de um periodo de inativacao. Assim, deve-se enviar a mensagem LocationUpdate para o IMS, a qual tera o papel apenas de solicitante de reenvio de mensagens pendentes. */

M':= New LocationUpdate $\left(M h_{\text {new }}\right.$, gethRECD $\left(M h_{\text {new }}\right)$, owner, null, 1); send (owner .getIMS (), M') ;

\section{Senão}

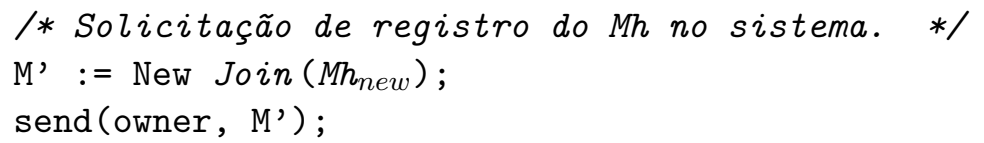

8. WhenDereg $\left(M h_{n e w}, M s s_{n}\right)$ :

Esta mensagem é processada em $M s s_{O}$ (Mss da antiga celula).

(a) /* Remocao de $\mathrm{Mh}_{\text {new }}$ do grupo LocalMhs. */

LocalMhs.remove $\left(M h_{\text {new }}\right)$;

(b) /* Aborta todas as mensagens enviadas e que o Mh ainda nao respondeu. */

$\forall \operatorname{mid} \in M s g L o g$ faça

Se MsgManager[mid].getInfoAboutEventProcessedInF1( ) = FALSE então

Se msgNotHandled ( $M h_{n e w}$, mid) então

*I Considera a resposta do Mh como "Nok". *I

objAux := New ObjReply(Mhnew, "Nok");

RepliesFromMh [mid] .add (objAux);

*I Indica que a mensagem ja foi tratada. */

atualizaHRECD $\left(M h_{\text {new }}\right.$, mid);

*/ Remove o Mh de DestMLocal. */

DestMLocal [mid] . remove(

mhnew); 
(c) */ Verifica a necessidade do envio da mensagem LocationUpdate no caso de migracao inter-dominio. *I

Se $M s s_{n} \notin$ Domain então

$$
\begin{aligned}
& \text { M': : New LocationUpdate }\left(M h_{\text {new }}, \operatorname{gethRECD}\left(M h_{\text {new }}\right),\right. \text { null, owner, 3); } \\
& \text { send(owner.getIMS (), M'); }
\end{aligned}
$$

(d) /* Envio da mensagem DeregAck para Mss ${ }_{n}$ informando o desvinculamento do Mh de sua antiga celula. *I M':= New DeregAck $\left(M h_{n e w}\right.$, gethRECD $\left(M h_{\text {new }}\right)$, owner $)$; send $\left(M s s_{n}, M^{\prime}\right)$;

9. WhenDeregAck $\left(M h_{n e w}, h R E C D, M s s_{o}\right)$ :

(a) /* Registro do novo Mh. */ LocalMhs. add $\left(M h_{\text {new }}\right)$;

(b) I* Envio da mensagem LocationUpdate para o IMS correspondente solicitando a atualizacao do mapeamento e envio de mensagens pendentes. */ M':= New LocationUpdate (Mh, hRECD, owner, $\left.M s s_{o}, 2\right)$;

(c) send (owner $\left.\cdot \operatorname{get} \operatorname{IMS}(), \mathrm{M}^{\prime}\right)$ );

10. WhenReFwdMsgFromIMS (Pendentes, Finais, Mh, Mss ${ }_{o}$ ):

Pendentes contém todas as mensagens que $M h$ ainda não recebeu e que é destinatário.

Finais contém os estados finais de todos os multicasts ainda não finalizados, independente de $M h$ ter ou não recebido tal estado final.

(a) */ Testa se o Mh nao migrou novamente. */

Se $M h \in$ LocalMhs então

$\forall \mathrm{M} \in$ Pendentes faça

Se msgNotHandled(Mh, M.id) então

Se MsgManager[M.id].getInfoAboutEventProcessedInF1( ) = FALSE então

*/ Retransmissao e prorrogacao do time-out. */

M' := New FwdMsgFromMss(M.id, M.Content);

send $\left(M h, M^{\prime}\right)$;

setTimer(New WaitingForReply $\left(M^{\prime}\right)$, ONCE, T1);

/* Indica que o evento de time-out anterior nao deve ser processado. */ MsgManager [M.id] .setPermitionToProcess (FALSE);

*I Adiciona o Mh no grupo de destinatarios local. *I

DestMLocal [M' .id] . add (Mh);

Senão /* Time-out ja processado. */

Se $M s s_{o} \neq$ owner então

/* Multicast deve ser abortado. */

objAux := New ObjReply(Mh, "Nok");

M':= New RespFromMss(M.id, New Vector(objAux));

/* Envio da resposta para o Mss inicializador. */

send (M.MssInit, M');

*/ Indica que a mensagem ja foi tratada. */

atualizaHRECD (Mh, M.id); 


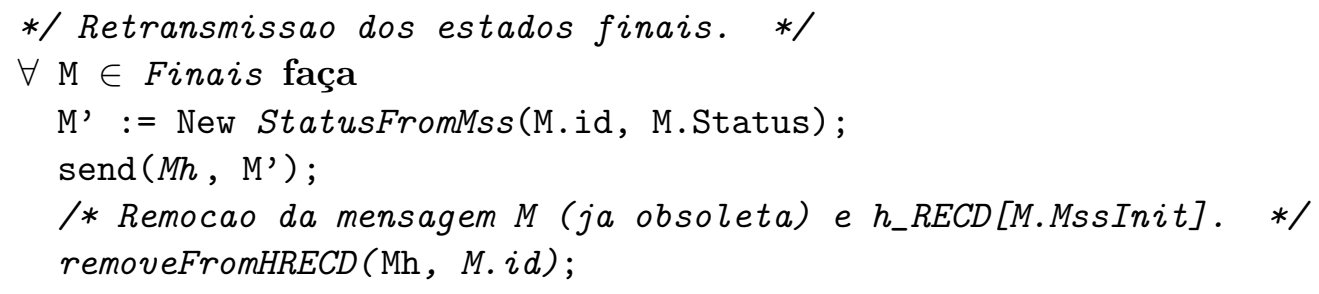

11. WhenJoin $\left(M h_{\text {new }}\right)$ :

(a) LocalMhs.add $\left(M h_{n e w}\right)$; /* Adiciona Mhnew no grupo de Mhs locais. */

(b) /* O IMS deve acrescentar o Mh no seu mapeamento. */ M':= New LocationUpdate $\left(M h_{\text {new }}\right.$, gethRECD $\left(M h_{\text {new }}\right)$, owner, null, 0);

(c) send (owner $\left.\operatorname{get} \operatorname{IMS}(), \mathrm{M}^{\prime}\right)$;

12. WhenLeave $(M h)$ :

(a) LocalMhs.remove(Mh); /* Remove Mh do grupo de Mhs locais. */

\section{D.4.3 Mensagens Tratadas no IMS:}

1. WhenFwdMsgFromMssInit (Mid, Dest, Content):

(a) /* Armazenamento da mensagem. */ Buffer $[M i d]$. add (M);

(b) mssDest := New $\operatorname{Group}()$;

(c) /* Filtro dos Msss $\in$ Domain e que possuem algum Mh $\in$ M.Dest. */ $\forall$ mss $\in$ Domain faça /* Grupo de Mhs locais ao Mss pertencente ao dominio do IMS. */ gMhs := Domain[mss];

$\forall \mathrm{mh} \in \mathrm{gMhs}$ faça

Se $\mathrm{mh} \in$ Dest então /* Adiciona o Mss no grupo de destinatarios. */ mssDest.add (mss); break;

(d) M':= New FwdMsgFromIMS(Mid, Dest, Content);

(e) /* Envio da mensagem somente para aqueles Msss que possuem algum Mh $\in$ M.Dest. $* 1$

$\forall$ mss $\in$ mssDest faça send (mss, M');

2. WhenStatusFromMssInit (Mid, Status, Dest):

(a) /* Armazenamento do estado final em Outcomes. */ Outcomes [Mid] . put (M);

(b) mssDest := New Group();

(c) /* Filtro dos Msss $\in$ Domain e que possuem algum Mh $\in$ M.Dest. */ 
$\forall$ mss $\in$ Domain faça

/* Grupo de Mhs locais ao Mss pertencente ao dominio do IMS. */

gMhs := Domain [Mss];

$\forall \mathrm{mh} \in g M h s$ faça

Se $\mathrm{mh} \in$ Dest então

/* Adiciona o Mss no grupo de destinatarios. */

mssDest.add (mss);

break;

(d) M' := New StatusFromIMS(Mid, Dest, Status);

(e) /* Envio da mensagem somente para aqueles Msss que possuem algum Mh $\in$ M.Dest. */

$\forall$ mss $\in$ mssDest faça

send (mss, M');

(f) /* Remocao da mensagem-conteudo do Buffer. */ Buffer $[M i d]$.remove();

3. WhenDelete(Mid):

(a) /* Remocao do estado final de Outcomes. */ Outcomes $[$ Mid] .remove ();

4. WhenLocationUpdate(Mh, hRECD, $\left.\operatorname{Mss}_{n}, \operatorname{Mss}_{o}, O p c a o\right)$ :

Sejam $M s s_{n}$ e $M s s_{o}$ os Mss da nova e antiga celula, respectivamente (lembremos que uma migracao gera uma mensagem LocationUpdate por parte de $M_{s s_{n}}$.

(a) Pendentes := New Vector () ;

(b) Finais := New Vector();

(c) Se $O p c a o=1$ ou $O p c a o=2$ então

/* Armazena em Pendentes toda mensagem presente em Buffer

que o Mh ainda nao a recebeu e que e destinatario. */

$\forall \mathrm{M} \in$ Buffer faça

Se msgNotReceived (Mh, M.id, hRECD) então

Pendentes.add (M);

Armazena em Finais todos os estados finais presentes em Outcomes

e que $o$ Mh e destinatario. *I

$\forall \mathrm{M} \in$ Outcomes faça

Finais.add (M);

(d) Caso Opcao Seja:

0: /* Solicitacao de Atualizacao de Mapeamento. 10. registro no sistema.*I /* Adicao do Mh no grupo de $\operatorname{Mss}_{n}$. */

$\operatorname{Domain}\left[\mathrm{Mss}_{n}\right]$.add $($ Mh $)$;

1: /* Solicitacao de Envio de Mensagens Pendentes. */

M' := New ReFwdFromIMS(Mh, Pendentes, Finais);

send $\left(M s s_{n}, \mathrm{M}^{\prime}\right)$;

2: /* Casos 0 e 1. */

Domain $\left[M s s_{O}\right]$.remove $(M h)$; 


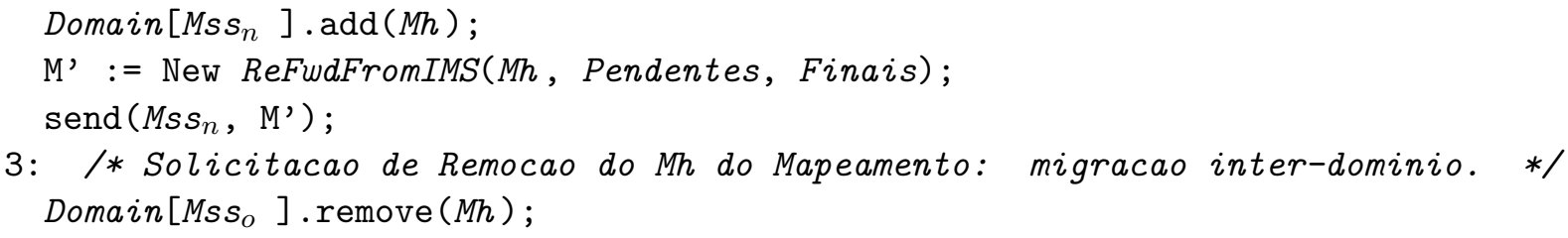

\section{D.4.4 Mensagens Tratadas no Mh:}

1. WhenFwdMsgFromMss (Mid, Content):

(a) Se a aplicacao e capaz de processar a mensagem então reply := "Ok";

Senão reply := "NOk";

(b) $M^{\prime}:=$ New RespFromMh (owner, Mid, reply);

(c) /* Envia resposta para o Mss resposavel pelo Mh.*/ send (Mss owner,$\left.M^{\prime}\right)$;

2. WhenStatusFromMss ${ }_{n}$ (Mid, Status):

/* Acknowledgment enviado para Mss responsável pelo Mh confirmando o recebimento do estado final de uma mensagem. */

(a) $M^{\prime}:=$ New AckMh (owner, Mid);

(b) send (Mss owner,$\left.M^{\prime}\right)$; 


\section{Referências Bibliográficas}

[1] A. Acharya and B.R. Badrinath. Delivering Multicast Messages in Networks with Mobile Hosts. In Proc. of 13th Intl. Conference on Distributed Computing Systems, Pittsburgh. IEEE Computer Society, May 1993.

[2] S. Alagar and S. Venkatesan. Causal ordering in distributed mobile systems. IEEE Transactions on Computers, 46(3):353-361, 1997.

[3] Kenneth P. Birman. Building secure and reliable network applications. In $W W C A$, pages $15-28,1997$.

[4] Uyless Black. Mobile and Wireless Networks. Prentice Hall, 1996.

[5] R.C.A. da Rocha and M. Endler. MobiCS: An environment for prototyping and simulating distributed protocols for mobile networks. In 3rd. IEEE International Conference in Mobile and Wireless Communication Networks (MWCN'2001), Recife, Brazil, pages 44-51, August 2001.

[6] Ricardo C.A. da Rocha. MobiCS: Um Simulador de Protocolos para Computaçâo Móvel. IME/USP, 2000. www.ime.usp.br/〜rcarocha/mobics/.

[7] Ricardo C.A. da Rocha and Markus Endler. Flexible Simulation of Distributed Protocols for Mobile Computing. In 3rd. Workshop on Modeling Analyses and Simulation of Wireless and Mobile Systems (MSWIM), Boston, pages 123-126, 2000.

[8] Ricardo C.A. da Rocha and Markus Endler. MobiCS: An Environment for Prototyping and Simulating Distributed Protocols for Mobile Networks. In Proc. 3rd IEEE Intern. Conference on Mobile and Wireless Communications Networks (MWCN2001), Recife - Brazil, pages 44-51, August 2001. 
[9] A. Myles David B. Johnson and Charles Perkins. A mobile host protocol supporting route optimization and authentication. IEEE Journal on Selected Areas in Communications, 13(5):839-849, June 1995.

[10] Mateus de Freitas Ribeiro and M. Endler. Um Protocolo Indireto para Multicast Atômico em Computação Móvel. In III Workshop de Comunicação sem Fio e Computação Móvel (WCSF'2001), Recife, Brazil, pages 84-91, August 2001.

[11] Carlos de M. Cordeiro, Djamel H. Sadok, and Judith Kelner. Um Mecanismo de Retransmissão Eficiente para Multicast. In XVIII Simpósio Brasileiro de Redes de Computadores (SBRC), Belo Horizonte, $M G$, May 2000.

[12] M. Endler, Dilma M. da Silva, and Kunio Okuda. RDP: A Result Delivery Protocol for Mobile Computing. In Proc. of the Int. Workshop on Wireless Networks and Mobile Computing (WNMC) with 20th ICDCS, Taiwan, R.O.C. IEEE, April 2000.

[13] Markus Endler. A protocol for atomic multicast among mobile hosts. In Dial $M$ Workshop/Mobicom'99, Seatle (USA), pages 56-63. ACM, August 1999.

[14] João E. Ferreira and Marcelo Finger. Controle de concorrência e distribuição de dados: a teoria clássica, suas limitações e extensões modernas. X Escola de Computação, São Paulo, 2000.

[15] Georges Forman and John Zahorjan. The challenges of mobile computing. IEEE Computer, pages 39-47, April 1994. ftp://ftp.cs.washington.edu/tr/1993/11/UW-CSE-93-11-03.PS.Z.

[16] Jim Geier. Wireless LANs. Implementing High Performance IEEE 802.11 Networks. SAMS Publishing, 2001.

[17] Alberto Bartoli Giuseppe Anastasi and Francesco Spadoni. A reliable multicast protocol for distributed mobile systems: Design and Evaluation. In IEEE Transactions on Computers, October 2001.

[18] T.G. Harrison, C.L. Williamson, W.L Mackrell, and R.B. Bunt. Mobile Multicast (MoM) Protocol: Multicast Support for Mobile Hosts. In Proc. 3rd Inter. Conference on Mobile Computing and Networking (Mobicom 97), Budapest, Hungary, pages 151-160, September 1997.

[19] N. Kanodia, T.-C. Lin, Zamora V., and Schlosser S. Adaptive Routing for Mobile Multicast Users. WWW, February 1998. www.andrew.cmu.edu/schlos/mwn/new_proposal. 
[20] E. Schooler M. Handy, H. Schulzrinne and J. Rosemberg. SIP: Session initiation protocol. Rfc. 2543, Columbia University, March 1999. www.cs.columbia.edu/ hgs/sip/papers.html.

[21] A. Schiper M. Raynal and S. Toueg. The causal ordering abstraction and a simple way to implement it. Information Processing Letters, 39(6):343-350, 1991.

[22] Silvano Maffeis, Walter Bischofberger, and Kai-Uwe Maetzel. A generic multicast transport service to support disconnected operation. In USENIX Association, editor, Proceedings of the second USENIX Symposium on Mobile and Location-Independent Computing: April 10-11, 1995, Ann Arbor, Michigan, USA, pages 79-90, Berkeley, CA, USA, April 1995. USENIX.

[23] Geraldo Robson Mateus and Antonio A. Ferreira Loureiro. Introdução à Computação Móvel. II Escola de Computação Móvel, Rio, 98.

[24] Charles Perkins. IP mobility support. Request for Comments 2002, October 1996. IETF Mobile IP Group.

[25] Evaggelia Pitoura and George Samaras. Data Management for Mobile Computing. KAP, 1998.

[26] M. Raynal R. Prakash and M. Singhal. An Adaptive Causal Ordering Algorithm Suited to Mobile Computing Environments. Journal of Parallel and Distributed Computing, pages 190204, March 1997.

[27] Djamel H. Sadok, Carlos de M. Cordeiro, and Judith Kelner. A reliable subcasting protocol for wireless environments. In C. Guy Omidyar, editor, Mobile and Wireless Communication Networks, number 1818 in Lecture Notes in Computer Science, pages $174-185$. Springer-verlag, 2000.

[28] James D. Solomon. Mobile IP: The Internet Unplugged. Prentice Hall, 1998.

[29] J.Z. Wang. A fully distributed location registration strategy for universal personal communication systems. IEEE Journal on Selected Areas in Communications, 11(6):850-860, August 1993.

[30] C.L. Williamson, T.G. Harrison, W.L Mackrell, and R.B. Bunt. Performance evaluation of the mom mobile multicast protocol. ACM Baltzer Journal on Mobile Networks and Applications, 3(2):189-201, August 1998. 
[31] George Xylomenos and George C. Polyzos. IP multicast for mobile hosts. IEEE Communications Magazine, 35(1):54-58, 1997. 